\title{
COMPARISON OF OLDER ADULTS WALKING WITH AN ANTERIOR, POSTERIOR AND WITHOUT A WHEELED WALKER
}

\author{
A Dissertation \\ Presented to \\ The Faculty of the Curry School of Education \\ University of Virginia
}

In Partial Fulfillment

of the Requirement for the Degree

Doctor of Philosophy

by

Ann E. Tuzson MS, PT

May 2008 


\author{
Department of Human Services \\ Curry School of Education \\ University of Virginia \\ Charlottesville, Virginia
}

\title{
APPROVAL OF THE DISSERTATION
}

This dissertation, Comparison of Older Adults Walking with an Anterior, Posterior and Without a Wheeled Walker, has been approved by the Graduate Faculty of the Curry School of Education in partial fulfillment of the requirements for the degree of Doctor of Philosophy.

Christopher Ingersoll, PhD, ATC, Advisor

B. Ann Boyce, PhD, Committee Member

Jay Hertel, PhD, ATC, Committee Member

Bradford Bennett, PhD, Committee Member

William Walker, $\mathrm{PhD}$, Committee Member 


\section{ACKNOWLEGEMENTS}

Early in my doctoral program, my advisor left the university and I became an academic orphan. I really have to thank Chris Ingersoll for taking responsibility for the completion of my doctoral degree. In spite of my obvious weaknesses in the subject area of athletic injury rehabilitation, he readily filled the position of my advisor which had become vacant through some unusual and unfortunate events. I feel very fortunate and grateful that he chose to fill this void.

In writing of my mentors and academic influences, these acknowledgements would be incomplete if I did not include a statement about my master's program advisor, Dr. Kevin Granata. If my PhD had been in English, perhaps I could better express the continuum of emotions which I feel in the wake of his death on April 16. Instead, I will simply express thankfulness for his teachings and deep regret of his untimely and unbelievable death.

I have to thank all the folks at the Senior Center Inc. in Charlottesville who were very generous with scheduling space and helping me find research participants. They are a great resource to both the community and the University.

Of course I have to thank my husband Bernard who, in the course of my doctoral program, was required to perform tedious and thankless tasks including but not limited to chauffeur, mover, photographic model, video editor, practice participant, GARS training session host, computer consultant, software expert, parking enforcement lookout and therapist. 
Thanks to all the folks in the Therapy Services Department at UVA who allowed me to arrange my work schedule around my class work and research. I could not have completed this program without that employment and their flexibility. Thanks also to the therapists who assisted with this research.

Also, I have to thank my parents. Had they known my future held 4 college degrees, perhaps they would have stressed education a little less in my formative years. Thanks to all the members of my doctoral and my program committees. I find it hard to believe that this is finally coming to completion. I'm convinced that I will have to call them all together at least one more time due to some requirement which I have overlooked. But until then, thank you for your input, guidance and support. 
TABLE OF CONTENTS

Page

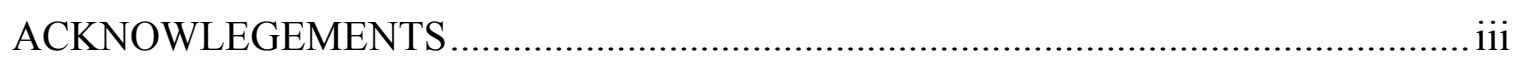

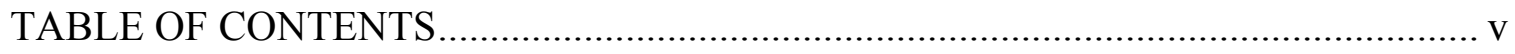

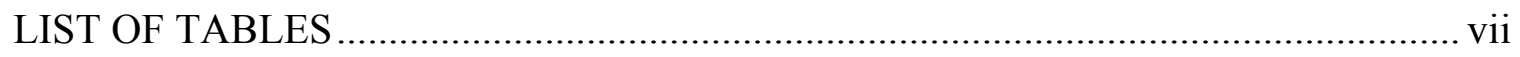

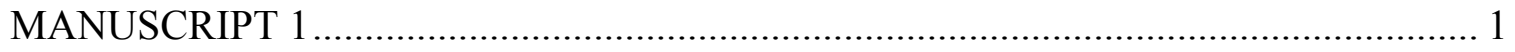

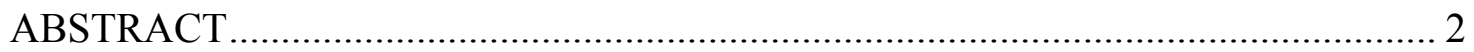

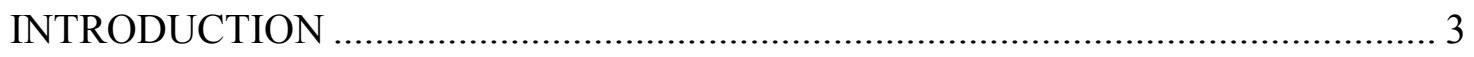

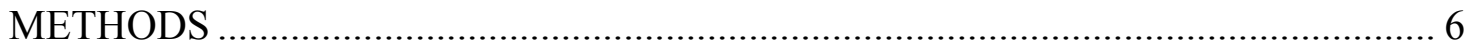

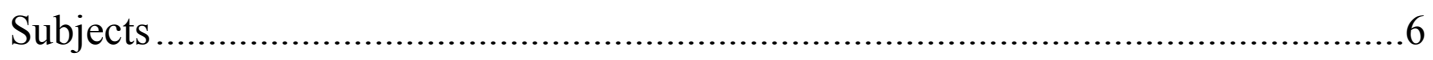

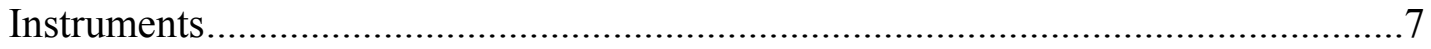

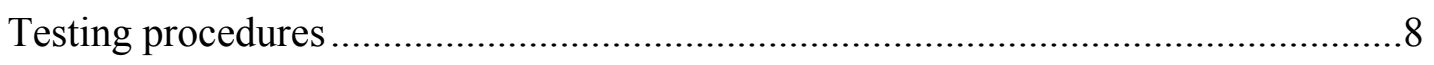

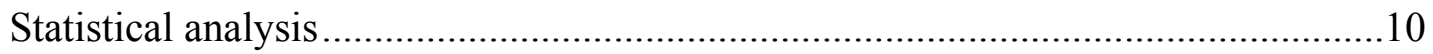

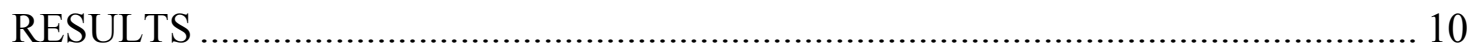

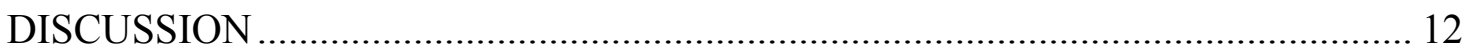

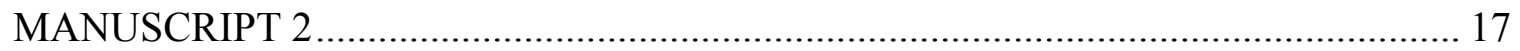

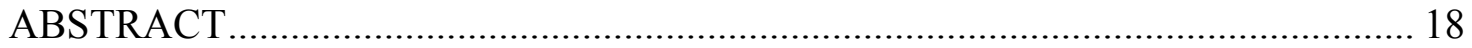

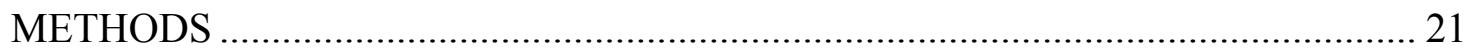

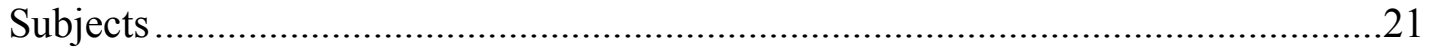

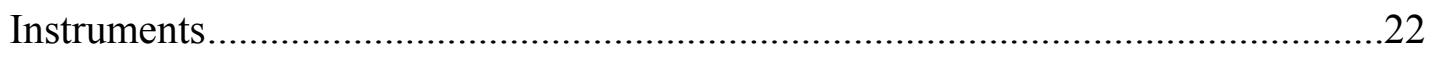

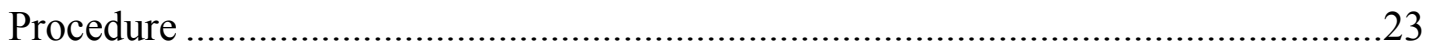

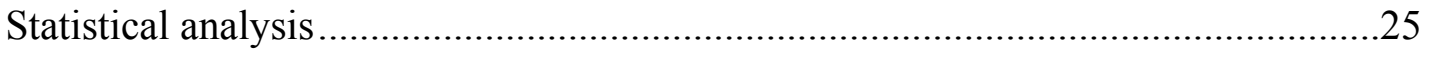

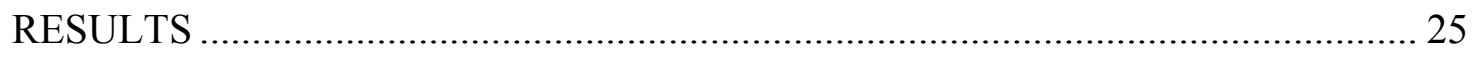

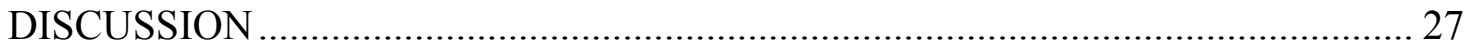




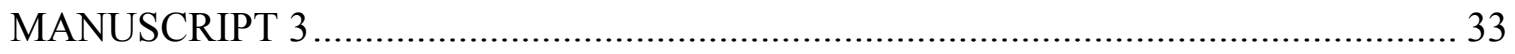

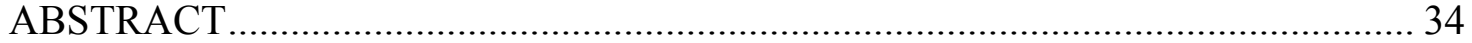

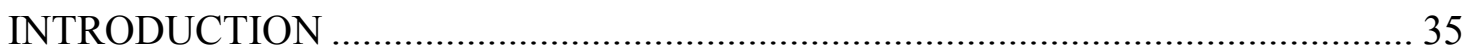

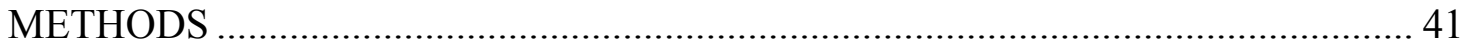

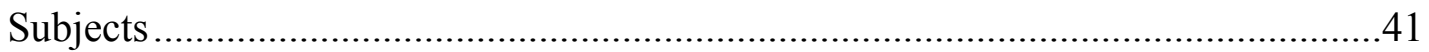

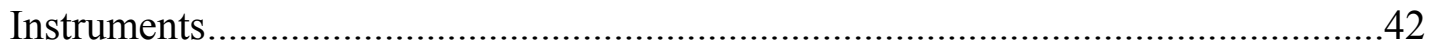

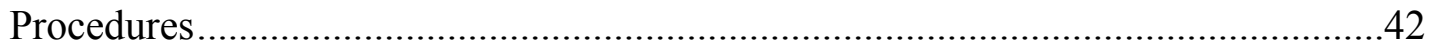

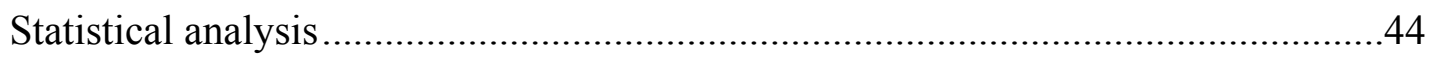

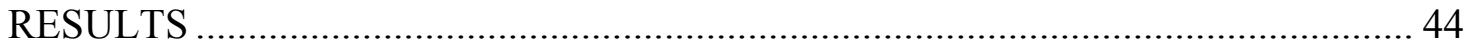

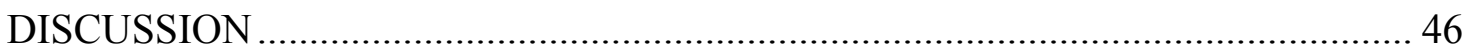

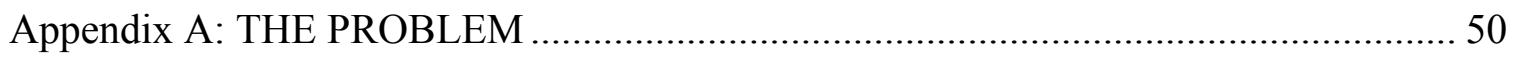

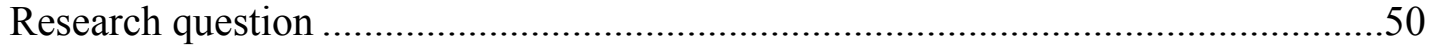

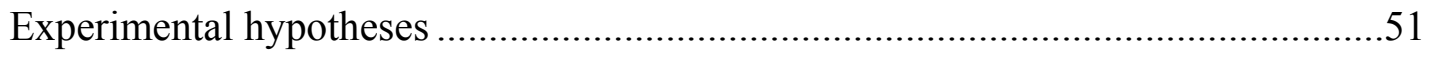

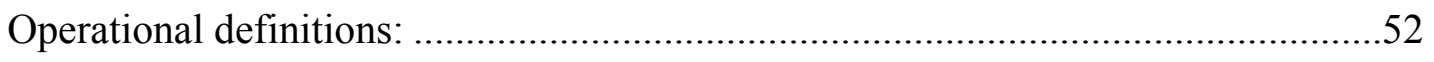

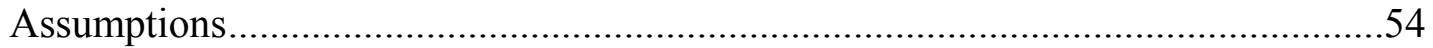

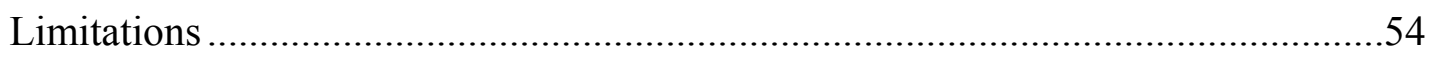

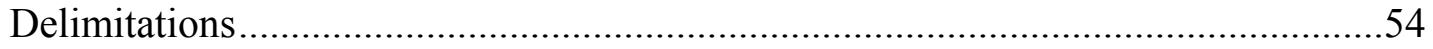

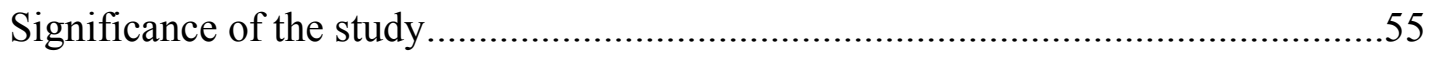

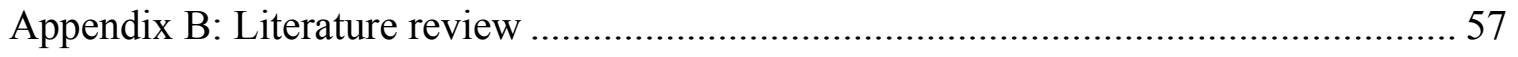

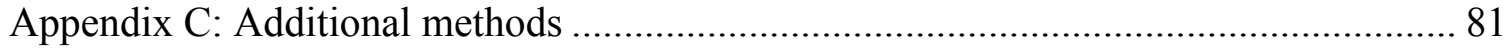

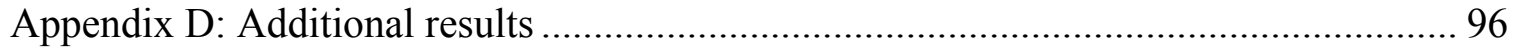

Appendix E: Recommendations for future research ............................................. 124

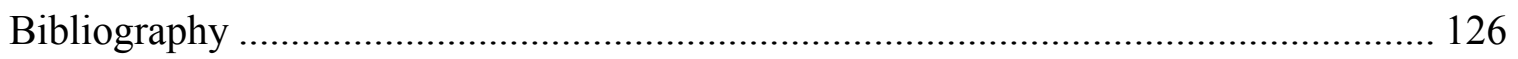




\section{LIST OF TABLES}

Table 1. Averaged results of gait kinematics and parameters walking with anterior,

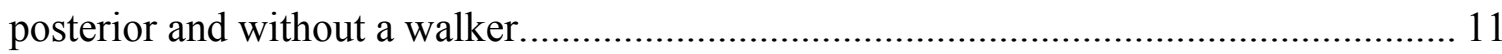

Table 2 Questionnaire about anterior and posterior walkers..................................... 25

Table 3. Obstacle course times with the two different walkers reported in seconds ....... 26

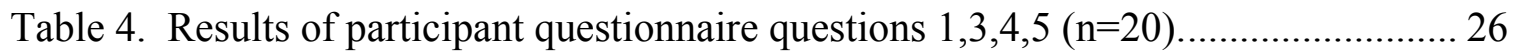

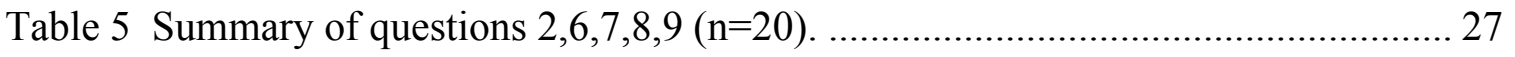

Table 6. Gait Abnormality Rating Scale (GARS): .................................................. 36

Table 7. GARS Scores comparing gait with anterior and posterior walker................... 45

Table 8. Therapist preferences: Results of general questionnaire comparing gait with

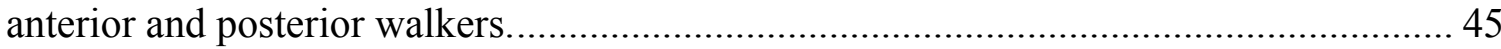

Table B 1: Measurements recorded in research studies comparing anterior and posterior

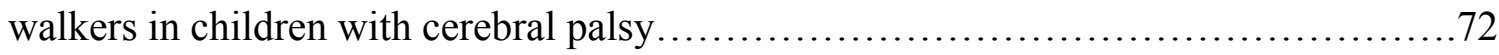

Table B 2: Effect sizes and projected sample sizes for significant differences in hip position and stride length walking with an anterior vs. posterior walker in children with

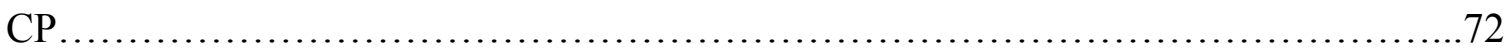

Table C 1. Informed Consent.................................................. 81

Table C 2. Questionnaire about anterior and posterior walkers......................88

Table C 3. Evaluation form and questionnaire to be completed by physical therapists ...90

Table C 4. Assignment of raters and participants and rating order for GARS assessment. 
Table D 1: Kinematic results: Raw data

Table D 2. Descriptive statistics for peak back extension during gait with anterior, posterior and no walker. 106

Table D 3. Within subject effects of walker type on peak back extension angle during gait 107

Table D 4. Estimated marginal means for peak back extension angle with 1)Anterior, 2)

posterior and 3) No walker 107

Table D 5. Pairwise comparisions for peak back extension angle with 1) Anterior, 2)

Posterior and 3) No walker.

Table D 6. Descriptive statistics for minimum back extension angle during gait cycle with anterior, posterior and no walker.

Table D 7. Within subject effects of walker type on minimum back extension angle. . 108 Table D 8 Estimated marginal means for minimum back extension angle with 1) anterior 2)posterior and 3) no walker. 108

Table D 9 Pairwise comparisons of minimum back extension angle during gait with 1) anterior 2) posterior and 3) no walker

Table D 10. Descriptive statistics for maximum hip flexion angle during gait with anterior, posterior and no walker.

Table D 11. Within subjects effects for walker type on maximum hip flexion angle during gait. 109 Table D 12 Estimated marginal means of maximum hip flexion angle during gait with 1) anterior 2) posterior and 3) no walker 
Table D 13 Pairwise comparisons of maximum hip flexion angle during gait with 1) anterior 2) posterior and 3) no walker

Table D 14. Descriptive statistics for maximum hip extension angle during gait with 1) anterior 2) posterior and 3) no walker.....

Table D 15. Within subject effect of walker type on maximum hip extension angle

during gait with 1) anterior 2) posterior and 3) no walker.

Table D 16 Estimated marginal means for maximum hip extension during gait with 1)

anterior 2) posterior and 3) no walker

Table D 17 Pairwise comparisons for maximum hip extension angle during gait with 1) anterior 2) posterior and 3) no walker

Table D 18 Descriptive statistics for maximum knee flexion angle during gait with 1) anterior 2) posterior and 3) no walker.

Table D 19 Within subject effect of walker type on maximum knee flexion angle during gait

Table D 20 Marginal estimates of maximum knee angle during gait with 1) anterior, 2) posterior and 3) no walker. 112 Table D 21 Pairwise comparisons of maximum knee angle during gait with 1) anterior 2) posterior and 3) no walker.

Table D 22. Descriptive statistics of maximum knee extension angle during gait with 1) anterior 2) posterior and 3) no walker 113

Table D 23. Within subject effect of walker type on maximum knee extension angle. 113 Table D 24. Marginal estimates of maximum knee extension angle during gait with 1) anterior 2) posterior and 3) no walker 
Table D 25. Pairwise comparisons of maximum knee extension angle during gait with 1)anterior 2) posterior and 3) no walker.

Table D 26. Descriptive statistics of maximum plantarflexion angle during gait with 1) anterior 2) posterior and 3) no walker. 115

Table D 27. Within subject effects of walker type on maximum plantarflexion angle. 115 Table D 28. Estimated marginal means for maximum plantarflexion angle with 1) anterior 2) posterior and 3) no walker. 115

Table D 29. Pairwise comparisons for maximum plantarflexion angle during gait with 1) anterior 2) posterior and 3) no walker. 116

Table D 30. Descriptive statistics for maximum dorsiflexion angle during gait with 1) anterior 2) posterior and 3) no walker. 116

Table D 31. Within subject effects of walker type on maximum dorsiflexion angle during gait 116

Table D 32. Estimated marginal means for maximum dorsiflexion angle during gait with 1) anterior 2) posterior and 3) no walker . 117

Table D 33. Pairwise comparisons for maximum dorsiflexion angle during gait with 1) anterior 2) posterior and 3) no walker.

Table D 34. Descriptive statistics for preferred gait speed (m/s) with 1) anterior 2) posterior and 3) no walker.

Table D 35. Within subject effect of walker type on gait speed. Table D 36. Estimated marginal means of gait speed (m/s) with 1) anterior, 2) posterior and 3) no walker. 118 Table D 37. Pairwise comparisons of gait speed with 1) anterior 2) posterior and 3) no 
walker. 118

Table D 38. Descriptive statistics for stride length (m) with 1) anterior 2) posterior and

3) no walker. 119

Table D 39. Within subject effects of walker type on stride length (m). 119

Table D 40. Estimated marginal means for stride length (m) during gait with 1) anterior

2) posterior and 3) no walker.

Table D 41. Pairwise comparisons for stride length (m) with 1) anterior, 2) posterior and

3) no walker.

Table D 42. Paired statistics for obstacle course times (s) with anterior and posterior walkers.

Table D 43. Correlations between obstacle course times with anterior and posterior walkers. 120

Table D 44. Paired t-test with obstacle course times with anterior and posterior walkers 121

Table D 45 Within subject effects of rater and walker on GARS scores 121

Table D 46 Multivariate tests of within subject effects on GARS scores 122

Table D 47 Repeated measures ANOVA of GARS scores with anterior walker. 122

Table D 48 Repeated measures ANOVA of GARS scores with posterior walker 123

Table D 49 ICC form $(2,1)$ for GARS scores of 5 raters and 5 subjects 123 


\section{LIST OF FIGURES}

Figure 1. Wenzelite Posterior Safety Roller (left) and the Guardian Envoy 460 Economy

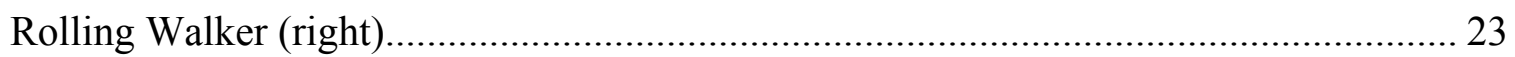

Figure 2. Obstacle course adapted from Special Olympics Summer Sports Rules, Athletics, 25 meter motorized wheelchair obstacle course......................................... 24

Figure 3. Nimbo lightweight posterior safety roller by Wenzelite Rehab a division of

Drive Medical Design \& manufacturing............................................................... 30

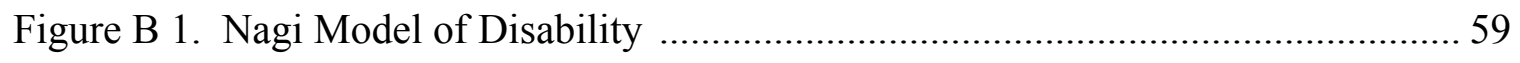

Figure B 2. Illustration of child with anterior walker (left) and posterior walker (right) 69

Figure B 3. Child with cerebral palsy walking with posterior walker 
MANUSCRIPT 1

Gait kinematics of older adults walking with anterior and posterior

walkers 


\begin{abstract}
Objective: To determine the effect of walker type (anterior, posterior or none) on kinematics and gait parameters in older adults. Design: Repeated measures, within subject design. Setting: Senior Center, Charlottesville, VA Participants: 20 independent, community-living adults 79.1 years $( \pm 6.7)$ years. Measurements: Peak extension and flexion angles of the back, hip, knee, and ankle during gait with an anterior, posterior and without a wheeled walker. Stride length and preferred gait velocity were also measured. Results: There was no significant effect of walker on gait kinematics. There was a significant effect of walker type on stride length $(\mathrm{P}=0.027,1$ $\beta=0.68$ ), but upon further analysis, the effect size was small and there were no significant individual differences found between the stride lengths with different walker types.

Conclusions: In this population of older adults, there is minimal or no difference in gait kinematics, stride length or preferred walking speed when walking with an anterior, posterior or without a wheeled walker. However, in this older population, small differences in gait kinematics may have great clinical significance. Future research should try to reduce error and variability in gait kinematics and should additionally measure gait kinetics in an attempt to examine the clinical significance of small changes in gait when walking with various assistive devices.
\end{abstract}




\section{INTRODUCTION}

Optimizing gait in adults with disabilities is of great importance to general health. Ambulation is known to be important in maintaining general health and independence ${ }^{1-5}$. As our population ages, it behooves society to help individuals with balance and strength deficits to maintain and maximize their mobility as long as possible. Improved mobility in this older population has significant economic benefits by saving Medicare and Medicaid expenditure for immobility related health problems and has been shown to be related to improved quality of life ${ }^{4,6}$.

In reviewing the gait literature of older adults, significant differences are clearly present when comparing the gait parameters of younger adults and older adults. Multiple research studies ${ }^{7-11}$ have shown that older adults have shorter stride length, decreased hip extension, and decreased posterior pelvic tilt during gait when compared to younger adults. Stride length and hip extension are both related to a decrease in function and an increased risk of falling in older adults ${ }^{7,10,12}$. Given that an increase in hip extension is necessary in order to increase stride length, it follows that the two should have a similar effect on function. Decreased stride length and decreased hip extension during gait may be two indicators of the same gait phenomena.

In a study by Kerrigan et al. ${ }^{7}$, peak hip extension during gait was shown to be decreased in older adults when compared to younger adults and even further decreased in older adults who fall than those who do not. This relationship between increased hip flexion and falling was further examined in a study by Jacobs et al. ${ }^{13}$ The authors found that when even healthy older adults stood with exaggerated hip flexion, they displayed a decreased ability to respond to a perturbation and an increased propensity to fall. Both 
these studies illustrate the destabilizing effects of functioning with decreased hip extension and display the importance of adequate hip extension in function in this older population. Given these indications of the importance of hip position during gait, interventions which attempt to improve gait in older adults should closely examine changes in hip range of motion and step length.

Interventions for general gait instability include strengthening, balance training, stretching, or the introduction of an assistive device. Although the former interventions have shown promise for improving balance and gait ${ }^{14-16}$, ambulatory devices, such as walkers, canes and crutches, remain the main form of treatment for most gait disorders ${ }^{17}$. Twenty-four percent of those who use mobility devices to assist with gait use some type of walker. Of those who use walkers, $78 \%$ are over the age of 65 years. In total, 1.4 million adults over the age of 65 use walkers to ambulate ${ }^{17}$.

All of the walkers commonly used in the adult population, two wheeled, four wheeled and no wheeled, are placed anterior to the user. Research comparing gait with and without a wheeled walker showed that when adults push a walker in front of them, they walk with decreased ankle dorsiflexion, knee extension and hip extension range of motion. Unfortunately, these are not desirable changes for older adults with gait limitations ${ }^{18}$. The research on gait and function in older adults suggests that gait interventions in this population should promote knee and hip extension ${ }^{7,8,13}$. Anterior walkers, walkers pushed in front of the individual, do not promote these parameters. Although adults use primarily anterior walkers, wheeled walkers placed posterior to the user are commonplace in pediatrics, particularly with children with cerebral palsy (CP). With a posterior walker, the user's hands still rest on the walker at his or her sides, 
however, there is no equipment directly in front of the user. Instead the walker wraps around behind the user and is open in front. Although the research is somewhat limited, some literature does compare anterior and posterior four wheeled walkers in this younger population ${ }^{19-23}$.

In general, the results show an improvement in the biomechanics of gait in this pediatric, disabled population when they used the posterior walker. All of the research studies which measured hip kinematics showed increased hip extension during gait with the posterior walker ${ }^{19-21}$. Some studies also indicated an increase in knee extension, posterior pelvic tilt and trunk extension. Two out of three studies ${ }^{20,21}$ showed an increase in stride length with the posterior walker where the last one ${ }^{19}$ failed to find a significant difference between the walkers. Although the results are somewhat inconsistent with some researchers finding significance where others did not, this is likely due, in part, to small numbers of research participants.

Children with cerebral palsy tend to ambulate in a 'crouch' gait with increased hip flexion, increased knee flexion and increased anterior pelvic tilt when compared to age matched children without cerebral palsy. The changes seen with the posterior walker, increased hip extension, knee extension, posterior pelvic tilt and increased step length are all considered biomechanical improvements in this population. Hence, the research suggests that children with cerebral palsy ambulate with improved biomechanics with a posterior walker when compared to an anterior walker. None of the studies concluded that the anterior walker was preferable.

Although the pathology and gait limitations of older adults are different from those of children with cerebral palsy, the posterior walker might prove beneficial for this 
older population. If the posterior walker increases hip extension, knee extension and stride length in older adults, as it did in the children with CP, this could improve general function and safety in this older population.

The purpose of this research is to compare gait kinematics of older adults while ambulating with an anterior and posterior wheeled walker. The hypothesis states that older adults will show increased hip extension and a longer stride length when ambulating with the posterior wheeled walker than when ambulating with the anterior wheeled walker. Knee extension, low back angle and plantar flexion will be similar between the two walkers. Other outcome variables will include preferred gait speed and joint angles of the low back, the knee and the ankle during gait.

\section{METHODS}

This study used a crossover design The independent variable included the type of walker (anterior, posterior or no walker). The dependent variables included peak back, hip, knee flexion and extension angles, peak ankle dorsiflexion and plantar flexion angles, stride length, preferred gait speed.

\section{Subjects}

Subjects included adults older than 55 years of age with decreased balance, endurance or strength who may benefit from using a wheeled walker. Subjects were recruited through local senior centers using flyers and posters. The consent, protocol and recruitment materials were approved by the University of Virginia Institutional Review Board-Health Sciences Research (IRB HSR \#12712).

Volunteers were individuals who occasionally or regularly benefited from an assistive device such as a cane. However, individuals needed to be able to walk 60 feet 
on a level surface independently without an assistive device, without assistance and without risk of falling. A brief gait evaluation of the subject was performed to determine inclusion or exclusion criteria. Individuals qualified for participation if any of the following were found: lateral gait deviation, shortened stride length, loss of balance, weaving gait, or shuffling gait. Volunteers were excluded if they had an observable asymmetric gait, poor motor control or if they had lower extremity contractures. In order to participate, volunteers needed to have adequate upper extremity function to hold onto the walker and needed to be able to understand and follow the instructions in English.

\section{Instruments}

Kinematic data were collected at $200 \mathrm{~Hz}$ using Biopac software (Biopac Systems Inc., Goleta, CA) and were analyzed using Matlab (Mathworks Inc., Natick, MA). Kinematic output variables included low back, hip, knee and ankle angles throughout the gait cycle. Maximum and minimum angles during each gait cycle were obtained for the low back, hip, knee and ankle. All maximums and minimums for the available gait cycles will be averaged for each condition. Stride length and gait speed were obtained using gait data and triggers to mark the distance walked. Other output variables included preferred gait speed.

A telemetry system was used for back and lower extremity kinematics during gait. Biopac TEL $100 \mathrm{C}$ amplifier was used for each of the four electrogoniometers. Data was filtered with a low pass filter at $30 \mathrm{~Hz}$ and with a $60 \mathrm{~Hz}$ notch filter. No filtering was done in the lower frequencies. The signal was digitized via a Biopac 16 bit analog to digital converter. The goniometers were calibrated at the beginning of each testing session. 
Custom made timing gates were fashioned from common, commercially available infra red chiming mechanisms (Safety Beam model 671 manufactured by Cutting Edge). The signal from the infrared beam was transferred into Biopac using a coaxial cable connection. Whenever the beam was crossed, a voltage difference relayed into biopac. Two sets of timing gates were used, one for the starting position, one for the ending position ( 25 feet apart). These trigger signals were used to determine stride length and gait speed.

Two commercially available walkers were used for comparison. The posterior wheeled walker chosen was the Wenzelite Posterior Safety Roller by Drive Medical Design and Manufacturing (Port Washington, NY). This was the only posterior wheeled walker made for adults found available for purchase at the time of this research. The anterior wheeled walker was the Guardian Envoy 460 Economy Rolling Walker, part number 07886G (Sunrise Medical, Carlsbad, CA). This anterior walker was chosen because it has four wheels like the posterior walker and is commonly used by adults with gait limitations.

\section{Testing procedures}

Informed consent was obtained prior to participation. Data collection was performed at the local senior center.

The two walkers were fit to the user based on conventional fitting recommendations. According to O'Sullivan \& Schmitz ${ }^{24}$, the top of the walker should come to the height of the participant's greater trochanter and should allow for 20-30 degrees of elbow flexion. Both walkers were the exact same height at the hand rests. 
Four electrogoniometers were placed on the participant's back, hip, knee and ankle to measure joint angles during walking. The electrogoniometer used to measure the low back angle was positioned at the levels of the pelvis and L1 in order to measure the angle of low back flexion. For continuous hip angle measurement, the goniometer was aligned with the midline of the iliac crest and with the midline of the femur. For knee angle measurement, the electrogoniometer was positioned along the midline of the femur and the midline of the fibula. For ankle range of motion, the electrogoniometer was placed along the lateral midline of the fibula and the lateral aspect of the fifth metatarsal on the outside of the participant's shoe. Goniometer placement adapted from conventional positioning to allow for smaller size of electrogoniometer, for low back measurement, and for shoes ${ }^{25}$. Given that older adults walk differently with and without shoes ${ }^{26}$ and that the CDC generally recommends that older adults wear shoes when walking to avoid falls ${ }^{27}$, the participants wore shoes for the data collection. The ankle goniometer was placed on the lateral aspect of the shoe along the fifth metatarsal. Prior to walking, 5 seconds of standing data was taken to measure the joint angles of the back, hip, knee and ankle while standing still.

Prior to data collection, the participant was asked to walk back and forth once with each of the devices to familiarize themselves with the device. Then, the participant was asked to walk along a straight path of 30 feet while joint data was collected. The participant walked the length of the path with the anterior four wheeled walker, the posterior four wheeled walker and without a walker. The participant was asked to walk the path 2 times, once in each direction, for each condition. The order of the walkers was counter balanced to avoid an order effect. 


\section{Statistical analysis}

The peak maximum and minimum values from each gait cycle were chosen from the continuous joint angle walking data using Matlab (Mathworks Inc., Natick, MA) and custom made Matlab programs. Peak maximum and minimum values were chosen for each gait cycle for each of the back, hip, knee and ankle for a total of 8 values for each gait cycle. The peak values were averaged across all the gait cycles which lay between the timing gates resulting in a total of 8 values for each of the three walker conditions (anterior, posterior and none) for a total of 24 values for each participant.

The results were analyzed using one way repeated measures ANOVAs for each of the 8 different peak gait kinematics. If and when significant differences were found at $\alpha$ $\leq 0.05$, a Bonferroni correction factor was used to account for multiple comparisons.

According to the pediatric literature on posterior walkers, hip extension during gait increased with the posterior walker an average of 12 degrees $( \pm 8)$, resulting in an averaged effect size of 1.5 for hip position. Stride length during gait, increased an average of $0.13 \mathrm{~m}( \pm 0.11)$ for an averaged effect size of 1.20 for stride length ${ }^{18-21}$. Using a sample size of 20 and a power of 0.8 , we calculated that an effect size of 0.88 would be necessary to reject the null hypothesis at a level of 0.05 for hip position. Similarly, an effect size of 0.89 would be needed to reject the null hypothesis at a level of 0.05 for step length.

\section{RESULTS}

Maximum and minimum joint angles during the gait cycle were found for the back, hip, knee and ankle joints in 10 men and 10 women with an average age of 79.1 years $( \pm 6.7)$. All participants at least occasionally used a cane as per inclusion 
requirements. All participants successfully completed the protocol. The average preferred walking velocity for all trials with all walkers was $0.92 \mathrm{~m} \cdot \mathrm{s}^{-1}\left( \pm .34 \mathrm{~m} \cdot \mathrm{s}^{-1}\right)$. The average stride length was $0.93 \mathrm{~m}( \pm .22 \mathrm{~m})$.

Separate one-way, repeated measures ANOVAs of the peak joint kinematics revealed no significant differences between joint angles when the individuals walked with an anterior, posterior and without a walker. Also, there was no significant difference between the walking velocities with or without the different walkers.

The main effect of walker on stride length within subject showed significance (P $\left.=0.027, \mathrm{~F}_{2,38}=3.993, \eta_{\mathrm{p}}{ }^{2}=0.174,1-\beta=0.68\right)$. However, when individual differences were examined, none of the stride lengths were significantly different from the others and the observed power was low $(1-\beta=0.569)$. (See Table 1 for summary of results.)

Table 1. Averaged results of gait kinematics and parameters walking with anterior, posterior and without a walker.

\begin{tabular}{|c|c|c|c|c|c|c|c|}
\hline \multicolumn{8}{|c|}{ WALKER TYPE } \\
\hline & \multicolumn{2}{|c|}{ ANTERIOR } & \multicolumn{2}{|c|}{ POSTERIOR } & \multirow{2}{*}{$\begin{array}{c}\text { NONE I } \\
\text { CONTROL } \\
\text { Mean } \pm \text { SD }\end{array}$} & \multirow[b]{2}{*}{$\mathrm{df}, \mathrm{F}$} & \multirow[b]{2}{*}{$\mathrm{p}$} \\
\hline & Mean \pm SD & $\mathrm{d}$ & Mean \pm SD & $\mathrm{d}$ & & & \\
\hline \multicolumn{8}{|l|}{ GAIT KINEMATICS } \\
\hline BACK EXT & $17 \pm 9$ & 0.14 & $18 \pm 9$ & 0.04 & $18 \pm 9$ & $2,1.29$ & 0.286 \\
\hline BACK FLEX & $9 \pm 7$ & 0.23 & $10 \pm 8$ & 0.01 & $10 \pm 7$ & $2,1.98$ & 0.151 \\
\hline HIP EXT & $3 \pm 9$ & 0.40 & $2 \pm 10$ & 0.20 & $0 \pm 9$ & $2,2.67$ & 0.082 \\
\hline HIP FLEX & $33 \pm 13$ & 0.26 & $30 \pm 12$ & 0.08 & $31 \pm 11$ & $2,2.09$ & 0.137 \\
\hline KNEE EXT & $1 \pm 8$ & 0.15 & $2 \pm 8$ & 0.03 & $2 \pm 7$ & $2,1.10$ & 0.344 \\
\hline KNEE FLEX & $55 \pm 10$ & 0.27 & $57 \pm 12$ & 0.17 & $58 \pm 11$ & $2,0.64$ & 0.534 \\
\hline ANKLE DF & $-1 \pm 7$ & 0.17 & $-3 \pm 5$ & 0.15 & $-2 \pm 6$ & $2,1.06$ & 0.358 \\
\hline ANKLE PF & $27 \pm 9$ & 0.02 & $26 \pm 9$ & 0.16 & $28 \pm 9$ & $2,0.39$ & 0.681 \\
\hline \multicolumn{8}{|c|}{ GAIT PARAMETERS } \\
\hline VELOCITY & $.90 \pm .38$ & 0.02 & $.83 \pm .33$ & 0.19 & $.91 \pm .39$ & $2,2.58$ & 0.089 \\
\hline STRIDE LENGTH & $.96 \pm .21$ & 0.06 & $.89 \pm .22$ & 0.28 & $.95 \pm .24$ & 2, 3.99 & 0.027 \\
\hline
\end{tabular}

Significant trends are in bold.

$*(+)=$ extension. $(-)=$ flexion.

$\dagger \dagger(+)=$ flexion. $(-)=$ extension. 


\section{DISCUSSION}

These results failed to find a significant difference in back, hip, knee or ankle position when participants walked with the anterior, posterior or without any walker. The original hypothesis predicted significant differences in hip extension angles and stride length during walking with the two different walkers. These predictions were made based on the literature on assistive device use in the pediatric population and in young healthy adults ${ }^{18-20,22,23}$.

In the articles comparing the biomechanics of gait with the anterior and posterior walker in children with $\mathrm{CP}$, all articles which examined hip position during gait, found significant differences between the anterior and posterior walker, even with a subject pool as small as 5 participants ${ }^{19-21,23}$. Similarly, Alkjaer et al. ${ }^{18}$ found significant differences in the average hip position of 7 young healthy adults walking without an assistive device when compared to walking with an anterior wheeled walker. Research on younger people both disabled and not, showed significant differences when walking with different assistive devices and yet, this current research failed to find any significant differences.

In the research comparing anterior and posterior walkers in children with cerebral palsy, authors found hip extension differences ranging from 5-10 degrees ${ }^{19-21}$. This difference in hip extension is large compared to other studies examining changes in hip extension during gait ${ }^{7,16,28,29}$. In their results, Alkjaer et al. ${ }^{18}$ found an increase of only 2.6 degrees in hip flexion when young healthy subjects walked with a walker compared with gait without a walker. Kerrigan et al. ${ }^{7}$ found a significant difference of only 3.2 degrees of hip extension in the gait of elderly fallers compared with nonfallers. In a 
related study by Kerrigan et al. ${ }^{16}$, a 10 week program of hip extension exercises, resulted in only an average increase of 1.6 degrees of static hip extension and 2 degrees of dynamic hip extension in older adults. Although small, this 2 degree difference in hip extension was found to be statistically significant. Where children with cerebral palsy show fairly large differences in hip extension when walking with an anterior and posterior walkers, hip extension in older adults appears more stable and more resistant to change.

Kerrigan et al's research on gait in older adults suggests that this small difference of 2-3 degrees of hip extension is not only statistically significant, but clinically significant $^{7}$. According to Kerrigan et al.'s kinematic comparison of older gait, peak hip extension was the only lower extremity kinematic difference which distinguished fallers from nonfallers ${ }^{7}$. The differences in peak hip extension between fallers and nonfallers were only 3.2 degrees. This suggests that small gains in hip extension might be very valuable in preventing falls in this older population.

Unfortunately, current motion analysis equipment, electrogoniometers or video based motion systems, may not be sensitive enough to identify a difference of only a couple of degrees. Biometrics reports their electrogoniometer to be accurate within 2 degrees $^{30}$. Electrogoniometer error likely stems from differences between the mechanics of the joint surface, where the goniometer is placed, and the mechanics of the actual joint itself $^{31}$. As the skin moves over the bones, the goniometer, placed on the skin, is merely approximating the movement of the bones and not measuring the bone movement itself.

Vicon, a popular video based motion analysis system, is able to measure a static angle within 0.6 degrees but has been shown to have questionable interrater and intrarater 
reliability ${ }^{32,33}$. Problems with Vicon stem from errors in joint marker placement on the skin and errors due to the miscalculation of the joint center from the marker reference points $^{34}$. Capturing differences in hip extension during gait in the range of 1 to 2 degrees, may be difficult with this current technology.

Kinematic differences, however, are not the only measurable joint parameter during gait. In addition to kinematic differences in gait, Alkjaer et al. ${ }^{18}$ found significant differences in young peoples' joint moments when they walked with a four wheeled anterior walker than when they walked without an assistive device. In addition, the effect sizes were greater when comparing joint moments than when comparing joint kinematics. Similarly, Kerrigan et al. ${ }^{35}$ found significant differences in the joint moments of the hip, knee, and ankle when they compared the gait kinetics of falling and nonfalling older adults. However, Kerrigan et al. only found differences in hip extension when they compared kinematic differences at the hip, knee and ankle between fallers and nonfallers. Where kinematic data reports the position of the joints, kinetic data reports the work taking place within the system. Joint kinetics can distinguish movements which appear similar, but which have different joint forces. Because walking is such a welllearned movement pattern, individuals might gravitate to their same normal gait pattern even when greater force is exerted across the joints. Hence, when gait looks the same, the moments across the joints might show differences. Perhaps joint moments are a more sensitive method for capturing differences in biomechanical phenomena like walker assisted gait.

Another possible limitation of this research was the basic design of the posterior walker. Although there are several different types of posterior wheeled walkers available 
for children with cerebral palsy, the Wenzelite Posterior Safety Roller by Drive Medical Design and Manufacturing (Port Washington, NY), is the only posterior walker available for the adult population. Given the lack of competition in the product area of adult posterior wheeled walkers, this walker might have suffered from limited product development. One design complaint identified during data collection was that while walking, participants feared the posterior walker would strike their heels at the end of the stance phase. This could facilitate a shortened stride length and may have confounded the stride length results seen in this research. An improved walker design, one which is lighter, and easier to maneuver might better facilitate gait in this adult population. Another recommendation for future research would be to narrow the patient population in question. The goal of this current research was to examine healthy older adults with gait deficits typically seen in the aging process. Perhaps this group is too broad, too healthy and presents with too much variability in gait patterns to show the effect of an intervention like a walker. Focusing on assistive device use in certain populations might decrease the variability seen between participants. For example, adults with Parkinson's Disease have very specific gait deviations which are particular to that disease. A cohesive research population like this one might show differences in gait kinematics in response to an intervention where other more diverse populations would not. Populations which show gait limitations more like those seen in cerebral palsy, may be of particular interest given the success of the posterior walker in that population. Similarly, older adults with more severe gait deficits might show greater differences in gait kinematics with different assistive devices. 
In spite of the limitations of this research, some conclusions can still be drawn. If there are any actual differences between gait kinematics with and without the two different walkers, the differences, in older adults with common gait deviations, are small. However, these small differences in joint kinematics might be clinically valuable in promoting healthy, independent gait in disabled older adults. Future research should attempt to maximize the reliability and accuracy in gait kinematic measurements, should include joint kinetic measurements and should decrease the variability of measured gait by choosing a more focused research population who use walkers. 
MANUSCRIPT 2

Use of an obstacle course and user preferences to compare anterior and posterior walkers in older adults 


\begin{abstract}
Objective: Determine the efficacy of an anterior versus a posterior wheeled walker in the older adult population. Design: Repeated measures, within subject design. Setting: Senior Center, Charlottesville, VA Participants: 20 independent, community-living adults 79.1 years $( \pm 6.7)$ years. Measurements: Time (s) required to perform a simple obstacle course with an anterior and a posterior wheeled walker. User preferences as determined by a simple questionnaire. Results: The obstacle course times were significantly longer with the posterior walker $(\mathrm{P}<0.0001)$. Seventy-five percent of the participants preferred the anterior walker, $15 \%$ preferred the posterior walker, and $10 \%$ had no preference. Conclusions: Although improved design might increase the popularity and maneuverability of the posterior walker, the anterior walker appears superior in this older population.
\end{abstract}




\section{INTRODUCTION}

Ideally, a mobility device should be examined in the setting and manner in which it will be used. Usually, however, this is not possible. More often, use of an assistive device is examined in a clinical setting. Within the clinic, however, clinicians can simulate the tasks and obstacles the user will encounter with the device during their daily life. Using a mobility device in an open, unobstructed area, in a straight line does not provide the user or the clinician a clear indication of the user's ability to function with the device in a real life environment. For this reason, maneuvering through obstacles is often included in the evaluation and training of assistive devices. Few research studies ${ }^{36-38}$, however, include obstacle courses in their investigation of assistive devices or general mobility.

Although cited infrequently, obstacle courses have been used in the literature to compare two different models of similar equipment. Nielsen et al ${ }^{36}$ evaluated regular and rocker bottom crutches on a course of ramps, stairs and level surfaces. Similarly, Hughes et al. ${ }^{37}$ used an obstacle course with a variety of surfaces and tasks to evaluate two different types of wheelchair wheels. In both cases, the time to complete the course failed to show a significant difference in the two products, however, upon assessing user preferences, in both studies, users reported preferences of one product over the other.

The research comparing anterior and posterior walkers in children with cerebral palsy did not use obstacle courses in their methods. The literature did, however, investigate user preferences on uneven surfaces such as grass and gravel ${ }^{19}$. The results of this research showed that the participants either preferred the posterior walker on gravel and grass or found no difference between the two walkers on the uneven surfaces. 
Similarly, the child participants in Grenier et al. ${ }^{19}$ rated the posterior walker easier to use during play than the anterior walker. Even though these studies on anterior and posterior walkers in children examined user preferences on different surfaces, they did not obtain any objective measurements of users walking with the device over the various surfaces. Performing timed trials over the various surfaces would have provided a more objective measurement comparing the walkers' performance.

Approximately $30-50 \%$ of all assistive devices issued to individuals are not used $1,39,40$. One of the main reasons cited for device abandonment or disuse is that the device is too "cumbersome" to use ${ }^{40}$. Assessing a device in the context of an obstacle course or maze may demonstrate the maneuvering limitations of the mobility device. Assistive devices with improved design promoting maneuverability and ease of use might be less likely to be abandoned by the user.

A negative evaluation of the device as well as lack of user involvement in selection of the device have also been cited as common reasons for device abandonment 1,40. These reasons both indicate the importance of user feedback in selecting a mobility device. Even though a device might prove to be clinically beneficial, if the user does not approve of the device, it may remain unused.

In summary, the purpose of an obstacle course was twofold: Firstly, the time required to complete the course provided an objective measure of the relative efficacy of the two walkers. Secondly, after performing an obstacle course with each of the two walkers, the participant obtained relevant experience with which to evaluate the devices. This experience assisted the participant in choosing a preference and providing feedback 
evaluating the two walkers. The purpose of this study is to compare the efficacy of the anterior and posterior walkers on the criteria of maneuverability and user preference.

\section{METHODS}

This study followed a crossover design. The independent variable was the type of walker (anterior or posterior). The dependent variables were the time required to complete the obstacle course and the user preference data. Some of the user preference questions were closed ended (anterior or posterior) and some were open ended. The open ended question data was reported in a qualitative descriptive manner.

\section{Subjects}

Twenty adults older than 55 years of age who may benefit from using a wheeled walker were recruited through local physical therapy clinics and senior centers using flyers and posters. Flyers and posters were approved by the University of Virginia Institutional Review Board-Health Sciences Research (IRB-HSR \# 12712).

The volunteers are individuals who benefit from the use of a wheeled walker due to gait instability. Inclusion in the study was determined by an physical therapist with extensive experience issuing walkers to older adults. A brief gait evaluation of the subject was performed to determine inclusion or exclusion criteria. Individuals qualified for participation if any of the following were found: lateral gait deviation, shortened stride length, loss of balance, weaving gait, shuffling gait. Volunteers were excluded if they had an observable asymmetric gait, poor motor control or if they had lower extremity contractures. In order to participate, volunteers needed to have adequate upper 
extremity function to hold onto the walker and needed to be able to understand and follow the instructions in English.

\section{Instruments}

The questionnaire (Table 2) used to assess user preferences was created for this study. Face validity of the questionnaire was determined by potential participants and was approved by University of Virginia Institutional Review Board-Health Sciences Research. Two commercially available walkers were used for comparison. The posterior wheeled walker chosen was the Wenzelite Posterior Safety Roller by Drive Medical Design and Manufacturing (Port Washington, NY). This was the only posterior wheeled walker made for adults which was found to be commercially available at the time of this research. The anterior wheeled walker was the the Guardian Envoy 460 Economy Rolling Walker, part number 07886G (Sunrise Medical, Carlsbad, CA). The anterior walker was chosen because it has four wheels like the posterior walker and is commonly used by adults with gait limitations. 

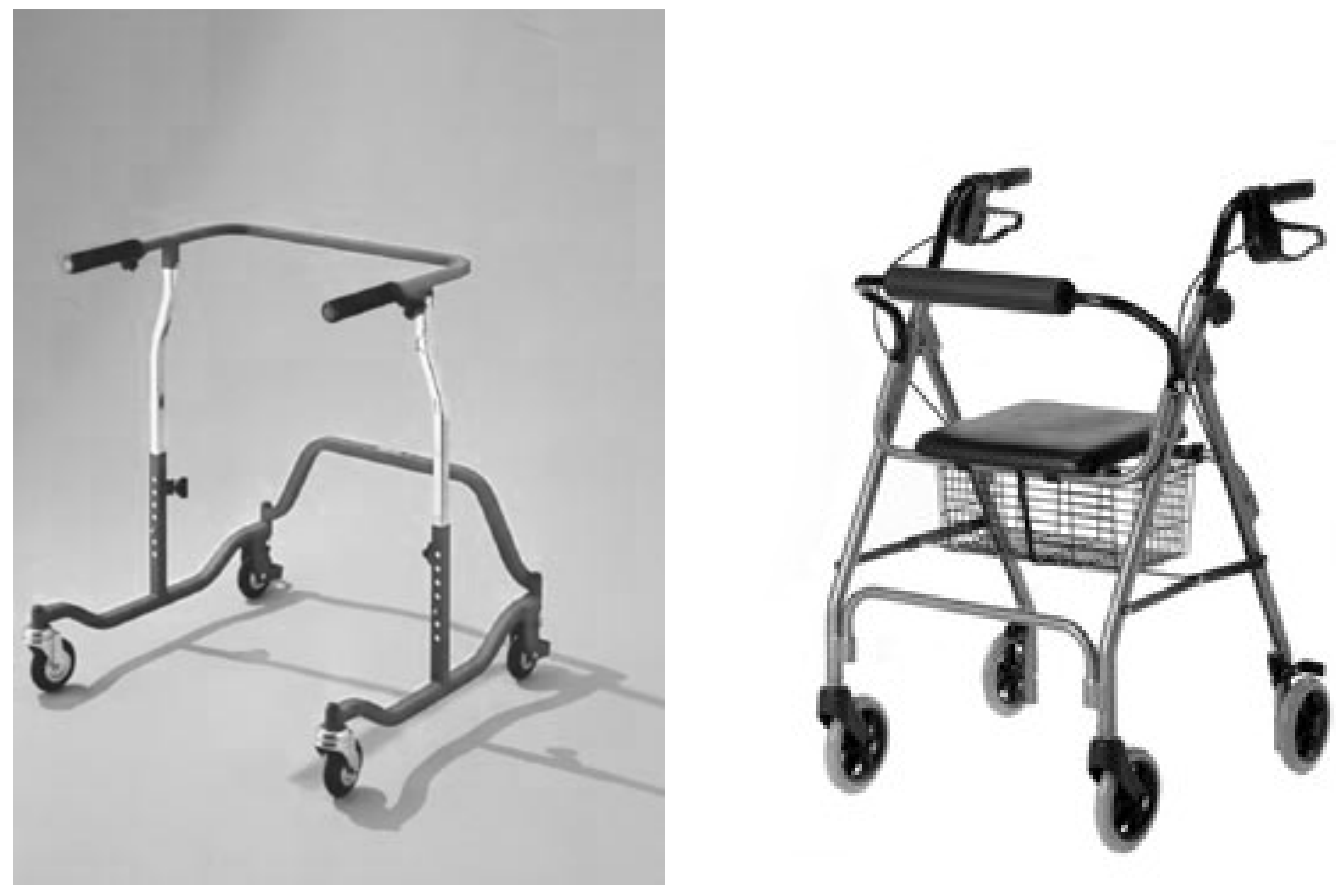

Figure 1. Wenzelite Posterior Safety Roller (left) and the Guardian Envoy 460 Economy Rolling Walker (right).

\section{Procedure}

Informed consent was obtained prior to participation. Consent forms, recruitment material and study protocol were all approved by the University of Virginia Human investigation committee (IRB HSR \#12712).

The two walkers were fit to the user based on conventional fitting recommendations ${ }^{24}$. According to O'Sullivan \& Schmitz ${ }^{24}$, the top of the walker should come to the height of the participant's greater trochanter and should allow for 20-30 degrees of elbow flexion. Both walkers, after fitting, were the same height at the hand rests.

An obstacle course adapted from Special Olympics 25m motorized wheelchair obstacle course was constructed on the linoleum floor of the senior center. The pathway 
was created using tape markings on the floor and cones to guide the participant. The obstacle course was explained prior to performance. The length of the course was 16 meters and the course had several turns in it (See Figure 2). The course was modified from the original 25 meter length to 41 feet due to limitations in the testing area and in order to make it more appropriate for a walker. The participants were instructed to perform the course at their preferred pace. The course was timed and completed with both the anterior and the posterior walker. No gait kinematics were recorded during the obstacle course. The course starting and finishing times were recorded using a stopwatch.

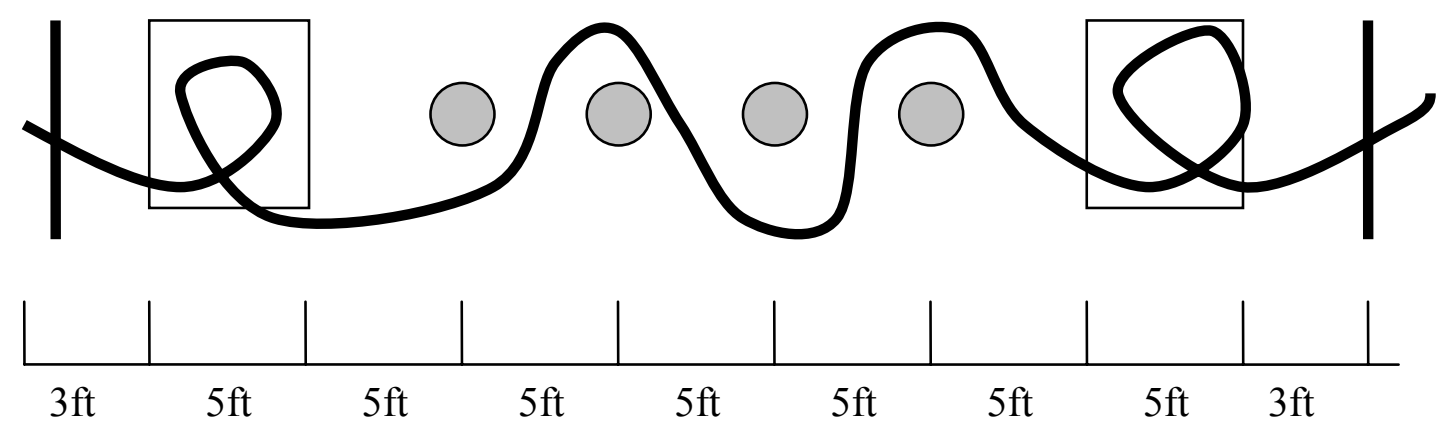

Figure 2. Obstacle course adapted from Special Olympics Summer Sports Rules, Athletics, 25 meter motorized wheelchair obstacle course.

After completing the obstacle course, the participants were asked to complete a questionnaire about their opinions of the walkers (Table 2). The participants had the option of reading and answering the questionnaire independently or the option of the 
researcher reading the questions to the participant and recording his or her answers. The questionnaire's content was validated by the author prior to the study. Questions on the questionnaire included both multiple choice and open ended:

Table 2 Questionnaire about anterior and posterior walkers.

1. Which walker did you prefer?

2. Why did you prefer it?

3. Which walker felt easier to use?

4. Which walker made you feel more safe or more stable?

5. Which do you think is more practical for daily use?

6. What did you like (if anything) about the anterior walker?

7. What did you NOT like (if anything) about the anterior walker?

8. What did you like (if anything) about the posterior walker?

9. What did you NOT like (if anything) about the posterior walker?

\section{Statistical analysis}

Statistical analysis of the obstacle course times will be analyzed using a paired ttest with a two tailed test of significance and a significance level of 0.05 . The questionnaire results will be reported descriptively.

\section{RESULTS}

Ten men and 10 women with an average age of 79.1 years $( \pm 6.7)$ completed the obstacle course and the preference questionnaire. All participants at least occasionally used a cane as per inclusion requirements. The obstacle course times ranged from 22 seconds to 74 seconds (Table 3 ). The users performed the course significantly slower with the posterior walker than with the anterior walker $(t=-5.06, P<0.0001, d=1.27,1$ $\beta=0.96)$. All participants were able to complete the obstacle course with both walkers without assistance. Occasional verbal cues were required in order to perform the second circle and to walk across the finish line. 
The participants preferred the anterior walker over the posterior walker. Some reasons cited for their preferences included easier maneuverability, being able to see the walker, and the presence of the seat and brakes. The results from the preference questionnaire are reported descriptively in Tables 4 and 5.

Table 3. Obstacle course times with the two different walkers reported in seconds $(\mathrm{p}<0.0001, \mathrm{~d}=1.27)$.

\begin{tabular}{ccc}
\hline \hline Participant & Anterior walker & Posterior walker \\
\hline 1 & 25.34 & 30.5 \\
2 & 27.15 & 32.61 \\
3 & 40.72 & 49.25 \\
4 & 43.93 & 37.6 \\
5 & 41.17 & 56.31 \\
6 & 31.06 & 53.49 \\
7 & 28.78 & 39.15 \\
8 & 41.19 & 50.88 \\
9 & 37.07 & 45.44 \\
10 & 50.5 & 53.75 \\
11 & 33.77 & 38.89 \\
12 & 28.53 & 39.18 \\
13 & 45.53 & 58.51 \\
14 & 30.59 & 33.04 \\
15 & 51.09 & 74.59 \\
16 & 34.85 & 51.36 \\
17 & 35.84 & 34.22 \\
18 & 31.37 & 35.42 \\
19 & 22.17 & 28.75 \\
20 & 27.6 & 31.23 \\
AVG & 35.41 & 43.71 \\
SD & 8.29 & 11.97 \\
\hline
\end{tabular}

Table 4. Results of participant questionnaire questions $1,3,4,5(\mathrm{n}=20)$.

\begin{tabular}{lccc}
\hline \hline & $\begin{array}{c}\text { Anterior } \\
\text { walker }\end{array}$ & $\begin{array}{c}\text { Posterior } \\
\text { walker }\end{array}$ & $\begin{array}{c}\text { No } \\
\text { preference }\end{array}$ \\
\hline Which walker did you prefer? & $75 \%$ & $15 \%$ & $10 \%$
\end{tabular}


Which walker felt easier to use?

Which walker made you feel more safe or more stable?

Which walker is more practical for daily use?
$70 \%$

$75 \%$

$95 \%$
$15 \%$

$20 \%$

$0 \%$
$15 \%$

$5 \%$

$5 \%$

Table 5 Summary of questions 2,6,7,8,9 $(n=20)$.

\begin{tabular}{|c|c|c|}
\hline \multicolumn{3}{|c|}{$\begin{array}{l}\text { Number of individual comments on various } \\
\text { walker characteristics }\end{array}$} \\
\hline & Better with & Better with \\
\hline & Anterior & Posterior \\
\hline Brakes & 4 & \\
\hline Seat & 6 & \\
\hline Maneuverability & 11 & \\
\hline Could visualize & 7 & \\
\hline Stand up straighter & & 2 \\
\hline Stability & 1 & 2 \\
\hline Less work & 3 & \\
\hline Size/weight/bulky & 4 & 1 \\
\hline Easier to get into & 1 & \\
\hline
\end{tabular}

\section{DISCUSSION}

The existing literature on posterior walkers did not use obstacle courses to evaluate their effectiveness ${ }^{19-23}$. However, with regard to preferences, the children as well as their parents consistently preferred the posterior walker over different surfaces and for a variety of activities ${ }^{19,23}$. Furthermore, when oxygen consumption was used as a measure of the amount of work needed to walk with the two walkers, the only study 
which found a significant difference between the two walkers, found the posterior walker required less oxygen consumption than the anterior walker ${ }^{21}$. The pediatric research on posterior walkers found the posterior walker to be superior to the anterior walker in both user preference and energy expenditure ${ }^{19,21,23}$.

These current results, however, show that the adult population clearly does not find the posterior walker easier to use, nor preferable to the anterior walker. Some of the reasons for these differences between this research using adults and the pediatric research are discussed here.

One of the reasons participants in this study preferred the anterior walker to the posterior walker was a sense of security when being able to see the anterior walker in front of them. Older adults are clearly concerned about safety and falling ${ }^{41}$. As a result, they feel strongly about stability and controlling the walker. Children, on the other hand, are much less concerned about falling and safety. Instead, they have a fearless, desire to explore movement and the world around them ${ }^{42}$. This difference in their confidence level and desire for personal safety is one distinct difference between these two populations which may, in part, explain the differing opinions about the posterior walker.

Another reason for this difference in opinion could be the type of disability experienced by these two groups. Older adults have decreased balance, strength and range of motion due to aging ${ }^{7,43,44}$. Children with $\mathrm{CP}$ have an upper motor neuron disorder which causes spasticity and poor motor control ${ }^{45,46}$. The older adults in this population were neurologically intact with no upper motor neuron dysfunction. This fundamental difference in the type of disability clearly creates different needs for an assistive device. 
A third explanation for the different outcomes seen in the pediatric and adult populations could be the amount of time provided for the users to become accustomed to the device. In Park et al. ${ }^{21}$, pediatric participants were given both types of walkers 1 month prior to data collection to allow the participants to become accustomed to the devices. Providing additional time in which to learn how to use and maneuver the posterior walker might have yielded different results in this current study. In this research, participants were only given a short practice period immediately prior to data collection in order to become accustomed to the device. Many older adults have some experience pushing an anterior walker in front of them, however, few have ever used a posterior walker. This lack of experience with a posterior walker might lead to slower obstacle course times and poor opinions of the unfamiliar assistive device.

The purpose of this research was to assess differences between posterior and anterior walkers in the adult population. The posterior walker which was used was chosen because it was the only commercially available posterior walker which could be used by adults. The complaints about the posterior walker may stem from design details other than the posterior positioning of the device. For example, the wheels on the posterior walker are smaller than those of the anterior walker which was used in this study (See Figure 1). This might decrease the maneuvering capability of the device. A commonly used pediatric posterior walker (See Figure 3) has some design differences when compared to this adult posterior walker. Perhaps the design of the pediatric walker allows greater ease of use than that of the adult posterior walker. 


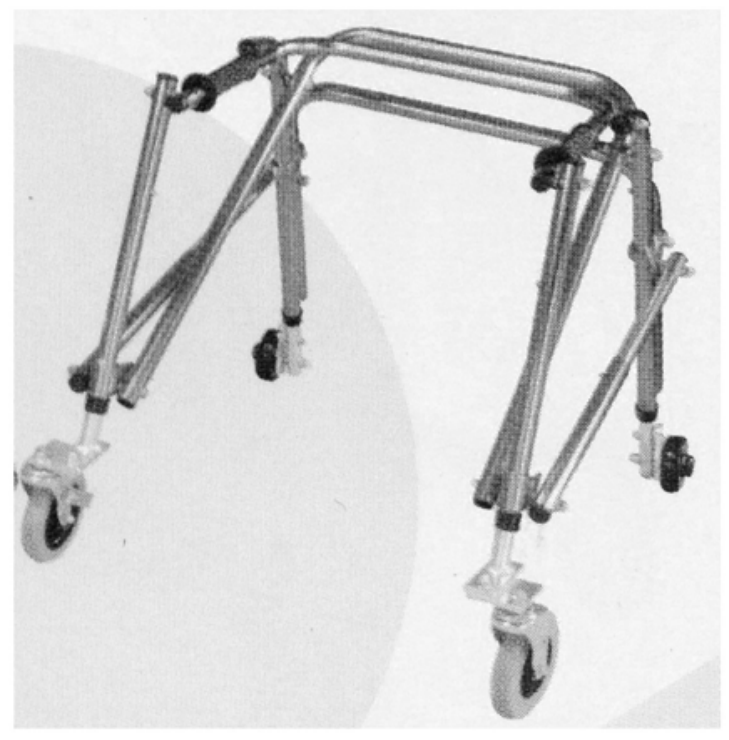

Figure 3. Nimbo lightweight posterior safety roller by Wenzelite Rehab a division of Drive Medical Design \& manufacturing.

Finally, due to the greater weight requirements of an adult user, the adult posterior walker must be stronger and more durable than a pediatric walker. Four participants commented in their questionnaires about the greater size/weight/bulkiness of the posterior walker when compared to the anterior walker (See Table 5). Perhaps future designs should use a material which allows stability and strength with less weight.

Two reasons the participants stated for preferring the anterior walker over the posterior walker were the presence of brakes and a seat on the anterior walker. Although the participants were instructed to not use the brakes during the testing session, they clearly saw these as positive features on an assistive device. The desire for brakes on an assistive device further indicates the preference for stability and safety. Future designs of a posterior walker should try and include brakes and a seat as these have been identified as desirable characteristics by potential users. Future research on the use of posterior 
walkers in adults should focus on improving the design of the posterior walker and finding specific adult populations which may benefit from this device.

It is possible that the posterior walker does not have a place in assisting the daily life of adults with disabilities. The posterior walker might be more appropriate as a rehabilitation tool used in clinics and hospitals to improve specific gait deficits in certain populations. Given that many adults felt less secure and safe with the posterior walker than with the anterior walker, one use might be as an assistive device to be used in the progression away from a wheeled walker toward independent gait without any assistive device. The current conventional progression from gait with a walker to independent gait would be from a walker, to a cane, and finally to walking without an assistive device of any kind ${ }^{47,48}$. The posterior walker might be useful as a transitional step between the anterior walker and the cane in individuals who have difficulty making the transitions. Another possibility for future research investigating uses of the posterior walker in older adults would be to use the posterior walker to target those adults who walk with extreme trunk flexion when walking with the anterior walker. The posterior walker has been shown to increase trunk and hip extension compared with the anterior walker in children with cerebral palsy. Even though the posterior walker had very modest effects on trunk position in this general older population, the posterior walker might be effective in adults who have extreme problems with trunk flexion with the anterior walker. The posterior walker might be a useful rehabilitation tool in correcting posture problems in adults who walk with assistive devices.

In spite of its lack of maneuverability and the generally negative responses by users of the posterior walker, the posterior walker may still have a useful role in the 
rehabilitation of disabled adults. Improving the design of the device to include larger wheels, an improved turning radius, decreased weight, and adding features such as brakes and a seat might improve the usefulness of this device. If this device fails to find a place in the daily life of adults with disabilities, it might be a useful rehabilitation tool to improve the gait biomechanics and gait ability of certain adults who use walkers for locomotion. However, given the results of this research, the anterior walker appears preferable to the posterior walker both in maneuverability and user preference.

In conclusion, the posterior walker was found to be significantly slower than an anterior walker in a simple obstacle course. Similarly, users qualitatively preferred the anterior walker to the posterior walker. Although some design improvements might make the posterior walker more popular and easier to manipulate, the anterior walker appears clearly preferable in this older adult population. 
MANUSCRIPT 3

Therapist evaluations of adult gait with anterior and posterior walkers 


\begin{abstract}
Objective: To evaluate the effectiveness of posterior walkers in older adults using visual gait analysis. Design: Repeated measures, within subject design.

Setting: Senior Center, Charlottesville, VA Participants: 20 independent, communityliving adults 79.1 years $( \pm 6.7)$ years. 5 physical therapist raters. Measurements: Five physical therapists were asked to observe video data of 5 older adults ( 75 years \pm 5 ) walking with both anterior and posterior walkers. While viewing the video data, the physical therapists were asked to complete a modified version of the Gait Abnormality Rating Scale (GARS) for each of the 5 participants with each of the 2 walkers for a total of 10 assessments. After completing the GARS assessments for each participant, the physical therapists were asked their general preference between the two walkers.
\end{abstract} Results: The GARS showed poor intraclass correlation coefficients $(\mathrm{ICC}=0.413,0.582)$ between the therapist raters. Also, there was no difference between the GARS scores with the anterior and posterior wheeled walkers. The physical therapists had mixed preferences about the two different walkers. Conclusions: Recommendations for the GARS include 1) several group training sessions with all raters in an attempt to maximize the ICC, 2) using only one rater, or 3) using a different assessment tool with better reliability for visual gait analysis. Future research should investigate using visual gait analysis to evaluate other assistive devices such as canes, crutches and walkers to see if consistent biomechanical differences with these walking aids can be quantified. In conclusion, the therapists saw no consistent improvement in gait biomechanics when the participants walked with the posterior walker versus the anterior walker. 


\section{INTRODUCTION}

The effectiveness of a walker is usually determined by some form of gait assessment of the user walking with the device. Clinical gait analysis can vary from an extensive computer instrumented evaluation lasting hours, to a simple observation lasting only minutes. Objective measurements of gait kinematics usually require expensive instrumentation and time consuming applications and analyses. More frequently, clinicians perform an uninstrumented visual gait analysis to quickly identify any gait deviations. In order to improve the reliability of uninstrumented gait analysis, Wolfson et al. ${ }^{9}$ created an instrument, the gait abnormality rating scale (GARS), for health care professionals to systematically evaluate the biomechanics of gait during a visual gait analysis.

The GARS (Table 6) was devised as a gait rating system that could be easily carried out in the clinic and would only require a video camera. The format of the GARS breaks down the assessment into three general categories: a) general, b) lower extremity and c) head, trunk and upper extremities. Within these main categories, there are 16 criteria which are graded by the assessor. The accuracy and sensitivity of many of the criteria, such as knee and hip range of motion during gait, could be assessed by comparing them to an instrumented gait analysis. However, review of the literature revealed no such comparison between the GARS and instrumented gait analysis. The GARS sensitivity and specificity has been determined by its ability to predict individuals who fall $(62.3 \%, 87.1 \%)$ and its validity has been determined using gait parameters such as stride length and gait speed ${ }^{49}$. The GARS has not been used to show changes due to 
an intervention. Whether the GARS is sensitive enough to detect changes within an

individual before and after treatment, remains to be seen.

Table 6.Gait Abnormality Rating Scale (GARS) ${ }^{9}$ :

A. General categories

1. Variability - a measure of inconsistency and arrhythmicity of stepping and of arm movements

$0=$ Fluid and predictably paced limb movements;

$1=$ Occasional interruptions (changes in velocity), approximately $<25 \%$ of time;

$2=$ Unpredictability of rhythm approximately $25-75 \%$ of time;

$3=$ Random timing of limb movements.

2. Guardedness - hesitancy, slowness, diminished propulsion and lack of commitment in stepping and arm swing.

$0=$ Good forward momentum and lack of apprehension in propulsion;

$1=$ Center of gravity of head, arms and trunk (HAT) projects only slightly

in front of push-off, but still good arm-leg coordination;

$2=$ HAT held over anterior aspect of foot, and some moderate loss of smooth reciprocation;

$3=$ HAT held over rear aspect of stance-phase foot, and great tentativity in stepping.

3. Weaving- an irregular and wavering line of progression

$0=$ Straight line of progression on frontal viewing;

$1=$ A single deviation from straight (line of best fit) line of progression;

$2=$ Two to three deviations from line of progression;

$3=$ Four or more deviations from line of progression.

4. Waddling - a broad-based gait characterized by excessive truncal crossing of the midline and side-bending

$0=$ Narrow base of support and body held nearly vertically over feet;

$1=$ Slight separation of medial aspects of feet and just perceptible lateral movement of head and trunk;

$2=3-4$ " separation feet and obvious bending of trunk to side so that COG of head lies well over ipsilateral stance foot;

3 = extreme pendular deviations of head and trunk (head passes lateral to ipsilateral stance foot) and further widening of base of support.

5. Staggering - sudden and unexpected laterally directed partial losses of

balance

$0=$ No losses of balance to side;

$1=$ A single lurch to side

$2=$ Two lurches to side;

$3=$ Three or more lurches to side.

B. Lower extremity categories 
1. \% time in swing - a loss in the percentage of the gait cycle constituted by the swing phase.

$0=$ Approximately 3:2 ratio of duration of stance to swing phase;

1=A 1:1 or slightly less ratio of stance to swing;

2 = Markedly prolonged stance phase, but with some obvious swing time remaining;

$3=$ Barely perceptible portion of cycle spent in swing

2. Foot contact - the degree to which heel strikes the ground before the

forefoot

$0=$ Very obvious angle of impact of heel on ground;

$1=$ Barely visible contact of heel before forefoot;

$2=$ Entire foot lands flat on ground;

$3=$ Anterior aspect of foot strikes ground before heel.

3. Hip ROM - the degree of loss of hip range of motion seen during a gait

cycle

$0=$ Obvious angulation of thigh backwards during double support (10

deg);

$1=$ Just barely visible angulation backwards from vertical;

$2=$ Thigh in line with vertical projection from ground.

$3=$ Thigh angled forwards from vertical at maximum posterior excursion.

4. Knee ROM - the degree of loss of knee range of motion seen during a gait cycle.

$0=$ Knee moves from complete extension at heel strike (and late stance) to 70-90 deg during swing phase.

$1=$ Slight bend in knee seen at heel strike and late stance and maximal flexion at midswing is closer to $45 \mathrm{deg}$ than $90 \mathrm{deg}$.

$2=$ Knee flexion at late stance more obvious than at heel-strike, very little clearance seen for toe during swing;

$3=$ Toe appears to touch ground during swing, knee flexion appears constant during stance, and knee angle during swing appears 45 deg or less.

C. Trunk, head, and upper extremity categories

1. Elbow extension - a measure of the decrease of elbow range of motion $0=$ Large peak-to-peak excursion of forearm (approximately $20 \mathrm{deg}$ ), with distinct maximal flexion at end of anterior trajectory;

$1=25 \%$ decrement of extension during maximal posterior excursion of upper extremity;

$2=$ Almost no change in elbow angle;

$3=$ No apparent change in elbow angle (held in flexion)

2. Shoulder extension; a measure of the decrease of shoulder range of motion

$0=$ Clearly seen movement of upper arm anterior (15 deg) and posterior (20 deg) to vertical axis of trunk; $1=$ Shoulder flexes slightly anterior to vertical axis; 
$2=$ Shoulder comes only to vertical axis, or slightly posterior to it during glexion;

$3=$ Shoulder stays well behind vertical axis during entire excursion.

3. Shoulder abduction - a measure of pathological increase in shoulder range of motion laterally

$0=$ Shoulders held almost parallel to trunk;

$1=$ Shoulders held 5-10 deg to side

$2=$ Shoulders held 10-20 deg to side

$3=$ Shoulders held greater than $20 \mathrm{deg}$ to side.

4. Arm-Heelstrike synchrony - the extent to which the contralateral movements of an arm and leg are out of phase.

$0=$ Good temporal conjunction of arm and contralateral leg at apex of shoulder and hip excursions all the time;

$1=$ Arm and leg slightly out of phase $25 \%$ of the time;

$2=$ Arm and leg moderately out of phase $25-50 \%$ of the time;

$3=$ Little or no temporal coherence of arm and leg.

5. Head held forward - a measure of the pathological forward projection of the head relative to the trunk

$0=$ Ear-lobe vertically aligned with shoulder tip;

1 = Ear-lobe vertical projection falls 1" anterior to shoulder tip;

2 = Ear-lobe vertical projection falls 2" anterior to shoulder tip;

3 = Ear-lobe vertical projection falls 3" or more anterior to shoulder tip;

6. Shoulders held elevated - the degree to which the scapular girdle is held higher than normal

$0=$ Tip of shoulder (acromion) markedly below level of chin (1-2");

$1=$ Tip of shoulder slightly below level of chin;

$2=$ Tip of shoulder at level of chin;

3 = Tip of shoulder above level of chin.

7. Upper trunk flexed forward - a measure of kyphotic involvement of the trunk

$0=$ Very gentle thoracic convexity, cervical spine flat, or almost flat;

$1=$ Emerging cervical curve, more distant thoracic convexity;

$2=$ Anterior concavity at mid chest level apparent;

$3=$ Anterior concavity at mid chest level very obvious.

In a principle component analysis performed by Brach et al. ${ }^{50}$, the modified GARS score was found to be a powerful predictor of physical function along with gait speed and grip force. In a regression model, Branch showed that age, gait speed and the 
modified GARS score accounted for $65 \%$ of the total variance seen in physical function. Age and gait speed alone only accounted for $58 \%$ of the variance.

The authors of the GARS determined an interrater reliability measure of 0.95 using a Spearman correlation coefficient ${ }^{9}$. The scores of two different raters were compared across 6 pilot subjects. A Spearman correlation coefficient of 0.95 shows a high degree of correlation or correspondence, however, correlation does not necessarily reflect agreement. Close correlation without agreement is possible when scores are consistently different while changing similarly across subjects. Hence, two sets of scores can have a high degree of correlation without a high degree of agreement. In order to address both phenomena, correspondence and agreement, more recent research instead uses the intraclass correlation coefficient to describe reliability. Published in 1990, Wolfson et al. reported only the Spearman correlation coefficient and did not report an ICC value for the GARS.

There are other visual gait scales such as the Rancho Los Amigos Gait Analysis form and Tinetti's Balance and Mobility Assessment profile ${ }^{51}$. However, these forms do not allow for intermediate grades of impairment. For example, on the Rancho Los Amigos Gait Analysis form, the grader evaluates the absence or presence of foot slap and pelvic drop with no allowance for intermediate grades of foot slap or pelvic drop. In such a form, the total score will only improve if one gait deviation disappears completely. Similar problems exist for Tinetti's assessment tool. Due to this binary type of scoring, these tools are unlikely to show score changes due to interventions within an individual.

The sensitivity of visual gait analysis tools are also, in part, limited by the sensitivity and accuracy of the clinician's ability to visually estimate joint position. 
According to a study by Molony et al. ${ }^{52}$, healthcare professionals who are accustomed to assessing joint angles are better than the general public at visually estimating angle measurements. Orthopedic surgeons who participated in the study were able to visually estimate a drawn angle within 7 degrees on average. Compared to the human eye, an instrumented form of joint angle assessment, the electrogoniometer made by Biometrics, reports an accuracy within 2 degrees. Vicon, a common video motion analysis system, is able to measure a static angle within 0.6 degrees ${ }^{33}$. Vicon however, has been shown to have some problems with inter rater and intra rater reliability due to variations in marker application. In a reliability study examining Vicon's ability to measure joint angle during clinical gait analyses, a wide range of ICC's were found for both inter and intra rater reliability ${ }^{32}$. Inter rater reliability of joint angle measurements during gait ranged from an ICC of -0.04 for peak hip extension to 0.83 for peak knee extension. Intra rater reliability from gait assessments performed on two different days ranged from and ICC of 0.05 for peak knee flexion to 0.70 for peak ankle extension. In summary, although vision is not as accurate as some of the instrumented forms of assessment, even instrumented forms of gait assessment can show significant error.

The purpose of this study was to use a team of physical therapists and the GARS to evaluate gait in older adults with two different walkers. The ICC of the GARS in this application with these raters must be assessed to determine its usefulness. I hypothesize that therapists will find fewer gait abnormalities with the GARS gait scale when participants use the posterior walker than when participants use the anterior walker. 


\section{METHODS}

This study was a cross-over design. The independent variable is the type of walker. The dependent variables are the GARS score, and the therapist preferences.

\section{Subjects}

Five adults older than 50 years of age with decreased balance, endurance or strength who may benefit from using a wheeled walker were recruited through local physical therapy clinics and senior centers using flyers and posters. Flyers and posters were approved by the University of Virginia Institutional Review Board-Health Sciences Research (IRB-HSR \#12712).

Volunteers were individuals who occasionally or regularly benefited from an assistive device such as a cane. However, individuals needed to be able to walk 60 feet on a level surface independently without an assistive device, without assistance and without risk of falling. A brief gait evaluation of the subject was performed to determine inclusion or exclusion criteria. Individuals qualified for participation if any of the following were found: lateral gait deviation, shortened stride length, loss of balance, weaving gait, or shuffling gait. Volunteers were excluded if they had an observable asymmetric gait, poor motor control or if they had lower extremity contractures. In order to participate, volunteers needed to have adequate upper extremity function to hold onto the walker and needed to be able to understand and follow the instructions in English.

Five physical therapists volunteered to participate in this study. All had active licensure in the state of Virginia and greater than one years experience. All participating therapists had experience with gait training of older adults with different assistive devices. 


\section{Instruments}

Gait with both walkers was captured with two digital video cameras. One camera taped a sagittal view, the second taped a frontal view of the participant walking with the two walkers. The video data was viewed by therapists on a personal computer of their choosing. The therapists had the ability to slow the movement to view it one frame at a time or to stop the video to see a still frame.

Two commercially available walkers were used for comparison. The posterior wheeled walker chosen was the Wenzelite Posterior Safety Roller by Drive Medical Design and Manufacturing (Port Washington, NY). This was the only posterior wheeled walker made for adults which was commercially available and easily obtained at the time of this research. The anterior wheeled walker was the Guardian Envoy 460 Economy Rolling Walker, part number 07886G (Sunrise Medical, Carlsbad, CA). The anterior walker was chosen because it has four wheels like the posterior walker and is commonly used by adults with gait limitations.

The GARS was shown to have high inter rater reliability with Spearman $\rho$ ranging from .6 to .9 on each of the items and a $\rho$ of .95 for the total scores ${ }^{9}$. In the authors' validation research, the total score from the GARS was significantly higher for fallers than non fallers, and the total score correlated negatively with stride length in this population of nursing home residents. The portions of the GARS pertaining to arm swing were removed (C1-4) because the participants' arm movement was restricted due to holding the walkers.

\section{Procedures}


Informed consent was obtained prior to participation. Consent forms, recruitment material and study protocol were all approved by the University of Virginia Human Investigation Committee (IRB HSR \# 12712). Video data was collected at Senior Center Inc. (1180 Pepsi Place, Charlottesville, VA 22901).

The two walkers were fit to the user based on conventional fitting recommendations ${ }^{24}$. Both walkers were the exact same height at the hand rests.

All five participants were videotaped walking in a straight line with two different walkers, an anterior walker and a posterior walker. The participants were videotaped from a side (sagittal) view and from an anterior (frontal) view. Informed consent included instruction that the participant would be videotaped and that the video would be shown to physical therapists for evaluation.

Five therapists from the University of Virginia Health System agreed to assist with the visual gait evaluations in this study. Each therapist was provided digital video data of the 5 participants walking with the two different walkers from the anterior and sagittal views. All therapists viewed the same 10 videos, 5 participants each with two different walkers. The therapists were provided instructions and copies of the GARS to evaluate each participant. (See Appendix C, Table C3). The order in which the video data was graded was counter balanced to avoid order effects. Prior to the GARS video ratings, all five therapists met together for one session in order to view, evaluate, and discuss the grading of one practice video. This was done in an attempt to improve the consistency of grading. The practice video was that of a participant ambulating without any walker. A video with no walker was chosen in order to avoid discussion of the study 
phenomena among the therapists and to prevent the development of a systematic rater bias.

After completing the GARS for each participant, the therapist was asked a few questions about their general preferences about the walkers.

\section{Statistical analysis}

The intraclass correlation coefficient (ICC) was found for the GARS scores for inter rater reliability. The ICC was determined using the methods outlined in Case 2 as described by Shrout and Fleiss ${ }^{53}$. Case 2 was chosen because in this application, all 5 participants were assessed by all 5 raters. Due to the two conditions of gait with an anterior and a posterior walker, two different ICC values were found. A repeated measures ANOVA was performed with the GARS scores to determine main effects of trends for raters, and walker type. A repeated measures ANOVA was used to compare the two GARS scores (one for each walker) within each subject.

\section{RESULTS}

The five participants who were videotaped while walking with the two walkers included 3 men and 2 women and had an average age of $75( \pm 5)$. Two ICC values were found describing the agreement between GARS raters in the condition of 1) the anterior walker and 2) the posterior walker. The ICC for the GARS assessing gait with the anterior walker was 0.413 . The ICC for the GARS assessing gait with the posterior walker was 0.582 . There was no difference in the GARS scores assessing gait with the two different walkers $(\mathrm{P}=.561)$. (For complete GARS scores see Table 7.) 
The therapists preferences are reported descriptively in Table 8 . The questionnaires revealed mixed responses with no clear preference between the two walkers. Even within each of the subjects, therapists disagreed on which walker was preferable.

Table 7. GARS Scores comparing gait with anterior and posterior walker

\begin{tabular}{ccccccccccc}
\hline \hline Rater & \#1 Ant & \#1 Post & \#2 Ant & \#2 Post & \#3 Ant & \#3 Post & \#4 Ant & \#4 Post & \#5 Ant & \#5 Post \\
\hline A & 8 & 7 & 11 & 9 & 10 & 11 & 4 & 3 & 8 & 4 \\
B & 9 & 8 & 12 & 9 & 10 & 10 & 5 & 5 & 9 & 8 \\
C & 4 & 5 & 13 & 13 & 5 & 7 & 7 & 6 & 7 & 8 \\
D & 12 & 7 & 13 & 12 & 9 & 7 & 6 & 5 & 5 & 9 \\
E & 6 & 10 & 7 & 10 & 6 & 9 & 5 & 3 & 8 & 9 \\
\hline Mean & 7.8 & 7.4 & 11.2 & 10.6 & 8 & 8.8 & 5.4 & 4.4 & 7.4 & 7.6 \\
SD & 3.0 & 1.8 & 2.5 & 1.8 & 2.3 & 1.8 & 1.1 & 1.3 & 1.5 & 2.1 \\
\hline
\end{tabular}

Table 8. Therapist preferences: Results of general questionnaire comparing gait with anterior and posterior walkers.

\begin{tabular}{|c|c|c|c|c|c|}
\hline & Therapist A & Therapist B & Therapist C & Therapist D & Therapist E \\
\hline \multicolumn{6}{|l|}{ Participant \#1 } \\
\hline prefer overall & No preference & Anterior & No preference & Anterior & Anterior \\
\hline safety & No preference & Anterior & No preference & Anterior & Anterior \\
\hline posture & No preference & Anterior & No preference & Posterior & No preference \\
\hline ease of use & No preference & Anterior & No preference & Anterior & Anterior \\
\hline biomechanics & No preference & Anterior & No preference & No preference & Anterior \\
\hline \multicolumn{6}{|l|}{ Participant \#2 } \\
\hline prefer overall & Posterior & Posterior & No preference & Anterior & Posterior \\
\hline
\end{tabular}




\begin{tabular}{|c|c|c|c|c|c|}
\hline safety & Posterior & No preference & No preference & Anterior & Anterior \\
\hline posture & Posterior & Posterior & No preference & No preference & Posterior \\
\hline ease of use & No preference & No preference & No preference & Anterior & Anterior \\
\hline biomechanics & Posterior & No preference & No preference & Anterior & No preference \\
\hline \multicolumn{6}{|l|}{ Participant \#3 } \\
\hline prefer overall & Anterior & Anterior & No preference & Anterior & Anterior \\
\hline safety & Anterior & Anterior & Anterior & Anterior & Anterior \\
\hline posture & Posterior & Anterior & Posterior & Posterior & Posterior \\
\hline ease of use & Anterior & Anterior & Anterior & Anterior & Anterior \\
\hline biomechanics & Posterior & Anterior & Anterior & No preference & No preference \\
\hline \multicolumn{6}{|l|}{ Participant \#4 } \\
\hline prefer overall & No preference & Posterior & No preference & Posterior & No preference \\
\hline safety & No preference & Posterior & No preference & No preference & No preference \\
\hline posture & No preference & Posterior & No preference & Posterior & No preference \\
\hline ease of use & No preference & Posterior & No preference & No preference & Anterior \\
\hline biomechanics & No preference & Posterior & No preference & Posterior & No preference \\
\hline \multicolumn{6}{|l|}{ Participant \#5 } \\
\hline prefer overall & No preference & Anterior & Anterior & Anterior & Posterior \\
\hline safety & No preference & Anterior & No preference & Anterior & Anterior \\
\hline posture & No preference & No preference & Posterior & Posterior & Posterior \\
\hline ease of use & No preference & Anterior & Anterior & Anterior & Anterior \\
\hline biomechanics & No preference & No preference & Anterior & Anterior & No preference \\
\hline
\end{tabular}

\section{DISCUSSION}

According to Portney \& Watkins ${ }^{54}$, ICC values greater than 0.75 are indicative of good reliability. The ICC values found for the GARS in this research were 0.58 and 0.41 . In the original article introducing the GARS, Wolfson et al. ${ }^{9}$ measured inter-rater reliability with a Spearman correlation coefficient of 0.95 . This correlation showed the close agreement between the two raters who performed the GARS assessments. The reasons behind the disparity between Wolfson et al.'s reported reliability and the ICC values found in this current research are discussed here. 
In their research presenting the GARS, Wolfson et al. ${ }^{9}$ describe their training sessions in preparation for using the GARS. They stated that the two raters participated in a series of video rating training sessions using 6 pilot subjects. During the training sessions, the two raters discussed and compared their scoring systems. This current research tried to duplicate this training session, however, the 5 raters graded and discussed only 1 pilot subject in only 1 session. It follows that more training sessions with additional pilot subjects might improve the consistency of scoring between the raters.

In this vein, a study by Russell et al. ${ }^{55}$ showed increased reliability measures after clinicians received additional training on the Gross Motor Function Measure (GMFM), an instrument used to assess general motor skills in children with cerebral palsy ${ }^{56}$. In order to ensure standardized training of test users and to maintain an acceptable level of reliability, the distributors of the GMFM currently include a self-training instructional $\mathrm{CD}$ when the test is purchased. Providing the appropriate training for a clinical tool is a difficult task and yet, in the case of the GMFM and perhaps the GARS, it appears necessary in order to maintain an acceptable level of reliability. Future GARS users should stress the importance of multiple training sessions in order to maximize the ICC between raters.

Another possible source of variation could arise from the greater number of raters used in this current research when compared to the Wolfson et al. study ${ }^{9}$. According to an article discussing inter-rater reliability, Saito et al. ${ }^{57}$ stated that in cases where between rater variance is uncertain, a design with approximately equal numbers of raters and subjects is favorable for determining inter-rater reliability. Wolfson et al. measured 
inter-rater reliability using only two raters and 49 subjects. This small number of raters and large number of subjects might have resulted in an greater correlation than if they had a larger rater to subject ratio.

As stated previously, Wolfson et al. ${ }^{9}$ used a Spearman correlation coefficient to measure the interrater reliability of their instrument. Historically, many research articles used correlation coefficients to describe reliability. However, more recent sources on this subject state that correlation coefficients are a misleading estimate of reliability. A correlation coefficient only reflects an association between two groups of scores and does not reflect an actual agreement between the ratings. Hence, the ICC is used to overcome these limitations. The ICC reflects both the degree of correspondence and agreement among ratings ${ }^{54}$. Further investigation into the reliability of the GARS should examine the agreement between the individual items on the GARS to determine which items are problematic and which are useful.

The GARS scores showed no difference between walking with the anterior walker and with the posterior walker. The similarity between GARS scores with each of the walkers follows a similarity in gait kinematics when the participants walked with the two walkers and the mixed response in the general therapist preferences between the two walkers. However, the lack of agreement between the GARS ratings by different therapists when viewing the exact same video data, suggests a poor reliability of the GARS measure in this research.

Another recommendation for improvement, would be to facilitate the visual joint assessment by having participants wear optimal clothing. In this current study, participants were only asked to wear pants (not a skirt) and comfortable walking shoes. 
Visual gait analysis might have been improved if the participants had worn tight fitting clothing, such as spandex, to allow better visual assessment of the joints and biomechanics during gait. Similarly, during the video taped gait trials, the participants were wearing electrogoniometers for related research, this added instrumentation might have distracted the therapists during their GARS assessment of the participants.

Future research should investigate methods to improve the reliability and sensitivity of visual gait assessment. Visual gait analysis is used frequently in the clinic to evaluate effectiveness of various interventions, however the methods are usually qualitative and unstandardized. Clinicians need a standardized, reliable and sensitive measure to determine differences in gait within an individual over time. Evaluating the gait of an individual with different assistive devices, such as canes, walkers and crutches would be a likely and useful application of a reliable, quantitative visual gait analysis measure.

In conclusion, the GARS failed to achieve an acceptable level of reliability among the 5 raters in this application. Also, the 5 physical therapists failed to reach a general consensus on whether the posterior walker improved gait biomechanics compared to an anterior walker. Recommendations include increasing the reliability of the GARS by increasing the number of training sessions, by using only 1 rater or instead, using a different visual gait analysis tool. In this population of older adults with only minor gait deviations, the posterior walker does not appear to consistently improve the biomechanics of gait when compared to an anterior walker. 


\section{APPENDIX A: THE PROBLEM}

\section{Research question}

Manuscript 1

This study was designed to address the following questions:

1. Does walking with a posterior walker facilitate increased hip extension in older adults when compared to gait with an anterior walker?

2. Does walking with a posterior walker facilitate increased stride length in older adults when compared to gait with an anterior walker?

3. Does walking with a posterior walker facilitate differences in peak low back, knee or ankle angles?

Manuscript 2:

This study was designed to address the following questions:

1. Are older adults able to maneuver a posterior walker through an obstacle course more quickly than an anterior walker?

2. Do older adults prefer walking with a posterior walker than an anterior walker? Manuscript 3:

This study was designed to address the following questions:

1. Is there a significant difference in the GARS score of older adults walking with a posterior walker when compared to an anterior walker?

2. Do therapists subjectively prefer the gait of adults walking with a posterior walker when compared to an anterior walker? 


\section{Experimental hypotheses}

Manuscript 1:

1. Older adults will walk with significantly more hip extension with the posterior walker than with the anterior walker.

2. Older adults will walk with longer stride length with the posterior walker than with the anterior walker.

3. Older adults will have similar low back and ankle angles when walking with an anterior or a posterior walker.

Manuscript 2:

1. Older adults will perform the obstacle course faster with the posterior walker than with the anterior walker.

2. Older adults will prefer walking with the posterior walker.

Manuscript 3:

1. The GARS score will be lower when the subjects walk with the posterior walker than when they walk with the anterior walker.

2. The therapists will prefer the gait with the posterior walker over the gait with the anterior walker. 


\section{Operational definitions:}

Ankle dorsiflexion: From neutral, the foot is aligned at an acute angle to the calf or is moving toward a position of an acute angle to the calf ${ }^{25}$.

Ankle plantarflexion: From neutral, the foot is aligned at an obtuse angle to the calf or is moving in the direction of an obtuse angle to the calf ${ }^{25}$.

Anterior walker: A walking frame which is positioned in front of the user and is pushed in front of the user.

Device abandonment: Discontinued use of an assistive device which was, at one time, considered appropriate due to physical functional limitations ${ }^{39}$.

Disabled: Adjective which describes individuals with physical limitations in fulfilling their societal roles ${ }^{58}$.

Functional limitation: Inability to perform an age appropriate activity which the individual must perform on a regular basis ${ }^{58}$.

Gait cycle: Time period taking place during walking from the point where the heel strikes the ground until the next time that same heel strikes the ground ${ }^{59}$.

Gait deviations: Movement deviations observed during walking which are considered by movement practitioners to be outside the normal limits of the walking parameters of young, healthy adults ${ }^{59}$.

Gait instability: Describes a walking pattern where the individual is unable to consistently control their center of mass and keep it within his or her base of support ${ }^{60}$. Gait mechanics: Continuous, relative positions of extremities, trunk and head during walking ${ }^{59}$. 
Hip extension: Hip angles where lower thigh and knee are positioned back behind the pelvis, or the act of the hip moving back behind the pelvis ${ }^{25}$.

Hip flexion: Hip angles where lower thigh and knee are positioned anterior to (in front of) the pelvis, or the act of the hip moving in the direction anterior to the pelvis ${ }^{25}$. Knee extension: Knee is in the straightest position possible or with the foot even slightly anterior to the thigh line, or the act of moving toward a straightened position ${ }^{25}$. Knee flexion: Knee is in a bent position or moving toward a bent position with the heel moving backwards toward the thigh ${ }^{25}$.

Low back extension: Trunk position or angle is positioned more posterior, or leaning backwards, from neutral, or the act of the trunk moving toward a more posterior or backwards position relative to the lower extremities ${ }^{25}$.

Low back flexion: Trunk position is leaning forward or more anterior from neutral, or the act of the trunk moving to a more anterior or forward position relative to the lower extremities $^{25}$.

Neutral position: The trunk and lower extremities in the neutral position are positioned as follows: the foot is positioned at a right angle to the calf, calf is positioned in a straight line with the thigh, thigh is aligned to bisect the iliac crest, pelvis is positioned with anterior superior iliac spine and posterior superior iliac spine at equal heights, rib cage aligned upright, directly above pelvis. In the neutral position, all joint angles (ankle, knee, hip, low back) are described as having zero degrees of flexion or extension ${ }^{25}$. Obstacle course: Artificially created mobility test varied locomotion tasks used to assess one's speed or ability. 
Posterior walker: A walking frame which is positioned behind the user and is pulled behind rather than pushed in front of the user.

Preferred gait speed: Comfortable walking velocity that an individual adopts in the absence of speed related instructions.

\section{Assumptions}

1. The kinematic data as captured by the electrogoniometers accurately reflect the actual joint angle(s) during gait.

3. Participants answered in an honest unbiased manner about their walker preferences.

4. The participating physical therapists correctly followed all instructions in performing the GARS and answered in an honest, unbiased manner.

5. The therapists and the participants understood all instructions and questionnaires.

\section{Limitations}

There are no known limitations to these studies.

\section{Delimitations}

1. Participants with physical deficits which resulted in an asymmetric gait were excluded including but not limited to those with paralysis, paresis, leg length discrepancies, and amputations.

2. Participants needed to be able to walk independently and safely with a walker.

3. Participants were over the age of 55 years.

4. The gait was observed on a flat, open, level surface. 
5. The participants only had a short period of time to become familiar with the device.

6. Participants had to have adequate upper extremity function to use a walker.

7. Participants who could not understand English or who were not capable of following instructions were excluded.

8. Participants were all active older adults who are not homebound and who regularly attend senior center activities.

\section{Significance of the study}

\section{Manuscript 1}

Certain gait parameters, like stride length and hip extension have been linked to a greater risk of falling and decline in function in older adults. Improving gait biomechanics may provide great economic benefits to society as well as improved quality of life in this population. Given the large number of people who use assistive devices to help with ambulation, investigation into the best walker design to optimize gait biomechanics is of great clinical interest. The variety of assistive devices available in the pediatric population are not available to the older population. The reasons behind this difference should be investigated to determine whether there is a clinical foundation or if the difference is simply due to custom. Using posterior walkers in older adults may improve their biomechanics of gait and, in turn, improve their safety and function. 


\section{Manuscript 2}

Although biomechanics of gait are important in determining the effectiveness of an assistive device, an effective mobility device needs to be maneuverable in a variety of contexts. Individuals use assistive devices not just for walking but for performing various activities of daily living. By performing a timed obstacle course, one can easily compare the maneuverability of two different walkers and perhaps find inadequacies in one design over another. A systematic comparison of two different walkers in an obstacle course provides important data about the effectiveness of the two assistive devices.

\section{Manuscript 3}

Physical therapists often play an important role in choosing assistive devices for older adults. Although objective computer-aided measurements provide important insight into gait, physical therapists have clinical experience and training which assists them in determining the most appropriate assistive device for an individual. Using clinicians and a clinical gait assessment tool will help determine the appropriateness of using posterior walkers in older adults. It is of great interest to survey the opinion of therapists in assessing a mobility device and to use their clinical abilities to assess the quality of gait with each of the assistive devices. 


\section{APPENDIX B: LITERATURE REVIEW}

The purpose of this literature review is to discuss disability in older adults, describe some common gait deviations seen in older adults, examine the role of various walkers in mitigating gait disability, and illustrate the importance of gait biomechanics in general function in older adults.

\section{Significance}

Optimizing gait in adults with disabilities is of great importance to general health. Ambulation is known to be important in maintaining general health and independence ${ }^{2-}$ 5,61. As our population ages, it behooves our society to help individuals with balance and strength deficits to maintain and maximize their mobility as long as possible. Assistive devices enable some to continue independent gait longer than otherwise might be possible ${ }^{62}$. When individuals instead begin using a wheelchair as their primary mode of transportation instead of walking, they have an increased risk of health complications ${ }^{63-}$ 65.

From an economic perspective, limiting disability in the older poplation greatly decreases the burden of Medicare and Medicaid expenses. One source estimated that the decrease in reported disability in the elderly between 1982 and 1994 saved 17.3 billion dollars in nursing home costs in 1994. Approximately half of all nursing home care is paid for by Medicaid. Because this older population uses a disproportionate share of healthcare resources, health initiatives targeting this population provide the greatest economic benefit ${ }^{6}$. In addition to monetary gains, independent mobility is linked to improved quality of life and decreased morbidity in older adults ${ }^{4}$. 


\section{Prevalence of disability}

A survey of the residents of the state of New York showed increasing trends in the percentage of adults who consider themselves disabled. Eighteen percent of adult New Yorkers considered themselves as disabled in 2001 and 20\% considered themselves disabled in 2003. The survey identified inadequate physical activity as a risk factor for disability. Disability rates trended upwards in all age groups during the reported time span ${ }^{66}$.

In a conflicting analysis, however, Cutler ${ }^{67}$, reported that disability rates are declining. To support his claim, the author cites a decline in nursing home residence from $5.4 \%$ of the population in 1985 to $4.6 \%$ of the population in 1995 . He also cites results from the National Long Term Care Survey (NLTCS) ${ }^{68}$ which states that $25 \%$ of elderly adults were dependent in 1984 but only $19 \%$ of the population were considered dependent in 1999. The survey data actually reports a decline in dependence across all age groups over time but, of course, the prevalence of dependence in older adults is much higher than that of younger adults.

The disparity in these reports on the rate of change of disability in the United States likely stems from the authors' different definitions of disability. Steele measured disability as anyone who felt he or she was limited in any way due to physical, emotional or mental problems. However, Cutler measured disability in a number of different ways including nursing home residency and dependence on others for assistance.

\section{Definition and description of disability}

To address discrepancies such as these, several different definitions of disability have been proposed. One common paradigm used to discuss disability is the Nagi model 
58. This model describes four levels or layers of disability. (See Figure 1.) The most basic level of disability addresses the cellular level of pathology. This describes the disruption at the tissue level itself. The next level, the impairment, describes the effect that the pathogen or injury has on the body. The third level, the functional limitation describes what specific activities the individual is unable to do as a result of the physiological disruption. Finally, the fourth level, the disability, describes how the individual is limited in his or her ability to fulfill his or her role(s) in society.

Using the relevant example of osteoarthritis, the concepts can be clearly illustrated. The pathology of osteoarthritis is the abnormal cartilaginous and bony changes which take place in the joint. The impairment might be pain with weight bearing through the joint. The functional limitation could be that the individual is unable to perform stairs . Finally, the disability may be that individual is unable to perform his or her job because it includes tasks involving stairs. Although Cutler and Steele's definitions both address the disability level, where Steele is including any individual with any limitations in his or her ability to function, Cutler includes only those who are unable to function without significant assistance from others ${ }^{66,67}$.

\begin{tabular}{|c|c|c|c|}
\hline $\begin{array}{l}\text { Pathology: } \\
\text { Disruption at } \\
\text { tissue or } \\
\text { cellular level }\end{array}$ & $\begin{array}{l}\text { Impairment: } \\
\text { Structural } \\
\text { abnormality, } \\
\text { body system } \\
\text { dysfunction }\end{array}$ & $\begin{array}{l}\text { Functional } \\
\text { Limitation: } \\
\text { Restriction in } \\
\text { basic, physical } \\
\text { or cognitive } \\
\text { activities }\end{array}$ & $\begin{array}{l}\text { Disability: } \\
\text { Limitations } \\
\text { in fulfilling } \\
\text { roles in } \\
\text { society }\end{array}$ \\
\hline
\end{tabular}

Figure B 1. Nagi Model of Disability ${ }^{58}$ 
Assistive devices such as walkers, canes and wheelchairs do not improve disabilities at the pathological or the impairment levels but instead try to address the disability at the functional limitation or disability level. A walker will not actually improve the pathological processes of arthritis or neurological dysfunction, but instead enable the individual to fulfill his or her roles in society. A walker could enable the individual to mobilize and perform roles such as a consumer, a grandparent or a church member. In his article, Cutler ${ }^{67}$ actually cites innovative assistive device design as a partial explanation of his findings of declining disability rates. Designing assistive devices that mitigate the functional limitations of the individual are of great value in decreasing the level of disability even though they do not address the disease process itself.

Disability should be viewed as a dynamic state rather than a static one.

Transitions between periods of being disabled and not being disabled are common in adults over 70 years of age ${ }^{4,61}$. Female sex, older age and physical frailty are associated with greater likelihood of transitioning to more disabled states. Gill et al. ${ }^{61}$ followed 754 community living, nondisabled adults over 70 years of age and investigated the number and severity of periods disability. Eighty three percent of the participants experienced at least one period of decreased ambulation ability during the 5 year study period.

However, the majority of those participants were able to return to an independent level of function. The findings suggest that efforts should not be restricted to preventing disability but also on restoring independent mobility in those who are experiencing a temporary period of disability.

\section{Age and disability}


Disability rates increase with increased age and increased co morbidities.

Disabled adults walk slower and avoid walking long distances. Similarly, they avoid going out in to the community due to obstacles such as crossing streets or performing stairs ${ }^{51}$. This cycle of disability where disabled adults mobilize less and in turn become more disabled results in great costs to society.

Approximately one third of people over 65 lead a sedentary life style. Research performed by the CDC showed that increasing activity in sedentary adults of all ages could save as much as 77 billion health care dollars. Moreover, the report states that the greatest economic gains would be obtained by increasing physical activity in women over 55 years of age ${ }^{69}$.

Arthritis is the most commonly reported cause of disability. Approximately half of people over the age of 65 report having arthritis. More than $1 / 3$ of those with arthritis have activity limitations due to arthritis ${ }^{69}$. Osteoarthritis is the most prevalent condition associated with mobility device use, affecting 1.2 million mobility device users as the primary cause of disability ${ }^{70}$.

\section{Characteristics of disabled and aged gait}

Even though a significant number of people use assistive devices for mobility impairments, most gait analysis research of adults with disabilities is performed on gait without assistive device. Assistive device use can make gait analysis more difficult and the added support of the assistive device can hide gait impairments which are valuable in diagnosis, treatment and research. For these reasons much of the gait literature on older adults includes only adults who can walk without an assistive device. Even though the research populations exclude a relevant portion of the older disabled population, this 
research provides insight into the gait changes seen with increased age and increased disability.

The literature consistently reports some common gait deviations in older adults when compared to younger adults. These include shorter stride length, lack of hip and knee extension during gait, increased hip extensor moment during gait, and decreased ankle power during gait ${ }^{7,8,10-12}$.

One study performed in Japan ${ }^{11}$ attempted to tease out the gait deviations caused by painful gait from gait differences due to pain free aging gait . The study compared gait parameters of adults 65- 94 years of age with and without activity related knee pain. As one would expect, the younger seniors, aged 65-79 years, performed better on functional tests than the older seniors, aged 80-94. Also, the younger seniors had longer stride lengths and chose a faster preferred walking speed than older adults. When comparing younger seniors with and without knee pain, the younger seniors with knee pain had shorter stride lengths and walked slower than those age matched participants without knee pain. However, in the older age group, adults 80-94. There were no differences in functional tests, stride length or gait speed between older seniors with and without knee pain. According to these results, both pain and age have similar disabling effects. Furthermore, after a certain age, pain does not provide further mobility disablement beyond that of aging alone. Hence, some therapeutic interventions which improve gait limitations in older adults, may improve gait limitations in elderly with and without arthritic joint pain.

Devita and Hortobagyi ${ }^{8}$ compared gait of older and younger adults but at controlled gait speeds. They found that the older participants maintained more hip 
flexion throughout the gait cycle, but had greater range of motion excursion at the hip than the younger participants. When analyzing joint torques and powers the authors found a redistribution of joint torques and powers in the older adults when compared to the younger adults. The authors found that the older adults exerted the greatest percentage of torque at the hip. The younger adults exerted more similar extensor torques at the hip, knee and ankle. The total positive work performed across the three joints was similar in the older and younger adults, but the distribution between the joints differed.

Devita and Hortobagyi suggested one explanation for the more flexed position of the hip joint throughout gait might be in order to stretch the hip extensor muscles and as a result, produce a larger torque output at the hip. The authors state that as adults age, there is a "shift in the locus of function" (p. 1807) ${ }^{8}$ from the ankle to the hip. Hence, older adults use less ankle power in order to walk and more hip power. In the study, the authors concluded that the reason for the lack of ankle power in the older adults was not entirely due to weakness in the ankle musculature but due to a change in motor control strategy with aging.

McGibbon and Krebs ${ }^{10}$ also compared gait kinematics and moments in younger and older adults. They compared three groups: healthy younger adults, healthy older adults and disabled older adults. All disabled adults had musculoskeletal impairments, due to arthritis, deconditioning and/or weakness. Similar to Devita and Hortobagyi ${ }^{8}$, the authors found greater hip moments in disabled older adults when compared to young and old healthy adults. They also found decreased ankle plantar flexor moment in disabled older adults when compared to healthy older and younger adults. McGibbon and Krebs 
didn't find any significant differences in hip kinematics during gait in the three groups. However, the healthy and disabled elders had a significantly lower peak ankle plantar flexion angle than the younger adults.

Presence of absence of ankle power in older adults has also been investigated as an indicator of general function. Functional tasks such as stair climbing, gait and chair rising have been found to be correlated with the individual's peak isokinetic ankle power both in dorsiflexion and plantarflexion ${ }^{71}$. Similarly, low peak plantarflexion strength has been linked to falling in institutionalized older adults ${ }^{72}$. However, some have suggested that this lack of ankle torque could be related to hip function. Even though the testing positions in these studies isolated ankle function from hip function, lack of hip extension during gait and other weight bearing activities might lead to a decline in ankle power over time. When limitations exist in two parts of the kinetic chain, it is very difficult to determine which, if either, is the primary limitation.

A study by Kerrigan et al. showed that peak hip extension during gait was the only leg joint parameter measured during walking that was both lower in elderly nonfallers and fallers when compared to young adults, and was lower in elderly fallers when compared to elderly non fallers ${ }^{7}$. Even when the older adults increased walking speed to be equal to or greater than the walking speeds of young adults, peak hip extension did not increase significantly.

Kerrigan et al. ${ }^{16}$ performed a follow up study on the role of hip extension in gait in older adults where they examined the effects of a hip flexor stretching program in this population. Participants performed ten minutes of hip stretching exercises each day for ten weeks. Gait analysis was compared before and after the stretching intervention. 
Modest improvements averaging approximately 2 degrees were seen in both static and dynamic hip extension measurements when compared to a control group. No difference, however, was seen in hip extension torque, during gait, before and after the intervention. In addition to increases in hip extension during gait, increases were also seen in ankle plantarflexion angles and ankle plantar flexion power even though no direct intervention was performed at the ankle.

\section{Effect of joint kinematic differences on general function}

Although difficult to prove, some research does show that poor biomechanics do negatively impact function. As cited previously, Kerrigan et al. ${ }^{7}$ found a correlation between increased hip flexion position during gait and a history of falling. It is unclear whether the lack of hip flexion is a cause or a symptom of disability. However, this link between gait kinematics and function exists.

Another study by Jacobs et al. ${ }^{13}$ showed that even when healthy adults simulated pathological biomechanics, they experienced a decrease in stability. The authors asked healthy older adults (average age 64) to stand in a posture mimicking that of a person with Parkinson's disease. They were instructed to stand with flexed hips and flexed knees. The healthy participants stood with an average of 7 degrees of hip flexion, and 23 degrees of knee flexion. (This was statistically similar to the stance of the participants with Parkinson's disease.) In standing, their stability was measured using an index comparing the relative positions of the center of pressure and center of mass. Although the stability of the healthy participants did not decrease to equal that of the participants with Parkinson's disease, the stability of the healthy adults standing in a flexed posture was significantly decreased when compared to their stability in upright stance. 
These results by Jacobs et al. ${ }^{13}$ reinforce those of Kerrigan et. al ${ }^{7}$ suggesting that maintaining this stooped position of hip and knee flexion has a negative effect on stability. The decrease in stability seen in this position might explain why those subjects with increased hip flexion have greater falls. Kerrigan did not directly comment on knee position during gait in this research, however, other authors performing gait analysis of older adults have found knee position in addition to hip position to be more flexed during gait in older adults ${ }^{8,10}$.

Given this research linking gait kinematics to falls and stability, one can no longer deny the importance of rectifying the gait changes seen with aging. Previously, one might have argued that these changes in gait that accompany aging are a normal, healthy response of the body to the physiological changes of aging. However, this research by Jacobs ${ }^{13}$ and Kerrigan ${ }^{7}$ shows that these kinematic differences are dysfunctional and should be targeted with therapeutic interventions. These changes of increased hip and knee flexion during gait create instability and increase the risk of falling.

\section{Walker assisted gait}

Interventions for general gait instability include strengthening, balance training, stretching, or introduction of an assistive device. Although these other interventions have been shown to be effective for improving balance and gait ${ }^{14-16}$, ambulatory devices, such as walkers, canes and crutches, remain the main form of treatment for most gait disorders 73.

Of those who use mobility devices for disabilities, $64 \%$ use a cane, $24 \%$ use a walker and $21 \%$ use a wheelchair. Other mobility devices used include crutches, scooters, and medical shoes. Each of these are used by less than $10 \%$ of mobility device 
users. (These numbers add up to greater than $100 \%$ because some individuals regularly use more than one assistive device to mobilize.) Seventy-eight percent of walker users are over the age of 65 years. In total, 1.4 million adults over the age of 65 use walkers to ambulate ${ }^{17}$.

Although there exists a variety of walker designs, most walkers fall into one of three possible types: no wheeled, two wheeled or a four wheeled walker. According to an article by Van Hook, Demonbraun and Weiss ${ }^{73}$, which walker is issued depends on the amount of weight bearing the user needs to place through his or her upper extremities and through the device. If the user needs to place a lot of body weight through the device, as in the case of a broken leg, a standard, no wheeled walker is most appropriate. If the walker is being used more for balance or energy conservation and minimal weight needs to be placed through the device, then a four wheeled walker is most appropriate. In between the two is the two wheeled walker. This should be used if weight only occasionally or partially needs to be exerted through the device.

In spite of the frequency of walker use, there exists a dearth of research on gait with walkers. A Medline search of 'walker' combined with 'gait' combined with 'biomechanics' revealed 25 studies (1996 to present). None of the studies found examined gait kinematics of older adults while ambulating with a walker. Further searches including other terms for walkers such as rollator also failed to find research investigating lower extremity biomechanics of aging gait with walkers.

One study performed by Alkjaer et al. ${ }^{18}$ examined the gait of young healthy adults with and without a four wheeled walker. The authors found that with the four wheeled walker, the participants had decreased ankle dorsiflexion, knee flexion and hip 
extension during stance when compared to gait without the walker. Furthermore, the joint moments were significantly different. The peak knee joint moment was reduced by approximately 50\%. The peak ankle plantarflexion moment was similarly decreased with walker use. Conversely, the angular impulse of hip extensors was significantly larger when the participants used the walker than when they didn't. This increase in hip extensor impulse might be in part due to the more flexed position of the hip during gait. Another reason for the increase in hip extension impulse could be the need for increased hip extensor force in order to push the walker forward.

Regardless of the underlying reasons, this gait analysis of young healthy adults shows that pushing a walker causes gait changes which are similar to those seen with aging including increased hip flexion and decreased plantar flexion moment ${ }^{18}$. Interestingly, there was no difference in preferred gait speed when walking with and without the walker. The authors did not comment on stride length or cadence.

\section{Research comparing anterior and posterior walkers}

All of the walkers commonly used in the adult population are placed anterior to the user. In the pediatric population, however, wheeled walkers placed posterior to the user are commonly used, particularly with children with cerebral palsy. The user's hands still rest on the walker at his or her sides, however, there is no equipment directly in front of the user. Instead the walker wraps around behind the user and is open in front. (See Figures 2 and 3.) Although the research is somewhat limited, some literature does compare anterior and posterior four wheeled walkers in this younger population. 


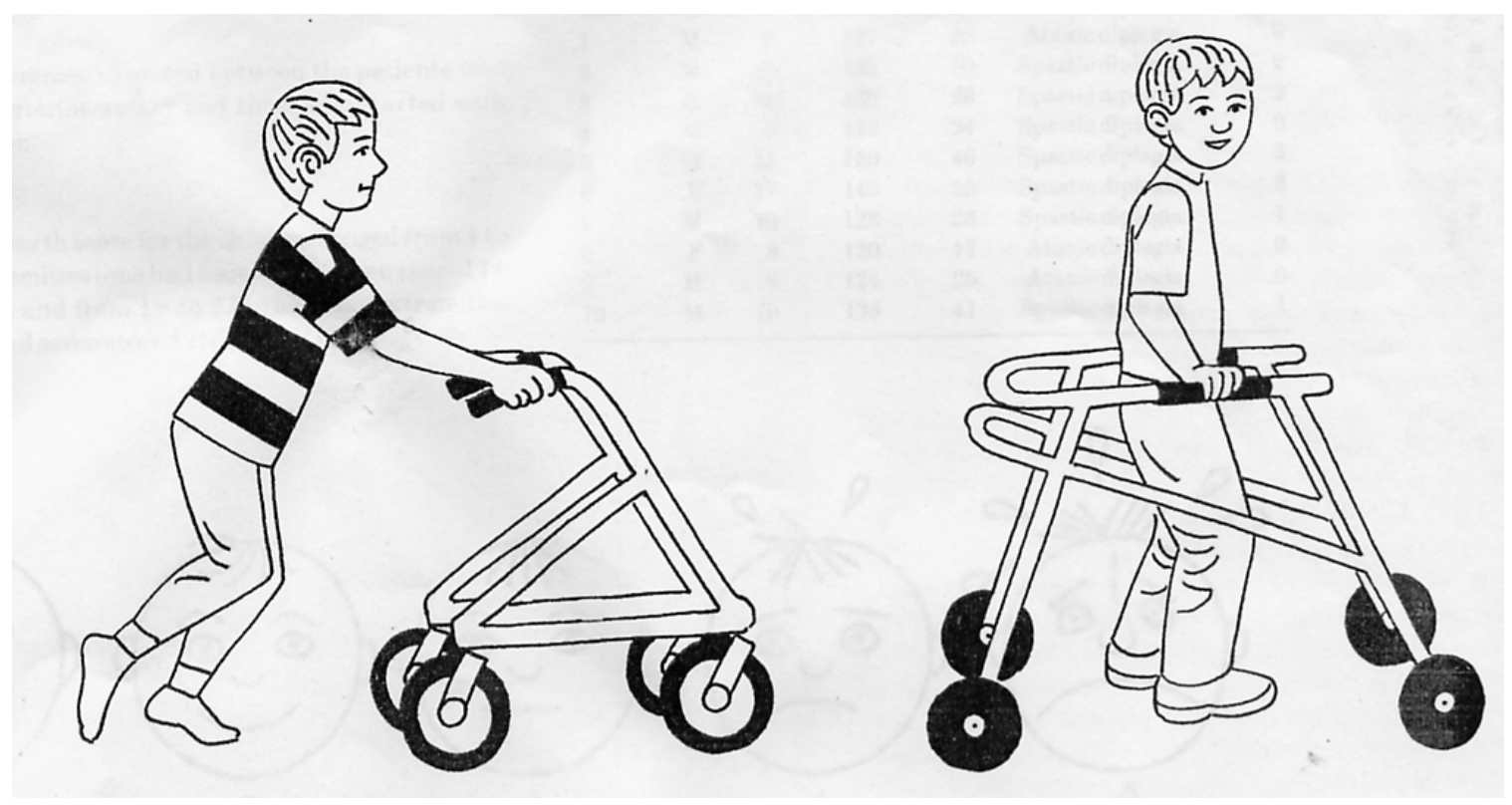

Figure B 2. Illustration of child with anterior walker (left) and posterior walker (right) ${ }^{23}$

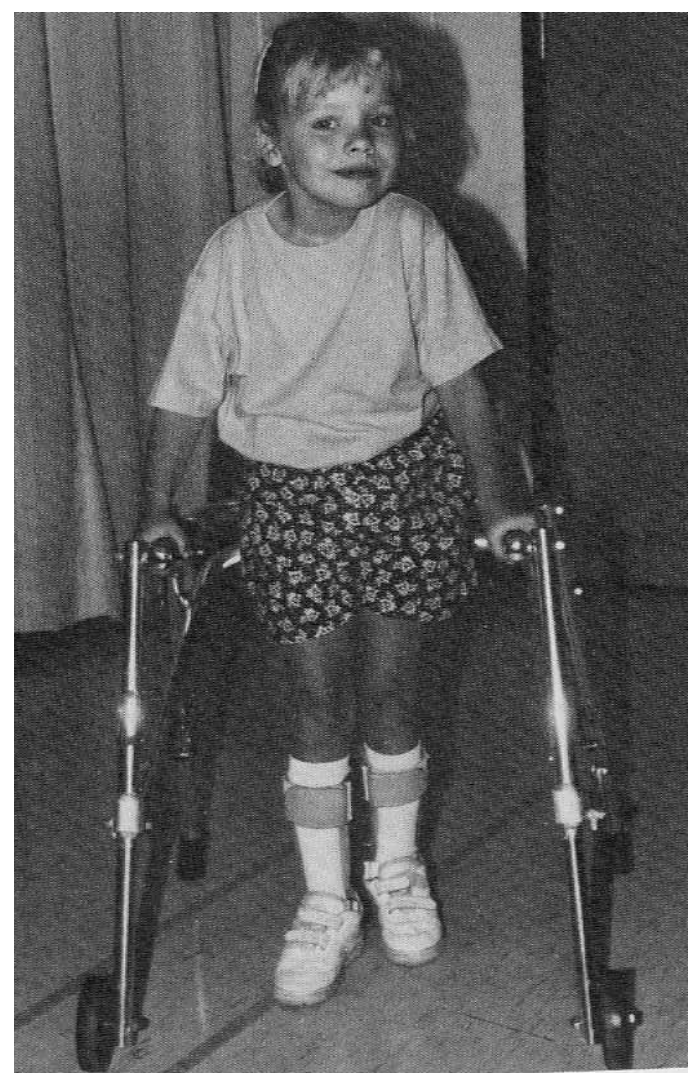

Figure B 3. Child with cerebral palsy walking with posterior walker ${ }^{42}$ 
Grenier, Czerniecki, and Deitz, ${ }^{19}$ compared gait parameters in 5 children with spastic diplegic cerebral palsy, using an anterior four wheeled walker and a posterior four wheeled walker. The authors compared the lower extremity joint angles and found that the hip was significantly more flexed with the anterior walker than the posterior walker both at the points of foot contact and mid stance. The trunk angle was also more flexed with the anterior walker than the posterior walker. Increasing hip and trunk extension in this population is of great therapeutic value as these children tend to ambulate in a crouch gait with increased hip, trunk and knee flexion. In addition to the kinematic improvements, preferred gait velocity was also greater with the posterior walker. Step length was not significantly different between the two walkers $(\mathrm{P}=0.09)$. With more qualitative measures, the authors asked the user and his or her parents which walker they preferred. With the exception of one parent who had mixed preferences, the parents and children all preferred the posterior walker over a variety surfaces and settings.

In another study comparing anterior and posterior walkers in 7 children with cerebral palsy and 1 with Down's Syndrome, Logan et al. ${ }^{20}$ found a significant increase in stride length with the posterior walker. The authors also showed increased hip extension and trunk extension at mid stance, and swing phase. They found no differences in gait speed between the two walkers. These authors did not investigate user preferences.

Levangie et al. ${ }^{22}$ compared gait in 13 children with cerebral palsy walking with three different walkers. They compared gait with an anterior two wheeled walker, a posterior two wheeled walker and a posterior four wheeled walker. They measured stride length, gait speed and toe angle during gait. They found significant differences in 
velocity and stride length between the posterior four wheeled walker when compared to either the posterior two wheeled walker or the anterior two wheeled walker. However, no differences in gait parameters were found between the anterior two wheeled walker and the posterior two wheeled walker. It is difficult to draw conclusions from this study because one cannot determine if it is the change from anterior to posterior or the change from the two to four wheels which caused the observed improvements.

Park, Park and $\mathrm{Kim}^{21}$ collected gait parameters on 10 children with spastic diplegic cerebral palsy while using anterior and posterior four wheeled walkers. They found increased step length but not gait speed with the posterior wheeled walker. They also found increases in hip extension, knee extension and posterior pelvic tilting with the posterior walker. In addition to gait parameters, this group compared energy expenditure between the two walkers using oxygen consumption measures. The posterior walker was found to be associated with lower oxygen consumption during walking when compared to the anterior walker.

Mattsson and Andersson ${ }^{23}$ also collected the oxygen consumption requirements of the anterior and posterior wheeled walkers in 10 children with cerebral palsy. Seven children had spastic diplegia, 3 had ataxic diplegia. The authors found no difference in the oxygen requirements of the two walkers. Similarly, they found no difference in heart rate, walking speed or rate of perceived exertion when using the two walkers. However, seven of the 10 children preferred the posterior walker to the anterior. Mattsson and Andersson ${ }^{23}$ did not compare any other gait parameters in these subjects. Park, Park and $\mathrm{Kim}^{21}$ suggested one of the reasons for the lack of results in this Swedish study might be due to the lack of homogeneity in the diagnoses of the participants. (For a summary of 
the results of studies comparing anterior and posterior walkers in the pediatric population, see Tables B1 and B2.)

Table B 1: Measurements recorded in research studies comparing anterior and posterior walkers in children with cerebral palsy

\begin{tabular}{|c|c|c|c|c|c|c|c|c|c|}
\hline Authors & $\mathrm{n}$ & $\begin{array}{c}\text { hip } \\
\text { angle }\end{array}$ & $\begin{array}{l}\text { knee } \\
\text { angle }\end{array}$ & $\begin{array}{c}\text { pelvic } \\
\text { tilt }\end{array}$ & $\begin{array}{l}\text { trunk } \\
\text { angle } \\
\end{array}$ & $\begin{array}{c}\text { gait } \\
\text { speed }\end{array}$ & $\begin{array}{c}\text { stride/step } \\
\text { length }\end{array}$ & preference & $\mathrm{O} 2$ cost \\
\hline $\begin{array}{l}\text { Greiner, Czerniecki \& } \\
\text { Deitz, } 1993\end{array}$ & 5 & $\mathrm{~S}$ & $\mathrm{~S}$ & NM & $\mathrm{S}$ & $\mathrm{S}$ & NS & $\mathrm{P}$ & NM \\
\hline Park, Park \& Kim, & 10 & $\mathrm{~S}$ & $\mathrm{~S}$ & $\mathrm{~S}$ & NM & NS & $\mathrm{S}$ & NM & $\mathrm{S}$ \\
\hline $\begin{array}{l}\text { Logan, Byers-Hinkley } \\
\& \text { Ciccone, } 1990 \\
\text { Mattsson \& Andersson }\end{array}$ & 7 & $\mathrm{~S}$ & NS & NM & $\mathrm{S}$ & NS & $\mathrm{S}$ & NM & NM \\
\hline 1997 & 10 & NM & NM & NM & NM & NS & NM & $\mathrm{P}$ & NS \\
\hline
\end{tabular}

Table B 2: Effect sizes and projected sample sizes for significant differences in hip position and stride length walking with an anterior vs. posterior walker in children with CP

\begin{tabular}{|c|c|c|c|c|c|}
\hline \multirow{2}{*}{ Authors } & \multirow{2}{*}{$\begin{array}{l}\text { Study sample } \\
\text { size }\end{array}$} & \multirow{2}{*}{$\begin{array}{l}\text { E.S. of hip } \\
\text { position }\end{array}$} & \multirow{2}{*}{$\begin{array}{l}\text { E.S. of stride } \\
\text { length }\end{array}$} & \multicolumn{2}{|c|}{ Projected sample size } \\
\hline & & & & hip angle & stride length \\
\hline $\begin{array}{l}\text { Greiner, Czerniecki \& Deitz, } \\
1993 \text { (avg. of R and L) }\end{array}$ & 5 & 0.86 & 0.81 & 10 & 9 \\
\hline $\begin{array}{l}\text { Park, Park \& Kim, } \\
2001\end{array}$ & 10 & 0.81 & 0.40 & 10 & 39 \\
\hline $\begin{array}{l}\text { Logan, Byers-Hinkley \& } \\
\text { Ciccone, } 1990\end{array}$ & 8 & 3.1 & 2.1 & 1 & 1 \\
\hline
\end{tabular}

Projected sample sizes were determined using a beta of 0.8 
To summarize the research comparing posterior and anterior wheeled walkers in children with cerebral palsy, the posterior walker was found to be superior for a variety of reasons. In those studies that investigated joint kinematics, increased hip extension was found for at least part if not all of the gait cycle when the participant used the posterior walker. In most studies comparing the two walkers, the participants walked the same speed with both walkers, however, they increased stride length when using the posterior walker ${ }^{19-21}$. Finally, in the studies which examined user preferences, the participants preferred the posterior walker to the anterior walker ${ }^{19,23}$.

Most of the studies had very few participants with a minimum of 5 in the study by Grenier et al. ${ }^{19}$ and a maximum of 13 in Levangie et al. ${ }^{22}$. Some failures to find significance are likely related to the small numbers of participants. The effect sizes of many of these results are, in fact, quite large. (See Table B2.) In this specific population with gait limitations, the posterior walker significantly improved hip position and stride length.

Although there are many differences between this pediatric population and older adults with disabilities, the possibility exists that a posterior walker could improve hip position and stride length in this older population in a manner similar to that of the children with cerebral palsy. These gait parameters which improved with the posterior walker, hip extension and stride length, are the exact parameters which research suggests should be targeted in the older disabled population. Given the large effect sizes and the changes seen in analyses of the posterior walker it appears that a posterior walker would be beneficial in older adults.

\section{User preferences: anterior versus posterior walkers}


Some of the articles comparing anterior and posterior walkers in children included information on user preferences ${ }^{19,23}$. User preferences, in addition to biomechanics, must be considered in evaluating the effectiveness of an assistive device. Adaptive or assistive equipment issued to disabled adults is often left unused. According to research, as much as half of all adaptive equipment issued is no longer used one month after discharge home from care facilities ${ }^{39,40}$. Mobility aids are abandoned more frequently than other device categories. Other, less frequently abandoned device categories include dressing aids, cushions and wheelchairs ${ }^{74}$. Reasons most commonly cited for assistive device abandonment include a) changing needs of the user, b) difficulty obtaining the device, c) device performance, and d) lack of user involvement in device selection ${ }^{74}$.

In a study of adults with arthritis and assistive device use ${ }^{1}$, approximately $30 \%$ of people questioned did not use their prescribed walking aid. Actual use of a walking aid was associated with higher age, increased pain and disability, and a positive evaluation of the aid. This research indicates the importance of the user approving of the device (i.e. user preference).

\section{Walker maneuverability}

Another main reason cited for device abandonment or disuse is that the device is too "cumbersome" to use ${ }^{40}$. It is important when evaluating an assistive device to consider the environment in which the device will be used. Walking with a mobility device in a wide open corridor such as is found in hospital can be quite different from walking with an assistive device in a crowded home environment. Simulating the activities performed in daily life is necessary to match the appropriate device with the needs of the user. 
Assessing a device in the context of an obstacle course or maze may demonstrate the maneuvering limitations of the mobility device and promote better assistive device design. An obstacle course which includes tight turns can help the user imagine how the device will function in his or her home environment. Few research studies, however, include obstacle courses in their investigation of assistive devices or general mobility.

In a study comparing two different types of crutches, Nielsen et al. ${ }^{36}$ evaluated regular and rocker bottom crutches on ramps as well as on stairs and level surfaces. The results showed that users preferred one type of crutch for stairs and another for going up ramps. Although the authors failed to find any difference in the oxygen consumption or maximum heart rate while using the two different types of crutches, the results of the user preference data showed the importance of evaluating assistive devices under a variety of real-world conditions. Different mobility devices might be appropriate for different conditions. Using this example of the crutches, if the user were to encounter stairs more frequently in his or her daily life, he/she would benefit from a different crutch than if he/she more frequently encountered ramps. It is only through the combination of an obstacle course and a user preference assessment that this information was obtained.

An obstacle course was also used by Hughes et al. ${ }^{37}$ to determine user preferences of two different wheelchair wheels (Spinergy wheels vs. steel spoke wheels). Similar to Nielsen et al. ${ }^{36}$, the authors did not time the obstacle course. The purpose of the obstacle course was to provide the user with the appropriate experience with which to evaluate wheel performance in a variety of conditions. In addition to an obstacle course, the researchers collected user heart rate and wheeling speed to measure the efficiency of the two wheels. Although no difference was found in efficiency, the users preferred the 
Spinergy wheels for comfort. Similar to the Nielsen et al. study, the only differences found between the two devices were user preferences based on the device performance during simulated daily tasks.

Chafetz et al. ${ }^{38}$ compared obstacle course times in children with spinal cord injuries who used wheelchairs. The obstacle course included completing activities of daily living (ADL) of dressing and transfers in addition to propelling the wheelchair down the hall and up a ramp. The children had to complete the obstacle course with and without a TLSO (thoracolumbosacral orthosis) back brace. Not surprisingly, the children performed the obstacle course more slowly when wearing the TLSO. In addition to the obstacle course time, the authors assessed user preferences by asking the children if they preferred performing each task better with or without the back brace. Not surprisingly, the children preferred to not wear the brace. Although the results of this study are somewhat predictable, the authors successfully used an obstacle course to show the functional limitations caused by the TLSO and showed how in this setting, user preferences corresponded with objective, functional measurements.

To avoid device abandonment, clinicians need to carefully consider the environment in which the assistive device will be used and consider the user's opinion about the device. By simulating the tasks which will need to be performed with device, the user and the clinician both gain insight into the efficacy of the device.

\section{Visual gait analysis}

The effectiveness of an mobility device is usually determined via gait assessment of the user walking with the device. Clinical gait analysis can vary from an extensive computer instrumented evaluation lasting hours, to a simple observation lasting only 
minutes. Objective measurements of gait kinematics usually require expensive instrumentation which require time consuming application. More frequently, clinicians perform an uninstrumented visual gait analysis to identify any gait deviations. In order to improve the reliability of uninstrumented gait analysis, Wolfson et al. ${ }^{9}$ created an instrument for health care professionals to systematically evaluate the biomechanics of gait of older adults while performing visual gait analysis.

The gait abnormality rating scale (GARS) (see appendix C, Table C3) was devised as a gait rating system that could be easily and quickly carried out in the clinic with only a video camera. The GARS was shown to have high inter rater reliability with Spearman $\rho$ ranging from 0.6 to 0.95 . The total score from the GARS was shown to be significantly higher for fallers than non fallers, and the total score correlated with stride length in this older population ${ }^{9}$. These results show the efficacy of the GARS in identifying pathological and unsafe gait patterns.

The format of the GARS breaks down the assessment into three general categories (a) general, b) lower extremity and c) head, trunk and upper extremities). Within these main categories, there are 16 criteria which are graded by the assessor. The sensitivity of many of the criteria, such as knee and hip range of motion during gait, could be assessed by comparing them to an instrumented gait analysis. However, review of the literature revealed no such comparison. The GARS sensitivity and specificity has been determined by its ability to predict individuals who fall and its relation to gait parameters such as stride length and gait speed. The GARS has not been used to show changes due to an intervention. Whether the GARS is sensitive enough to detect changes within an individual before and after treatment, remains to be seen. 
In a principle component analysis performed by Brach et al. ${ }^{50}$, the modified GARS score was found to be a powerful predictor of physical function along with gait speed and grip force. In a regression model, Brach showed that age, gait speed and the modified GARS score accounted for $65 \%$ of the total variance. Age and gait speed alone only accounted for $58 \%$ of the variance. As in the other studies, the authors concluded that the GARS was a valuable measure in predicting falls.

There exist other visual gait scales such as the Rancho Los Amigos Gait Analysis form and Tinetti's Balance and Mobility Assessment profile ${ }^{51}$. However, these forms do not allow for intermediate grades of impairment. For example, on the Rancho Los Amigos Gait Analysis form, the grader evaluates the absence or presence of foot slap and pelvic drop with no allowance for intermediate grades of foot slap or pelvic drop. In such a form, the total score will only improve if one gait deviation disappears completely. Similar problems exist for Tinetti's assessment tool. Due to this binary type of scoring, these tools are unlikely to show score changes due to interventions within an individual.

\section{Accuracy of vision, goniometers and video motion analysis}

The sensitivity of visual gait analysis tools are, in part, limited by the sensitivity and accuracy of the clinician's ability to visually estimate joint position. According to a study by Molony et al. ${ }^{52}$, healthcare professionals who are accustomed to assessing joint angles are better than the general public at visually estimating angle measurements. In the study, orthopedic surgeons were able to visually estimate a drawn angle within 7 degrees on average.

Compared to the human eye, instrumented joint angle measurements appear to be more accurate. One instrumented form of joint angle assessment, the electrogoniometer 
made by Biometrics, reports an accuracy within 2 degrees. In a study by Rome $\&$ Cowieson ${ }^{31}$, the reliability of three types of goniometers were compared for measuring ankle dorsiflexion. Static maximum ankle dorsiflexion of the same five subjects was measured using each of the three goniometers: a universal goniometer, a fluid goniometer and an electrogoniometer. There were significant differences found between the measurements of the three goniometers. The authors did not provide intraclass correlation coefficients for the different goniometers. With the three different instruments, the authors reported a range in dorsiflexion measurements from 9-18 degrees. However, this range of measurements was taken by one individual across eight different subjects. With this methodology one cannot determine if the variability is due to differences between the individuals or differences in instrumentation. The authors did not successfully limit the variation to differences between the three goniometers. In their conclusion, the authors recommended the electrogoniometer and the fluid goniometer over the universal goniometer and recommended that when possible goniometric measurements should be taken by one individual to avoid inter rater variation. Although the methodology in this study was weak, the electrogoniometer proved to be one of the more reliable instruments with an intra rater variation of less than 7 degrees.

Another instrument for joint angle measurement, Vicon, a video motion analysis system, is able to measure a static angle within 0.6 degrees ${ }^{33}$. Vicon however, has been shown to have some problems with inter rater and intra rater reliability due to variations in application. In a reliability study examining Vicon's ability to measure joint angle during clinical gait analyses, a wide range of ICC's were found for both inter and intra rater reliability. Inter rater reliability of joint angle measurements during gait ranged 
from -0.04 for peak hip extension to .83 for peak knee extension. Intra rater reliability from gait assessments performed on two different days ranged from 0.05 for peak knee flexion to 0.70 for peak ankle extension. Even when only one rater was used, there was great variability between kinematic measurements using Vicon ${ }^{32}$.

In summary, visual joint kinematic assessment does not appear to be as accurate as instrumented joint kinematics. However, all forms of motion analysis show some error and problems with inter rater reliability. For single plane motion, electrogoniometers are at least as accurate as Vicon within one rater. Visual estimates by clinicians are accurate within approximately 7 degrees.

\section{Conclusions}

Even though walkers are commonly used by older adults, research examining the gait of older adults while ambulating with walkers is limited. Most walkers used in the older population are anterior walkers. Posterior wheeled walkers have been shown to improve the gait biomechanics of children with cerebral palsy but have not been systematically examined in older adults. If the posterior walker facilitates similar gait improvements in older adults as seen in children with cerebral palsy, older adults will benefit from walking with a posterior walker instead of an anterior walker. Methods for examining the effectiveness of walkers include instrumented and uninstrumented gait analysis, tests of maneuverability, and surveys of user preferences. 


\section{APPENDIX C: ADDITIONAL METHODS}

Table C 1. Informed Consent

\section{Consent of an Adult To be in a Research Study}

\section{Participant's Name}

\section{What is the Purpose of this Form?}

This form will help you decide if you want to be in the research study. You need to be informed about the study before you can decide if you want to be in it. You should have all your questions answered before you give your permission, or consent, to be in the study. This is called an "informed consent" form because it informs you before you sign to give your consent.

Please read this form carefully. Ask about any part you don't understand. Then decide if you want to be in this study. If you do want to be in the study, you will need to sign this form to give your consent. You will get your own copy of this signed form for your records.

\section{Introduction}

You are being asked to be in this study because you are over 55 years of age and have some limitations in walking.

The purpose of this study is to compare two different types of walkers. The study looks at posture, walking speed, user preferences and compares these outcomes between the two different walkers. Research comparing different walker designs might improve walker designs in the future.

Up to 25 people will be in this study at UVA.

\section{Who should not be in this study?}

\section{You can NOT be in this study if...}

Please be honest with us about your medical history! Certain conditions may mean it is not safe for you to be in the study. 
- You have had a stroke and have continued weakness which affects your walking.

- You have an asymmetric walking pattern.

- You have paralyzed muscles due to polio, muscular dystrophy or other neurological disorders.

- You have a problem with your hand(s) which makes it difficult to hold onto or guide the walker.

- You are unable to stand up straight even with assistance.

- You are unable to understand instructions in English.

The study involves 1 visit.

The one visit will last about one hour.

\section{What will be done if you are in the study?}

If you choose to participate in the study, you will be videotaped while you walk with two different rolling walkers and while you walk without a walker. If you need assistance to walk without a walker the researcher will assist you. Before walking with the walkers, sensors will be placed on one leg, on your back and on your shoes to measure the position of your legs, feet and back while walking.

You will also be asked to maneuver around some obstacles with each walker. This part of the study will be done without the sensors on your hip, back and feet.

Finally, you will be asked to complete a questionnaire about which walker you prefer and why.

As part of the research study, the videotape of you walking with both walkers will be shown to a group of physical therapists. The physical therapists will then give their opinions of the two walkers. The physical therapists who view your videotape will not be given your name or other identifying information. Only the researchers and the physical therapists involved in this research study will view the videotape of you walking.

When your videotape is not being used, it will be kept in a locked file cabinet. When the study is completed, the videotapes will be erased or destroyed.

\section{If you want to know about the results before the study is done:}

This study is not meant to find out if you have any other disease or problem. 
The study leader will tell you if any research results are important to your health during the study. That information is important for you to know, because it may help you decide whether you want to continue being in this study.

We cannot tell you any other information until the results have been studied. At that time you can ask for more information.

\section{What are the risks of being in this study?}

In this study you will be asked to walk with and without a walker on level surfaces. The risks are small, however, while walking there is always a risk of falling. Every precaution will be taken to make the testing environment as safe as possible. If you are uncomfortable with any portion of the study, you can stop at any time.

\section{Could you be helped by being in this study?}

You will not be helped by being in this study, however the information we get from this study may help others in the future.

\section{What are your other choices if you do not join this study?}

You are under no obligation to participate in this study. You can stop the study at any time.

\section{Will you be paid for being in this study?}

You will not be paid for participating in this study.

\section{What if you are hurt in this study?}

There is a small chance you could get hurt by this study in a way we did not expect. If you are hurt as a result of being in this study, we have no plans to pay you for lost wages, disability, or discomfort. If you are hurt in the study in a way that is unexpected (meaning in a way that is not listed in the risks part of this form), your insurance company may pay for your treatment. If they do not pay, University of Virginia will treat you free of charge. If you have questions about what will be covered if you are hurt in the study, talk to the study leader. You do not give up any legal rights by signing this form

\section{What happens if you change your mind?}

You can change your mind about being in the study any time. It is always up to you. You can choose not to join in the first place. Or you can choose to stop during the study. You 
do not have to be in this study to get services you can normally get at the University of Virginia.

The study leader will tell you if any research results are important to your health during the study. That information is important for you to know, because it can help you decide whether you want to continue being in this study. You can change your mind at any time.

Even if you do not change your mind, the study leader can take you out of the study. This might happen if the study leader is concerned about your health. Or it might happen if you do not follow instructions given to you.

If you choose to stop the study, simply tell the researcher and you can leave. Your data will then be destroyed.

\section{How will your personal information be protected?}

Federal and state privacy laws govern how UVA can use and share your personal and medical information. We will do everything we can to protect your privacy in this study. However, we will need to share your information with people who may not have to follow the same laws. Some of these people may be allowed to release your information without your permission.

\section{Signing this form:}

- gives your health care providers permission to provide information about you to UVA researchers for this study; and

- gives UVA researchers permission to gather, use, and release information about you for this study.

You do not have to sign, but if you do not, you cannot be a part of this study.

If you sign this form, there will be 3 general categories of people who can use and release information about you. They are:

1. People who do the research or manage the study

2. People who oversee the study to make sure it is being done correctly

3. People who evaluate the study results

\section{What information do we collect for the study?}

We may collect any, or all, of the following: 
- Personal information such as your name, address, and date of birth

- Records and test results that relate only to this study

\section{What will be done with this information?}

Your information will be used to:

- Track whether the study is being done correctly

- Observe the effects of the study and understand its results

- Report study results to sponsors and government agencies

- Publish the study results in medical journals. (This would be done in a way that protects your privacy. No one will be able to find out from the article that you were in this study.)

\section{Who will we share your information with?}

- Researchers at other places who are also doing this same study

- Government agencies such as the FDA or other organizations that oversee research at UVA

- People or committees who work to see that research at UVA is safe

- Tax reporting offices (if you are paid for being in the study)

\section{When can you see your records from this study?}

Information we collect about you for this study might be kept in a record that is separate from your medical record. You will not be able to see what is in the separate research record until the end of the study.

\section{How long does this permission last?}

This permission to use and release your information does not end unless you cancel it.

What if you sign the form but then decide you don't want your information used and shared?

You can change your mind about letting us use and share your information. To cancel your permission, you would have to send a letter to the researchers listed on this form. If you cancel your permission, you cannot continue to be in the study.

Even if you cancel your permission, we may still need to use some information about you. We will still use the information collected about you up until the time you decide to stop being in this study. We need that information to:

- avoid losing study results that have already included your information

- help those who oversee the study

\section{Contact Information}

\section{Please contact the people listed below to:}


- Learn more about the study

- Ask about the way the study is done or about treatments

- Report an illness, a research related injury, or other problem (you may also need to tell your regular doctors)

- Leave the study before it is finished

Report a concern about the study

Principal Investigator: Christopher Ingersoll Ph.D., A.T.C.

Human Services, Curry School of Education

Memorial Gym 203

Telephone: (434)924-6187

cdi9u@virginia.edu

Study Coordinator: Ann Tuzson M.S., P.T.

Human Services, Curry School of Education

aet2n@virginia.edu

Telephone: (434)295-7634

\section{What if you have a concern about a study?}

You may also report a concern about a study or ask questions about your rights as a research subject by contacting the Institutional Review Board listed below.

University of Virginia Institutional Review Board for Health Sciences Research PO Box 800483

Charlottesville, Virginia 22908

Telephone: 434-924-2620

Fax: 434-924-2932

When you call or write about a concern, please give as much information as you can. Include the name of the study leader, the IRB-HSR Number (at the top of this form), and details about the problem. This will help officials look into your concern. When reporting a concern, you do not have to give your name.

\section{Conclusion}

Please check one of the following:

You agree to be contacted after this study is done for follow up information or to be asked to be in other studies.

You do not agree to be contacted after this study is done for follow up information or to be asked to be in other studies. 


\section{What does your signature mean?}

Before you sign this form, please ask questions about any part of this study that is not clear to you. When you sign below, you are saying you understand the information we gave you about the study and in this form. If you sign the form it means that you agree to be in the study.

PARTICIPANT (SIGNATURE)
PARTICIPANT

(PRINT)
$\overline{\mathrm{DATE}}$
PERSON OBTAINING CONSENT (SIGNATURE)
PERSON OBTAINING

CONSENT

(PRINT)
DATE 
Table C 2. Questionnaire about anterior and posterior walkers

Questionnaire about anterior and posterior walkers

Instructions: Please answer the following questions.

1. Which walker did you prefer? (Please circle A or B or C.)
A) Anterior walker (the walker you push in front of you)
B) Posterior walker (the walker you pull behind you)
C) No preference.

2. Why did you prefer it?

3. Which walker felt easier to use? (Please circle A, B or C.)
A) Anterior walker (the walker you push in front of you)
B) Posterior walker (the walker you pull behind you)
C) No preference.

4. Which walker made you feel more safe or more stable? (Please circle $\mathrm{A}, \mathrm{B}$ or $\mathrm{C}$.)
A) Anterior walker (the walker you push in front of you)
B) Posterior walker (the walker you pull behind you) 
C) No preference.

5. Which do you think is more practical for daily use? (Please circle A, B or C.)
A) Anterior walker (the walker you push in front of you)
B) Posterior walker (the walker you pull behind you)
C) No preference.

6. What did you like (if anything) about the anterior walker (the walker you push in front of you)?

7. What did you NOT like (if anything) about the anterior walker (the walker you push in front of you)?

8. What did you like (if anything) about the posterior walker (the walker you pull behind you)?

9. What did you NOT like (if anything) about the posterior walker (the walker you pull behind you)? 
Table C 3. Evaluation form and questionnaire to be completed by physical therapists

Gait Abnormality Rating Scale (GARS) taken from:

Wolfson L, Whipple R, Amerman P \& Tobin JN. Gait assessment in the elderly: A gait abnormality rating scale and its relation to falls. Journal of Gerontology: Medical Sciences 1990; 45(1): M12-M19.

D. General categories

1. Variability - a measure of inconsistency and arrhythmicity of stepping and of arm movements

$0=$ Fluid and predictably paced limb movements;

$1=$ Occasional interruptions (changes in velocity), approximately $<25 \%$ of time;

2 = Unpredictability of rhythm approximately $25-75 \%$ of time;

$3=$ Random timing of limb movements.

2. Guardedness - hesitancy, slowness, diminished propulsion and lack of commitment in stepping and arm swing.

$0=$ Good forward momentum and lack of apprehension in propulsion;

$1=$ Center of gravity of head, arms and trunk (HAT) projects only slightly

in front of push-off, but still good arm-leg coordination;

$2=$ HAT held over anterior aspect of foot, and some moderate loss of smooth reciprocation;

$3=$ HAT held over rear aspect of stance-phase foot, and great tentativity in stepping.

3. Weaving- an irregular and wavering line of progression

$0=$ Straight line of progression on frontal viewing;

$1=$ A single deviation from straight (line of best fit) line of progression;

$2=$ Two to three deviations from line of progression;

$3=$ Four or more deviations from line of progression.

4. Waddling - a broad-based gait characterized by excessive truncal crossing of the midline and side-bending

$0=$ Narrow base of support and body held nearly vertically over feet;

$1=$ Slight separation of medial aspects of feet and just perceptible lateral movement of head and trunk;

$2=3-4$ " separation feet and obvious bending of trunk to side so that COG of head lies well over ipsilateral stance foot;

3 = extreme pendular deviations of head and trunk (head passes lateral to ipsilateral stance foot) and further widening of base of support.

5. Staggering - sudden and unexpected laterally directed partial losses of balance

$0=$ No losses of balance to side;

$1=$ A single lurch to side

$2=$ Two lurches to side;

$3=$ Three or more lurches to side. 
E. Lower extremity categories

1. \% time in swing - a loss in the percentage of the gait cycle constituted by the swing phase.

$0=$ Approximately $3: 2$ ratio of duration of stance to swing phase;

$1=$ A 1:1 or slightly less ratio of stance to swing;

2 = Markedly prolonged stance phase, but with some obvious swing time remaining;

$3=$ Barely perceptible portion of cycle spent in swing

2. Foot contact - the degree to which heel strikes the ground before the forefoot

$0=$ Very obvious angle of impact of heel on ground;

$1=$ Barely visible contact of heel before forefoot;

$2=$ Entire foot lands flat on ground;

$3=$ Anterior aspect of foot strikes ground before heel.

3. Hip ROM - the degree of loss of hip range of motion seen during a gait cycle

$0=$ Obvious angulation of thigh backwards during double support (10

deg);

$1=$ Just barely visible angulation backwards from vertical;

$2=$ Thigh in line with vertical projection from ground.

$3=$ Thigh angled forwards from vertical at maximum posterior excursion.

4. Knee ROM - the degree of loss of knee range of motion seen during a gait cycle.

$0=$ Knee moves from complete extension at heel strike (and late stance) to 70-90 deg during swing phase.

$1=$ Slight bend in knee seen at heel strike and late stance and maximal

flexion at midswing is closer to $45 \mathrm{deg}$ than $90 \mathrm{deg}$.

$2=$ Knee flexion at late stance more obvious than at heel-strike, very little clearance seen for toe during swing;

$3=$ Toe appears to touch ground during swing, knee flexion appears constant during stance, and knee angle during swing appears 45 deg or less.

F. Trunk, head, and upper extremity categories

1. Head held forward - a measure of the pathological forward projection of the head relative to the trunk

$0=$ Ear-lobe vertically aligned with shoulder tip;

$1=$ Ear-lobe vertical projection falls 1 " anterior to shoulder tip;

2 = Ear-lobe vertical projection falls 2" anterior to shoulder tip;

3 = Ear-lobe vertical projection falls 3 " or more anterior to shoulder tip;

2. Shoulders held elevated - the degree to which the scapular girdle is held higher than normal

$0=$ Tip of shoulder (acromion) markedly below level of chin (1-2");

$1=$ Tip of shoulder slightly below level of chin; 
2 = Tip of shoulder at level of chin;

3 = Tip of shoulder above level of chin.

3. Upper trunk flexed forward - a measure of kyphotic involvement of the trunk

$0=$ Very gentle thoracic convexity, cervical spine flat, or almost flat;

$1=$ Emerging cervical curve, more distant thoracic convexity;

2 = Anterior concavity at mid chest level apparent;

$3=$ Anterior concavity at mid chest level very obvious. 


\section{General questionnaire for therapists comparing the anterior and the posterior walkers:}

Additional questions for physical therapists to be answered for each subject after completing the GARS:

Instructions for questions 1-8: Complete one questionnaire (1-8) for each subject you evaluated.

1. For this subject, which walker did you prefer? Please circle a, b, or c.
a. Anterior walker
b. Posterior walker
c. No preference

Please explain your answer briefly:

2. Which walker looked safer? Please circle $a, b$, or c.
a. Anterior walker
b. Posterior walker
c. No preference

3. In which walker did the participant have better posture? Please circle a, b, or c.
a. Anterior walker
b. Posterior walker
c. No preference

4. Which walker looked easier to use for this participant? Please circle a, b, or c.
a. Anterior walker
b. Posterior walker
c. No preference

5. Which walker promoted better gait biomechanics overall? Please circle a, b, or c.
a. Anterior walker
b. Posterior walker
c. No preference 
Please explain your answer briefly:

Instructions for questions 6-9: Answer yes or no. If the answer is 'yes', describe what the difference was.

6. Could you see any difference in the hip position between the two walkers?

Please circle one: $\quad$ YES

If you circled yes, please describe the difference briefly:

7. Could you see any difference in the knee position between the two walkers?

Please circle one: $\quad$ YES NO

If you circled yes, please describe the difference briefly:

8. Could you see any difference in the trunk position between the two walkers?

Please circle one: $\quad$ YES NO

If you circled yes, please describe the difference briefly:

9. Could you see any difference in stride length between the two walkers?

Please circle one: $\quad$ YES NO

If you circled yes, please describe the difference briefly: 
Table C 4. Assignment of raters and participants and rating order for GARS assessment

\begin{tabular}{|c|c|c|}
\hline Therapist & Subject viewed & Walker type \\
\hline \multirow[t]{10}{*}{ Therapist A } & 1 & anterior \\
\hline & " & posterior \\
\hline & 2 & anterior \\
\hline & " & posterior \\
\hline & 3 & anterior \\
\hline & " & posterior \\
\hline & 4 & anterior \\
\hline & " & posterior \\
\hline & 5 & anterior \\
\hline & " & posterior \\
\hline \multirow[t]{10}{*}{ Therapist B } & 2 & anterior \\
\hline & " & posterior \\
\hline & 3 & posterior \\
\hline & " & anterior \\
\hline & 4 & anterior \\
\hline & " & posterior \\
\hline & 5 & posterior \\
\hline & " & anterior \\
\hline & 1 & posterior \\
\hline & " & anterior \\
\hline \multirow[t]{10}{*}{ Therapist C } & 3 & anterior \\
\hline & " & posterior \\
\hline & 4 & posterior \\
\hline & " & anterior \\
\hline & 5 & anterior \\
\hline & " & posterior \\
\hline & 1 & anterior \\
\hline & " & posterior \\
\hline & 2 & posterior \\
\hline & " & anterior \\
\hline
\end{tabular}

\begin{tabular}{|c|c|l|}
\hline Therapist & Subject viewed & Walker type \\
\hline Therapist D & 4 & anterior \\
\hline & $"$ & posterior \\
\hline & 5 & posterior \\
\hline & $"$ & anterior \\
\hline & 1 & posterior \\
\hline & $"$ & anterior \\
\hline & 2 & anterior \\
\hline & $"$ & posterior \\
\hline & 3 & posterior \\
\hline & $"$ & anterior \\
\hline Therapist E & 5 & anterior \\
\hline & $"$ & posterior \\
\hline & 1 & posterior \\
\hline & $"$ & anterior \\
\hline & 2 & anterior \\
\hline & $"$ & posterior \\
\hline & 3 & anterior \\
\hline & $"$ & posterior \\
\hline & 4 & posterior \\
\hline & $"$ & anterior \\
\hline
\end{tabular}




\section{APPENDIX D: ADDITIONAL RESULTS}

Table D 1: Kinematic results: Raw data

\begin{tabular}{ccccc}
\hline Participant & Age & ANT BACK EXT & POST BACK EXT & NONE BACK EXT \\
\hline 1 & 70 & 21 & 20 & 24 \\
2 & 69 & 38 & 34 & 32 \\
3 & 70 & 17 & 18 & 24 \\
4 & 76 & 11 & 11 & 11 \\
5 & 92 & 4 & 8 & 7 \\
6 & 79 & 26 & 40 & 39 \\
7 & 79 & 19 & 23 & 20 \\
8 & 75 & 3 & 4 & 10 \\
9 & 82 & 13 & 12 & 12 \\
10 & 88 & 11 & 11 & 10 \\
11 & 82 & 14 & 11 & 11 \\
12 & 83 & 1 & 0 & 0 \\
13 & 78 & 19 & 19 & 21 \\
14 & 83 & 15 & 15 & 13 \\
15 & 90 & 16 & 17 & 16 \\
16 & 69 & 24 & 24 & 25 \\
17 & 79 & 30 & 26 & 30 \\
18 & 85 & 18 & 18 & 16 \\
19 & 78 & 10 & 17 & 15 \\
20 & 75 & 28 & 28 & 18.2 \\
Average & 79.1 & 16.9 & 17.8 & 9.39 \\
SD & 6.56 & 9.10 & 9.44 & \\
\hline
\end{tabular}

ANT $=$ Anterior walker

POST $=$ Posterior walker

NONE $=$ Without any assistive device

$\mathrm{EXT}=$ Maximum extension angle during gait cycle

FLEX $=$ Maximum flexion angle during gait cycle

$\mathrm{PF}=$ Maximum plantar flexion angle during gait cycle

$\mathrm{DF}=$ Maximum dorsiflexion angle during gait cycle 


\begin{tabular}{ccccc}
\hline Participant & ANT BACK FLEX POST BACK FLEX & NONEBACK FLEX ANT HIP EXT \\
\hline 1 & 9 & 12 & 13 & -1 \\
2 & 17 & 15 & 14 & -1 \\
3 & 1 & 8 & 16 & 4 \\
4 & 6 & 6 & 7 & 5 \\
5 & -2 & 0 & 0 & -4 \\
6 & 9 & 26 & 14 & 18 \\
7 & 16 & 18 & 17 & 5 \\
8 & -1 & -1 & 1 & -17 \\
9 & 8 & 6 & 9 & 3 \\
10 & 8 & 9 & 7 & 1 \\
11 & 5 & 4 & 3 & 23 \\
12 & -2 & -2 & -2 & -10 \\
13 & 11 & 7 & 12 & 4 \\
14 & 10 & 9 & 9 & 2 \\
15 & 8 & 11 & 10 & 16 \\
16 & 16 & 17 & 17 & -9 \\
17 & 20 & 22 & 23 & 5 \\
18 & 10 & 12 & 10 & 13 \\
19 & 2 & 2 & 4 & 8 \\
20 & 24 & 24 & 22 & 3 \\
Average & 8.75 & 10.25 & 10.3 & 3.4 \\
SD & 7.06 & 7.92 & 6.78 & 9.30 \\
\hline
\end{tabular}




\begin{tabular}{ccccc}
\hline Participant & POST HIP EXT & NONE HIP EXT & ANT HIP FLEX & POST HIP FLEX \\
\hline 1 & -15 & -16 & 53 & 21 \\
2 & -5 & -8 & 21 & 26 \\
3 & -6 & 5 & 18 & 13 \\
4 & 0 & -12 & 30 & 31 \\
5 & -1 & 0 & 38 & 39 \\
6 & 15 & 15 & 39 & 33 \\
7 & 4 & 6 & 33 & 38 \\
8 & -8 & -5 & 12 & 15 \\
9 & 5 & 1 & 23 & 20 \\
10 & 3 & -2 & 35 & 34 \\
11 & 26 & 9 & 68 & 65 \\
12 & -11 & -13 & 30 & 22 \\
13 & -3 & -4 & 22 & 20 \\
14 & 6 & 3 & 23 & 23 \\
15 & 5 & -1 & 45 & 32 \\
16 & -8 & -12 & 25 & 24 \\
17 & 2 & 2 & 36 & 29 \\
18 & 20 & 21 & 37 & 36 \\
19 & 12 & 3 & 49 & 51 \\
20 & -10 & 3 & 29 & 21 \\
Average & 1.55 & -0.25 & 33.3 & 29.65 \\
SD & 10.38 & 9.12 & 12.93 & 12.08 \\
\hline
\end{tabular}




\begin{tabular}{ccccc}
\hline Participant & NONE HIP FLEX & ANT KNEE EXT & POST KNEE EXT & NONE KNEE EXT \\
\hline 1 & 31 & -3 & 0 & -5 \\
2 & 17 & -1 & 3 & 0 \\
3 & 15 & -8 & -9 & -3 \\
4 & 30 & -10 & -3 & -8 \\
5 & 42 & 0 & 0 & 0 \\
6 & 35 & -1 & 2 & -3 \\
7 & 39 & & -8 & 9 \\
8 & 30 & 8 & 10 & 10 \\
9 & 21 & 10 & 3 & 7 \\
10 & 39 & 5 & 11 & -10 \\
11 & 49 & 5 & -3 & 8 \\
12 & 24 & -12 & -5 & -1 \\
13 & 15 & 10 & 11 & 15 \\
14 & 26 & 20 & 20 & 14 \\
15 & 26 & 6 & 12 & 11 \\
16 & 23 & -7 & -9 & -9 \\
17 & 31 & -7 & -2 & 0 \\
18 & 48 & 1 & 6 & 6 \\
19 & 48 & 1 & 7 & 0 \\
20 & 21 & 1 & 0 & 0 \\
Average & 30.50 & 0.95 & 2.30 & 2.05 \\
SD & 10.57 & 7.79 & 7.62 & 7.34 \\
\hline
\end{tabular}




\begin{tabular}{ccccc}
\hline Participant & ANT KNEE FLEX POST KNEE FLEX NONE KNEE FLEX ANT ANKLE PF \\
\hline 1 & 56 & 55 & 55 & 20 \\
2 & 52 & 56 & 57 & 18 \\
3 & 54 & 59 & 69 & 46 \\
4 & 47 & 56 & 45 & 14 \\
5 & 50 & 63 & 62 & 21 \\
6 & 69 & 72 & 75 & 31 \\
7 & & 58 & 57 & 28 \\
8 & 61 & 57 & 67 & 45 \\
9 & 63 & 60 & 55 & 29 \\
10 & 68 & 74 & 60 & 29 \\
11 & 72 & 23 & 75 & 22 \\
12 & 56 & 52 & 57 & 43 \\
13 & 58 & 63 & 62 & 29 \\
14 & 53 & 65 & 49 & 16 \\
15 & 62 & 62 & 62 & 18 \\
16 & 38 & 38 & 40 & 19 \\
17 & 57 & 64 & 64 & 32 \\
18 & 52 & 60 & 58 & 24 \\
19 & 57 & 63 & 66 & 33 \\
20 & 28 & 30 & 31 & 29 \\
Average & 55.42 & 56.50 & 58.30 & 9.13 \\
SD & 10.13 & 12.36 & 10.62 & \\
\hline
\end{tabular}




\begin{tabular}{ccccc}
\hline Participant & POST ANKLE & NONE ANKLE PF & ANT ANKLE DF & POST ANKLE DF \\
\hline 1 & 22 & 20 & 2 & 3 \\
2 & 26 & 25 & -10 & -5 \\
3 & 44 & 40 & -9 & -5 \\
4 & 13 & 12 & 1 & -4 \\
5 & 18 & 22 & 5 & 3 \\
6 & 28 & 32 & 3 & -3 \\
7 & 18 & 19 & -10 & -3 \\
8 & 43 & 21 & 14 & -5 \\
9 & 39 & 45 & -4 & -6 \\
10 & 35 & 38 & 8 & 10 \\
11 & 23 & 23 & -5 & -3 \\
12 & 18 & 37 & -8 & -12 \\
13 & 31 & 34 & 5 & 4 \\
14 & 21 & 15 & -7 & -5 \\
15 & 14 & 19 & 4 & 2 \\
16 & 16 & 20 & 2 & 0 \\
17 & 24 & 32 & -2 & -10 \\
18 & 36 & 35 & -9 & -4 \\
19 & 25 & 31 & 2 & -10 \\
20 & 27 & 30 & -5 & -8 \\
Average & 26.05 & 27.50 & -1.15 & -3.05 \\
SD & 9.09 & 8.87 & 6.58 & 5.27 \\
\hline
\end{tabular}




\begin{tabular}{ccccc}
\hline Participant & NONE ANKLE DF & ANT1VEL (M/S) & ANT2VEL & AVGANTVEL \\
\hline 1 & 2 & 1.28 & 1.1 & 1.19 \\
2 & -7 & 1.69 & 1.6 & 1.65 \\
3 & -17 & 1.75 & 1.79 & 1.77 \\
4 & 0 & 1.49 & 1.62 & 1.55 \\
5 & -1 & 0.27 & 0.27 & 0.27 \\
6 & 2 & 1.13 & 1.1 & 1.11 \\
7 & -7 & 0.67 & 0.7 & 0.69 \\
8 & -7 & 0.67 & 0.58 & 0.63 \\
9 & 6 & 0.82 & 0.79 & 0.81 \\
10 & 11 & 0.64 & 0.7 & 0.67 \\
11 & -4 & 1.13 & 1.13 & 1.13 \\
12 & -8 & 0.61 & 0.76 & 0.69 \\
13 & 9 & 0.65 & 0.53 & 0.59 \\
14 & -6 & 0.61 & 0.67 & 0.64 \\
15 & 4 & 0.7 & 0.73 & 0.72 \\
16 & -1 & 0.61 & 0.61 & 0.61 \\
17 & -5 & 0.85 & 0.85 & 0.85 \\
18 & -5 & 0.64 & 0.73 & 0.69 \\
19 & -7 & 0.88 & 0.98 & 0.93 \\
20 & -4 & 0.82 & 0.73 & 0.78 \\
Average & -2.25 & 0.8955 & 0.8985 & 0.8985 \\
SD & 6.44 & 0.3842 & 0.3817 & 0.3797
\end{tabular}

ANT1VEL = Walking speed with the anterior walker on the first pass through the timing gates.

ANT2VEL $=$ Walking speed with the anterior walker on the second pass through the timing gates.

AVGANTVEL $=$ Average of the two walking speeds with the anterior walker 


\begin{tabular}{ccccc}
\hline Participant & POST1VEL & POST2VEL & AVGPOSTVEL & NONE1VEL \\
\hline 1 & 1 & 0.95 & 0.975 & 1.24 \\
2 & 1.37 & 1.46 & 1.41 & 1.37 \\
3 & 1.68 & 1.73 & 1.7 & 1.63 \\
4 & 1.34 & 1.59 & 1.46 & 1.8 \\
5 & 0.3 & 0.27 & 0.29 & 0.3 \\
6 & 1 & 0.91 & 0.96 & 1.28 \\
7 & 0.55 & 0.52 & 0.53 & 0.79 \\
8 & 0.61 & 0.61 & 0.61 & 0.67 \\
9 & 0.82 & 0.79 & 0.81 & 0.73 \\
10 & 0.55 & 0.58 & 0.56 & 0.67 \\
11 & 1.01 & 1.07 & 1.04 & 1.16 \\
12 & 0.82 & 0.85 & 0.84 & 0.85 \\
13 & 0.6 & 0.6 & 0.6 & 0.6 \\
14 & 0.61 & 0.55 & 0.58 & 0.46 \\
15 & 0.64 & 0.73 & 0.69 & 0.46 \\
16 & 0.58 & 0.59 & 0.58 & 0.64 \\
17 & 0.82 & 0.82 & 0.82 & 0.85 \\
18 & 0.76 & 0.79 & 0.78 & 0.79 \\
19 & 0.98 & 1.01 & 0.99 & 0.98 \\
20 & 0.61 & 0.67 & 0.64 & 0.95 \\
Average & 0.83 & 0.85 & 0.84 & 0.91 \\
SD & 0.33 & 0.36 & 0.34 & 0.39 \\
\hline
\end{tabular}

POST1VEL = Walking velocity with the posterior walker on the first pass through the timing gates.

POST2VEL = Walking velocity with the posterior walker on the second pass through the timing gates.

AVGPOSTVEL $=$ Average of the 2 walking velocities.

NONE1VEL = Walking velocity without a walker on the first pass through the timing gates.

NONE2VEL $=$ Walking velocity without a walker on the second pass through the timing gates.

AVGNONEVEL $=$ Averaged walking velocity of the two passes without a walker. 


\begin{tabular}{ccccc}
\hline Participant & NONE2VEL & AVGNONEVEL & ANT1STRLEN & ANT2STRLEN \\
\hline 1 & 1.16 & 1.2 & 1.37 & 1.15 \\
2 & 1.46 & 1.42 & 1.08 & 1.05 \\
3 & 1.56 & 1.59 & 1.19 & 1.21 \\
4 & 1.8 & 1.8 & 0.95 & 1.04 \\
5 & 0.27 & 0.29 & 0.43 & 0.46 \\
6 & 1.16 & 1.22 & 1.19 & 1.13 \\
7 & 0.76 & 0.78 & 0.95 & 0.95 \\
8 & 0.64 & 0.66 & 1.04 & 0.95 \\
9 & 0.73 & 0.73 & 0.73 & 0.67 \\
10 & 0.73 & 0.7 & 0.91 & 0.91 \\
11 & 1.16 & 1.16 & 1.37 & 1.37 \\
12 & 0.85 & 0.85 & 1.01 & 1.07 \\
13 & 0.5 & 0.55 & 0.85 & 0.64 \\
14 & 0.4 & 0.43 & 0.76 & 0.79 \\
15 & 0.37 & 0.41 & 0.85 & 0.88 \\
16 & 0.79 & 0.72 & 0.88 & 0.88 \\
17 & 0.88 & 0.87 & 0.95 & 0.91 \\
18 & 0.79 & 0.79 & 0.88 & 0.88 \\
19 & 1.13 & 1.05 & 1.13 & 1.16 \\
20 & 0.91 & 0.93 & 0.95 & 0.88 \\
Average & 0.90 & 0.91 & 0.97 & 0.95 \\
SD & 0.39 & 0.39 & 0.21 & 0.21 \\
\hline
\end{tabular}

ANT1STRLEN= Averaged stride length with the anterior walker on first pass through the timing gates.

ANT2STRLEN= Averaged stride length with the anterior walker on the second pass through the timing gates.

AVGANTSTRLEN= Averaged stridelength from first and second pass. 


\begin{tabular}{ccccc}
\hline Participant & AVGANTSTRLEN & POST1STRLEN & POST2STRLEN & AVGPOSTSTRLEN \\
\hline 1 & 1.26 & 1.13 & 1.07 & 1.1 \\
2 & 1.07 & 0.95 & 0.98 & 0.96 \\
3 & 1.2 & 1.11 & 1.14 & 1.13 \\
4 & 0.99 & 0.88 & 0.98 & 0.93 \\
5 & 0.44 & 0.55 & 0.49 & 0.52 \\
6 & 1.16 & 1.01 & 0.95 & 0.98 \\
7 & 0.95 & 0.73 & 0.79 & 0.76 \\
8 & 0.99 & 1.04 & 1.01 & 1.02 \\
9 & 0.7 & 0.76 & 0.73 & 0.75 \\
10 & 0.92 & 0.69 & 0.73 & 0.71 \\
11 & 1.37 & 1.28 & 1.37 & 1.33 \\
12 & 1.04 & 1.01 & 1.13 & 1.07 \\
13 & 0.75 & 0.8 & 0.78 & 0.79 \\
14 & 0.78 & 0.76 & 0.73 & 0.75 \\
15 & 0.87 & 0.4 & 0.46 & 0.43 \\
16 & 0.88 & 0.85 & 0.85 & 0.85 \\
17 & 0.93 & 0.73 & 0.76 & 0.75 \\
18 & 0.88 & 0.91 & 0.98 & 0.95 \\
19 & 1.14 & 1.19 & 1.19 & 1.19 \\
20 & 0.91 & 0.82 & 0.82 & 0.82 \\
Average & 0.96 & 0.88 & 0.90 & 0.89 \\
SD & 0.21 & 0.21 & 0.22 & 0.22 \\
\hline
\end{tabular}

POST1STRLEN $=$ Averaged stride length with the posterior walker on the first pass through the timing gates.

POST2STRLEN = Averaged stride length with the posterior walker on the second pass through the timing gates.

AVGPOSTSTRLEN = Average of the two stride lengths from the two passes with the posterior walker. 


\begin{tabular}{ccccc}
\hline Participant & NONE1STRLEN & NONE2STRLEN & AVGNONESTRLEN & Order \\
\hline 1 & 1.27 & 1.21 & 1.24 & APN \\
2 & 1.1 & 0.98 & 1.04 & PAN \\
3 & 1.08 & 0.98 & 1.03 & NAP \\
4 & 1.08 & 1.08 & 1.08 & NPA \\
5 & 0.55 & 0.46 & 0.5 & APN \\
6 & 1.25 & 1.16 & 1.2 & ANP \\
7 & 1.04 & 0.98 & 1.01 & APN \\
8 & 1.04 & 0.95 & 0.99 & PAN \\
9 & 0.85 & 0.76 & 0.81 & NAP \\
10 & 0.79 & 0.82 & 0.81 & NPA \\
11 & 1.4 & 1.43 & 1.42 & PNA \\
12 & 1.01 & 1.13 & 1.07 & ANP \\
13 & 0.73 & 0.63 & 0.69 & PNA \\
14 & 0.58 & 0.49 & 0.53 & PAN \\
15 & 0.59 & 0.51 & 0.55 & NAP \\
16 & 0.88 & 1.01 & 0.95 & NPA \\
17 & 0.95 & 0.95 & 0.95 & PNA \\
18 & 0.98 & 0.95 & 0.96 & ANP \\
19 & 1.07 & 1.25 & 1.16 & APN \\
20 & 1.01 & 0.98 & 0.99 & PAN \\
Average & 0.96 & 0.94 & 0.95 & \\
SD & 0.22 & 0.25 & 0.24 & \\
\hline
\end{tabular}

NONE1STRLEN = Averaged stride length on the first pass without a walker through the timing gates.

NONE2STRLEN = Averaged stride length on the second pass without a walker through the timing gates.

AVGNONESTRLEN = Average of the two stride lengths without a walker.

ORDER $=$ Order in which the participant performed the gait trials.

Table D 2. Descriptive statistics for peak back extension during gait with anterior, posterior and no walker

\begin{tabular}{lccc}
\hline \hline & Mean & Std. Deviation & $\mathrm{N}$ \\
\hline ANT BACK EXT (DEG; +=ext) & 16.90 & 9.341 & 20 \\
POST BACK EXT (DEG) & 17.80 & 9.688 & 20 \\
NONE BACK EXT & 18.20 & 9.633 & 20 \\
\hline
\end{tabular}


Table D 3. Within subject effects of walker type on peak back extension angle during gait

\begin{tabular}{|c|c|c|c|c|c|c|c|c|c|}
\hline Source & & $\begin{array}{l}\text { Type III } \\
\text { Sum of } \\
\text { Squares }\end{array}$ & df & $\begin{array}{l}\text { Mean } \\
\text { Square }\end{array}$ & $\mathrm{F}$ & Sig. & $\begin{array}{l}\text { Partial } \\
\text { Eta } \\
\text { Squared }\end{array}$ & $\begin{array}{l}\text { Noncent } \\
\text {.Para- } \\
\text { meter }\end{array}$ & $\begin{array}{c}\text { Observed } \\
\text { Power }\end{array}$ \\
\hline \multirow[t]{4}{*}{ walker } & $\begin{array}{l}\text { Sphericity } \\
\text { Assumed }\end{array}$ & 17.733 & 2 & 8.867 & 1.295 & .286 & .064 & 2.589 & .263 \\
\hline & $\begin{array}{l}\text { Greenhouse- } \\
\text { Geisser }\end{array}$ & 17.733 & 1.617 & 10.968 & 1.295 & .283 & .064 & 2.093 & .237 \\
\hline & Huynh-Feldt & 17.733 & 1.745 & 10.161 & 1.295 & .284 & .064 & 2.259 & .246 \\
\hline & Lower-bound & 17.733 & 1.000 & 17.733 & 1.295 & .269 & .064 & 1.295 & .191 \\
\hline \multirow[t]{4}{*}{ Error } & $\begin{array}{l}\text { Sphericity } \\
\text { Assumed }\end{array}$ & 260.267 & 38 & 6.849 & & & & & \\
\hline & $\begin{array}{l}\text { Greenhouse- } \\
\text { Geisser }\end{array}$ & 260.267 & 30.72 & 8.472 & & & & & \\
\hline & Huynh-Feldt & 260.267 & 33.16 & 7.849 & & & & & \\
\hline & Lower-bound & 260.267 & 19.00 & 13.698 & & & & & \\
\hline
\end{tabular}

a Computed using alpha $=.05$

Table D 4. Estimated marginal means for peak back extension angle with 1)Anterior, 2) posterior and 3) No walker

\begin{tabular}{lcccc}
\hline \hline & & & \multicolumn{2}{c}{$95 \%$ Confidence Interval } \\
\cline { 4 - 5 } walker & Mean & Std. Error & Lower Bound & Upper Bound \\
\hline 1 & 16.900 & 2.089 & 12.528 & 21.272 \\
2 & 17.800 & 2.166 & 13.266 & 22.334 \\
3 & 18.200 & 2.154 & 13.691 & 22.709 \\
\hline
\end{tabular}

Table D 5. Pairwise comparisions for peak back extension angle with 1) Anterior, 2) Posterior and 3) No walker.

\begin{tabular}{|c|c|c|c|c|c|c|}
\hline \multirow[b]{2}{*}{ (I) walker } & \multirow[b]{2}{*}{ (J) walker } & \multirow{2}{*}{$\begin{array}{c}\text { Mean } \\
\text { Difference } \\
(\mathrm{I}-\mathrm{J})\end{array}$} & \multirow[b]{2}{*}{ Std. Error } & \multirow[b]{2}{*}{ Sig.(a) } & \multicolumn{2}{|c|}{$\begin{array}{c}\text { 95\% Confidence Interval for } \\
\text { Difference(a) }\end{array}$} \\
\hline & & & & & Upper Bound & Lower Bound \\
\hline \multirow[t]{2}{*}{1} & 2 & -.900 & .900 & .699 & -3.255 & 1.455 \\
\hline & 3 & -1.300 & .943 & .457 & -3.769 & 1.169 \\
\hline \multirow[t]{2}{*}{2} & 1 & .900 & .900 & .699 & -1.455 & 3.255 \\
\hline & 3 & -.400 & .596 & .882 & -1.959 & 1.159 \\
\hline \multirow[t]{2}{*}{3} & 1 & 1.300 & .943 & .457 & -1.169 & 3.769 \\
\hline & 2 & .400 & .596 & .882 & -1.159 & 1.959 \\
\hline
\end{tabular}


Based on estimated marginal means

a Adjustment for multiple comparisons: Sidak.

Table D 6. Descriptive statistics for minimum back extension angle during gait cycle with anterior, posterior and no walker.

\begin{tabular}{lccc}
\hline \hline & Mean & Std. Deviation & $\mathrm{N}$ \\
\hline ANT BACK FLEX (DEG) & 8.75 & 7.239 & 20 \\
POST BACK FLEX & 10.25 & 8.123 & 20 \\
NONE BACK FLEX & 10.30 & 6.959 & 20 \\
\hline
\end{tabular}

Table D 7. Within subject effects of walker type on minimum back extension angle.

\begin{tabular}{|c|c|c|c|c|c|c|c|c|c|}
\hline Source & & $\begin{array}{l}\text { Type III } \\
\text { Sum of } \\
\text { Squares }\end{array}$ & $\mathrm{df}$ & $\begin{array}{l}\text { Mean } \\
\text { Square }\end{array}$ & $\mathrm{F}$ & Sig. & $\begin{array}{c}\text { Partial } \\
\text { Eta } \\
\text { Squared } \\
\end{array}$ & $\begin{array}{c}\text { Noncent } \\
\text { Para- } \\
\text { meter }\end{array}$ & $\begin{array}{l}\text { Observed } \\
\text { Power(a) } \\
\end{array}$ \\
\hline \multirow[t]{4}{*}{ walker } & $\begin{array}{l}\text { Sphericity } \\
\text { Assumed }\end{array}$ & 31.033 & 2 & 15.517 & 1.986 & .151 & .095 & 3.971 & .385 \\
\hline & $\begin{array}{l}\text { Greenhouse- } \\
\text { Geisser }\end{array}$ & 31.033 & 1.926 & 16.109 & 1.986 & .153 & .095 & 3.825 & .377 \\
\hline & Huynh-Feldt & 31.033 & 2.000 & 15.517 & 1.986 & .151 & .095 & 3.971 & .385 \\
\hline & Lower-bound & 31.033 & 1.000 & 31.033 & 1.986 & .175 & .095 & 1.986 & .268 \\
\hline \multirow[t]{4}{*}{$\begin{array}{l}\text { Error } \\
\text { (walker) }\end{array}$} & $\begin{array}{l}\text { Sphericity } \\
\text { Assumed }\end{array}$ & 296.967 & 38 & 7.815 & & & & & \\
\hline & $\begin{array}{l}\text { Greenhouse- } \\
\text { Geisser }\end{array}$ & 296.967 & 36.60 & 8.113 & & & & & \\
\hline & Huynh-Feldt & 296.967 & 38.00 & 7.815 & & & & & \\
\hline & Lower-bound & 296.967 & 19.00 & 15.630 & & & & & \\
\hline
\end{tabular}

Measure: MEASURE 1

a Computed using alpha $=.05$

Table D 8 Estimated marginal means for minimum back extension angle with 1) anterior 2)posterior and 3) no walker.

\begin{tabular}{lcccc}
\hline \hline & & & \multicolumn{2}{c}{$95 \%$ Confidence Interval } \\
\cline { 4 - 5 } walker & Mean & Std. Error & Lower Bound & Upper Bound \\
\hline 1 & 8.750 & 1.619 & 5.362 & 12.138 \\
2 & 10.250 & 1.816 & 6.448 & 14.052 \\
3 & 10.300 & 1.556 & 7.043 & 13.557 \\
\hline
\end{tabular}


Table D 9 Pairwise comparisons of minimum back extension angle during gait with 1) anterior 2) posterior and 3) no walker.

\begin{tabular}{|c|c|c|c|c|c|c|}
\hline \multirow[b]{2}{*}{ (I) walker } & \multirow[b]{2}{*}{ (J) walker } & \multirow{2}{*}{$\begin{array}{c}\text { Mean } \\
\text { Difference } \\
(\mathrm{I}-\mathrm{J})\end{array}$} & \multirow[b]{2}{*}{ Std. Error } & \multirow[b]{2}{*}{ Sig.(a) } & \multicolumn{2}{|c|}{$\begin{array}{l}\text { 95\% Confidence Interval for } \\
\text { Difference(a) }\end{array}$} \\
\hline & & & & & Upper Bound & Lower Bound \\
\hline \multirow[t]{2}{*}{1} & 2 & -1.500 & .967 & .358 & -4.030 & 1.030 \\
\hline & 3 & -1.550 & .838 & .221 & -3.744 & .644 \\
\hline \multirow[t]{2}{*}{2} & 1 & 1.500 & .967 & .358 & -1.030 & 4.030 \\
\hline & 3 & -.050 & .841 & 1.000 & -2.252 & 2.152 \\
\hline \multirow[t]{2}{*}{3} & 1 & 1.550 & .838 & .221 & -.644 & 3.744 \\
\hline & 2 & .050 & .841 & 1.000 & -2.152 & 2.252 \\
\hline
\end{tabular}

Based on estimated marginal means

a Adjustment for multiple comparisons: Sidak.

Table D 10. Descriptive statistics for maximum hip flexion angle during gait with anterior, posterior and no walker.

\begin{tabular}{lccl}
\hline \hline & Mean & Std. Deviation & $\mathrm{N}$ \\
\hline ANT HIP FLEX & 33.30 & 13.263 & 20 \\
(DEG; +=flex) & & 12.390 & 20 \\
POST HIP FLEX & 29.65 & 10.846 & 20 \\
NONE HIP FLEX & 30.50 & & \\
\hline
\end{tabular}

Table D 11. Within subjects effects for walker type on maximum hip flexion angle during gait.

\begin{tabular}{|c|c|c|c|c|c|c|c|c|c|}
\hline Source & & $\begin{array}{l}\text { Type III } \\
\text { Sum of } \\
\text { Squares }\end{array}$ & df & $\begin{array}{l}\text { Mean } \\
\text { Square }\end{array}$ & $\mathrm{F}$ & Sig. & $\begin{array}{l}\text { Partial } \\
\text { Eta } \\
\text { Squar } \\
\text { ed } \\
\end{array}$ & $\begin{array}{c}\text { Noncent } \\
\text {. Para- } \\
\text { meter }\end{array}$ & $\begin{array}{l}\text { Observed } \\
\text { Power(a) }\end{array}$ \\
\hline \multirow[t]{4}{*}{ walker } & $\begin{array}{l}\text { Sphericity } \\
\text { Assumed }\end{array}$ & 145.900 & 2 & 72.950 & 2.093 & .137 & .099 & 4.185 & .403 \\
\hline & $\begin{array}{l}\text { Greenhouse- } \\
\text { Geisser }\end{array}$ & 145.900 & $\begin{array}{r}1.74 \\
4\end{array}$ & 83.658 & 2.093 & .145 & .099 & 3.649 & .374 \\
\hline & Huynh-Feldt & 145.900 & $\begin{array}{r}1.90 \\
5\end{array}$ & 76.571 & 2.093 & .140 & .099 & 3.987 & .392 \\
\hline & Lower-bound & 145.900 & $\begin{array}{r}1.00 \\
0\end{array}$ & 145.900 & 2.093 & .164 & .099 & 2.093 & .279 \\
\hline \multirow[t]{3}{*}{$\begin{array}{l}\text { Error } \\
\text { (walker) }\end{array}$} & $\begin{array}{l}\text { Sphericity } \\
\text { Assumed }\end{array}$ & 1324.767 & 38 & 34.862 & & & & & \\
\hline & $\begin{array}{l}\text { Greenhouse- } \\
\text { Geisser }\end{array}$ & 1324.767 & $\begin{array}{r}33.1 \\
3\end{array}$ & 39.980 & & & & & \\
\hline & Huynh-Feldt & 1324.767 & $\begin{array}{r}36.2 \\
0\end{array}$ & 36.592 & & & & & \\
\hline
\end{tabular}




\begin{tabular}{rrrr}
\hline \hline Lower-bound & 1324.767 & $\begin{array}{r}19.0 \\
0\end{array}$ & 69.725 \\
\hline
\end{tabular}

a Computed using alpha $=.05$

Table D 12 Estimated marginal means of maximum hip flexion angle during gait with 1) anterior 2) posterior and 3) no walker.

\section{Estimates}

Measure: MEASURE_1

\begin{tabular}{lcccc}
\hline & & & \multicolumn{2}{c}{$95 \%$ Confidence Interval } \\
\cline { 4 - 5 } walker & Mean & Std. Error & Lower Bound & Upper Bound \\
\hline 1 & 33.300 & 2.966 & 27.093 & 39.507 \\
2 & 29.650 & 2.770 & 23.851 & 35.449 \\
3 & 30.500 & 2.425 & 25.424 & 35.576 \\
\hline
\end{tabular}

Table D 13 Pairwise comparisons of maximum hip flexion angle during gait with 1) anterior 2) posterior and 3) no walker.

\begin{tabular}{|c|c|c|c|c|c|c|}
\hline \multirow[b]{2}{*}{ (I) walker } & \multirow[b]{2}{*}{ (J) walker } & \multirow{2}{*}{$\begin{array}{c}\text { Mean } \\
\text { Difference } \\
(\mathrm{I}-\mathrm{J})\end{array}$} & \multirow[b]{2}{*}{ Std. Error } & \multirow[b]{2}{*}{ Sig.(a) } & \multicolumn{2}{|c|}{$\begin{array}{l}\text { 95\% Confidence Interval for } \\
\text { Difference(a) }\end{array}$} \\
\hline & & & & & Upper Bound & Lower Bound \\
\hline \multirow[t]{2}{*}{1} & 2 & 3.650 & 1.817 & .167 & -1.105 & 8.405 \\
\hline & 3 & 2.800 & 2.174 & .513 & -2.888 & 8.488 \\
\hline \multirow[t]{2}{*}{2} & 1 & -3.650 & 1.817 & .167 & -8.405 & 1.105 \\
\hline & 3 & -.850 & 1.560 & .932 & -4.932 & 3.232 \\
\hline \multirow[t]{2}{*}{3} & 1 & -2.800 & 2.174 & .513 & -8.488 & 2.888 \\
\hline & 2 & .850 & 1.560 & .932 & -3.232 & 4.932 \\
\hline
\end{tabular}

Based on estimated marginal means

a Adjustment for multiple comparisons: Sidak.

Table D 14. Descriptive statistics for maximum hip extension angle during gait with 1) anterior 2) posterior and 3) no walker.

\begin{tabular}{lccc}
\hline \hline & Mean & Std. Deviation & $\mathrm{N}$ \\
\hline ANT HIP EXT (DEG) & 3.40 & 9.539 & 20 \\
POST HIP EXT & 1.55 & 10.655 & 20
\end{tabular}




\begin{tabular}{llll}
\hline \hline NONE HIP EXT & -.25 & 9.352 & 20 \\
\hline
\end{tabular}

Table D 15. Within subject effect of walker type on maximum hip extension angle during gait with 1) anterior 2) posterior and 3) no walker.

\begin{tabular}{|c|c|c|c|c|c|c|c|c|c|}
\hline Source & & $\begin{array}{l}\text { Type III } \\
\text { Sum of } \\
\text { Squares }\end{array}$ & df & $\begin{array}{c}\text { Mean } \\
\text { Square }\end{array}$ & $\mathrm{F}$ & Sig. & $\begin{array}{l}\text { Partial } \\
\text { Eta } \\
\text { Squar } \\
\text { ed } \\
\end{array}$ & $\begin{array}{c}\text { Noncent } \\
\text { Para- } \\
\text { meter } \\
\end{array}$ & $\begin{array}{l}\text { Observed } \\
\text { Power(a) }\end{array}$ \\
\hline \multirow[t]{4}{*}{ walker } & $\begin{array}{l}\text { Sphericity } \\
\text { Assumed }\end{array}$ & 133.233 & 2 & 66.617 & 2.679 & .082 & .124 & 5.359 & .499 \\
\hline & $\begin{array}{l}\text { Greenhouse- } \\
\text { Geisser }\end{array}$ & 133.233 & 1.911 & 69.730 & 2.679 & .084 & .124 & 5.120 & .487 \\
\hline & Huynh-Feldt & 133.233 & 2.000 & 66.617 & 2.679 & .082 & .124 & 5.359 & .499 \\
\hline & Lower-bound & 133.233 & 1.000 & 133.233 & 2.679 & .118 & .124 & 2.679 & .343 \\
\hline \multirow[t]{4}{*}{$\begin{array}{l}\text { Error } \\
\text { (walker) }\end{array}$} & $\begin{array}{l}\text { Sphericity } \\
\text { Assumed }\end{array}$ & 944.767 & 38 & 24.862 & & & & & \\
\hline & $\begin{array}{l}\text { Greenhouse- } \\
\text { Geisser }\end{array}$ & 944.767 & 36.30 & 26.024 & & & & & \\
\hline & Huynh-Feldt & 944.767 & 38.00 & 24.862 & & & & & \\
\hline & Lower-bound & 944.767 & 19.00 & 49.725 & & & & & \\
\hline
\end{tabular}

a Computed using alpha $=.05$

Table D 16 Estimated marginal means for maximum hip extension during gait with 1) anterior 2) posterior and 3) no walker.

\begin{tabular}{ccccc}
\hline \hline & & & \multicolumn{2}{c}{$95 \%$ Confidence Interval } \\
\cline { 4 - 5 } walker & Mean & Std. Error & Lower Bound & Upper Bound \\
\hline 1 & 3.400 & 2.133 & -1.064 & 7.864 \\
2 & 1.550 & 2.382 & -3.437 & 6.537 \\
3 & -.250 & 2.091 & -4.627 & 4.127 \\
\hline
\end{tabular}

Table D 17 Pairwise comparisons for maximum hip extension angle during gait with 1) anterior 2) posterior and 3) no walker.

\begin{tabular}{|c|c|c|c|c|c|}
\hline & & Mean & & & $\begin{array}{l}\text { 95\% Confidence Interval for } \\
\text { Difference(a) }\end{array}$ \\
\hline (I) walker & (J) walker & $\begin{array}{l}\text { Difference } \\
\quad(\mathrm{I}-\mathrm{J})\end{array}$ & Std. Error & Sig.(a) & Upper Bound \\
\hline
\end{tabular}




\begin{tabular}{ccccccc}
\hline 1 & 2 & 1.850 & 1.466 & .529 & -1.986 & 5.686 \\
& 3 & 3.650 & 1.737 & .140 & -.896 & 8.196 \\
2 & 1 & -1.850 & 1.466 & .529 & -5.686 & 1.986 \\
& 3 & 1.800 & 1.514 & .577 & -2.163 & 5.763 \\
& 1 & -3.650 & 1.737 & .140 & -8.196 & .896 \\
& 2 & -1.800 & 1.514 & .577 & -5.763 & 2.163 \\
\hline
\end{tabular}

Based on estimated marginal means

a Adjustment for multiple comparisons: Sidak.

Table D 18 Descriptive statistics for maximum knee flexion angle during gait with 1) anterior 2) posterior and 3) no walker.

\begin{tabular}{lccc}
\hline \hline & Mean & Std. Deviation & N \\
\hline ANT KNEE FLEX (DEG) & 55.42 & 10.405 & 19 \\
POST KNEE FLEX & 56.42 & 13.023 & 19 \\
NONE KNEE FLEX & 58.37 & 11.186 & 19 \\
\hline
\end{tabular}

Table D 19 Within subject effect of walker type on maximum knee flexion angle during gait.

\begin{tabular}{|c|c|c|c|c|c|c|c|c|c|}
\hline Source & & $\begin{array}{l}\text { Type III } \\
\text { Sum of } \\
\text { Squares }\end{array}$ & df & $\begin{array}{l}\text { Mean } \\
\text { Square }\end{array}$ & $\mathrm{F}$ & Sig. & $\begin{array}{l}\text { Part } \\
\text { ial } \\
\text { Eta } \\
\text { Squ } \\
\text { are } \\
\text { d }\end{array}$ & $\begin{array}{l}\text { Noncent } \\
\text { Para- } \\
\text { meter }\end{array}$ & $\begin{array}{l}\text { Observed } \\
\text { Power(a) }\end{array}$ \\
\hline \multirow[t]{4}{*}{ walker } & $\begin{array}{l}\text { Sphericity } \\
\text { Assumed }\end{array}$ & 85.368 & 2 & 42.684 & .638 & .534 & .034 & 1.277 & .148 \\
\hline & $\begin{array}{l}\text { Greenhouse- } \\
\text { Geisser }\end{array}$ & 85.368 & 1.299 & 65.701 & .638 & .472 & .034 & .829 & .128 \\
\hline & Huynh-Feldt & 85.368 & 1.358 & 62.840 & .638 & .478 & .034 & .867 & .130 \\
\hline & Lower-bound & 85.368 & 1.000 & 85.368 & .638 & .435 & .034 & .638 & .118 \\
\hline \multirow[t]{4}{*}{$\begin{array}{l}\text { Error } \\
\text { (walker) }\end{array}$} & $\begin{array}{l}\text { Sphericity } \\
\text { Assumed }\end{array}$ & 2407.298 & 36 & 66.869 & & & & & \\
\hline & $\begin{array}{l}\text { Greenhouse- } \\
\text { Geisser }\end{array}$ & 2407.298 & 23.38 & 102.927 & & & & & \\
\hline & Huynh-Feldt & 2407.298 & 24.45 & 98.446 & & & & & \\
\hline & Lower-bound & 2407.298 & 18.00 & 133.739 & & & & & \\
\hline
\end{tabular}

a Computed using alpha $=.05$

Table D 20 Marginal estimates of maximum knee angle during gait with 1) anterior, 2) posterior and 3) no walker. 


\begin{tabular}{lcccc}
\hline \hline & & & \multicolumn{2}{c}{$95 \%$ Confidence Interval } \\
\cline { 4 - 5 } walker & Mean & Std. Error & Lower Bound & Upper Bound \\
\hline 1 & 55.421 & 2.387 & 50.406 & 60.436 \\
2 & 56.421 & 2.988 & 50.144 & 62.698 \\
3 & 58.368 & 2.566 & 52.977 & 63.760 \\
\hline
\end{tabular}

Table D 21 Pairwise comparisons of maximum knee angle during gait with 1) anterior 2) posterior and 3) no walker.

\begin{tabular}{|c|c|c|c|c|c|c|}
\hline \multirow[b]{2}{*}{ (I) walker } & \multirow[b]{2}{*}{ (J) walker } & \multirow{2}{*}{$\begin{array}{c}\text { Mean } \\
\text { Difference } \\
(\mathrm{I}-\mathrm{J})\end{array}$} & \multirow[b]{2}{*}{ Std. Error } & \multirow[b]{2}{*}{ Sig.(a) } & \multicolumn{2}{|c|}{$\begin{array}{l}\text { 95\% Confidence Interval for } \\
\text { Difference }(\mathrm{a})\end{array}$} \\
\hline & & & & & Upper Bound & Lower Bound \\
\hline \multirow{2}{*}{1} & 2 & -1.000 & 3.002 & .983 & -8.898 & 6.898 \\
\hline & 3 & -2.947 & 1.384 & .135 & -6.588 & .694 \\
\hline \multirow{2}{*}{2} & 1 & 1.000 & 3.002 & .983 & -6.898 & 8.898 \\
\hline & 3 & -1.947 & 3.192 & .909 & -10.346 & 6.451 \\
\hline \multirow{2}{*}{3} & 1 & 2.947 & 1.384 & .135 & -.694 & 6.588 \\
\hline & 2 & 1.947 & 3.192 & .909 & -6.451 & 10.346 \\
\hline
\end{tabular}

Based on estimated marginal means

a Adjustment for multiple comparisons: Sidak.

Table D 22. Descriptive statistics of maximum knee extension angle during gait with 1) anterior 2) posterior and 3) no walker.

\begin{tabular}{lccc}
\hline \hline & Mean & Std. Deviation & N \\
\hline ANT KNEE EXT (DEG) & .95 & 8.003 & 19 \\
POST KNEE EXT & 2.84 & 7.632 & 19 \\
NONE KNEE EXT & 1.68 & 7.550 & 19 \\
\hline
\end{tabular}

Table D 23. Within subject effect of walker type on maximum knee extension angle. 
a Computed using alpha $=.05$

\begin{tabular}{|c|c|c|c|c|c|c|c|c|c|}
\hline Source & & $\begin{array}{l}\text { Type III } \\
\text { Sum of } \\
\text { Squares }\end{array}$ & df & $\begin{array}{c}\text { Mean } \\
\text { Square }\end{array}$ & $\mathrm{F}$ & Sig. & $\begin{array}{l}\text { Partial } \\
\text { Eta } \\
\text { Squar } \\
\text { ed } \\
\end{array}$ & $\begin{array}{c}\text { Noncent } \\
\text {. Para- } \\
\text { meter }\end{array}$ & $\begin{array}{l}\text { Observed } \\
\text { Power(a) }\end{array}$ \\
\hline \multirow[t]{4}{*}{ walker } & $\begin{array}{l}\text { Sphericity } \\
\text { Assumed }\end{array}$ & 34.667 & 2 & 17.333 & 1.100 & .344 & .058 & 2.200 & .228 \\
\hline & $\begin{array}{l}\text { Greenhous } \\
\text { e-Geisser }\end{array}$ & 34.667 & 1.655 & 20.950 & 1.100 & .336 & .058 & 1.820 & .208 \\
\hline & $\begin{array}{l}\text { Huynh- } \\
\text { Feldt }\end{array}$ & 34.667 & 1.801 & 19.247 & 1.100 & .339 & .058 & 1.981 & .217 \\
\hline & $\begin{array}{l}\text { Lower- } \\
\text { bound }\end{array}$ & 34.667 & 1.000 & 34.667 & 1.100 & .308 & .058 & 1.100 & .168 \\
\hline \multirow[t]{4}{*}{$\begin{array}{l}\text { Error } \\
\text { (walker) }\end{array}$} & $\begin{array}{l}\text { Sphericity } \\
\text { Assumed }\end{array}$ & 567.333 & 36 & 15.759 & & & & & \\
\hline & $\begin{array}{l}\text { Greenhous } \\
\text { e-Geisser }\end{array}$ & 567.333 & 29.78 & 19.047 & & & & & \\
\hline & $\begin{array}{l}\text { Huynh- } \\
\text { Feldt }\end{array}$ & 567.333 & 32.42 & 17.499 & & & & & \\
\hline & $\begin{array}{l}\text { Lower- } \\
\text { bound }\end{array}$ & 567.333 & 18.00 & 31.519 & & & & & \\
\hline
\end{tabular}

Table D 24. Marginal estimates of maximum knee extension angle during gait with 1) anterior 2) posterior and 3) no walker.

\begin{tabular}{ccccc}
\hline \hline & & & \multicolumn{2}{c}{$95 \%$ Confidence Interval } \\
\cline { 4 - 5 } walker & Mean & Std. Error & Lower Bound & Upper Bound \\
\hline 1 & .947 & 1.836 & -2.910 & 4.805 \\
2 & 2.842 & 1.751 & -.837 & 6.521 \\
3 & 1.684 & 1.732 & -1.955 & 5.323 \\
\hline
\end{tabular}

Table D 25. Pairwise comparisons of maximum knee extension angle during gait with 1)anterior 2) posterior and 3) no walker.

\begin{tabular}{|c|c|c|c|c|c|c|}
\hline \multirow[b]{2}{*}{ (I) walker } & \multirow[b]{2}{*}{ (J) walker } & \multirow{2}{*}{$\begin{array}{c}\text { Mean } \\
\text { Difference } \\
(\mathrm{I}-\mathrm{J})\end{array}$} & \multirow[b]{2}{*}{ Std. Error } & \multirow[b]{2}{*}{ Sig.(a) } & \multicolumn{2}{|c|}{$\begin{array}{c}\text { 95\% Confidence Interval for } \\
\text { Difference(a) }\end{array}$} \\
\hline & & & & & Upper Bound & Lower Bound \\
\hline \multirow{2}{*}{1} & 2 & -1.895 & 1.006 & .211 & -4.540 & .751 \\
\hline & 3 & -.737 & 1.282 & .922 & -4.109 & 2.635 \\
\hline \multirow{2}{*}{2} & 1 & 1.895 & 1.006 & .211 & -.751 & 4.540 \\
\hline & 3 & 1.158 & 1.524 & .840 & -2.852 & 5.168 \\
\hline \multirow{2}{*}{3} & 1 & .737 & 1.282 & .922 & -2.635 & 4.109 \\
\hline & 2 & -1.158 & 1.524 & .840 & -5.168 & 2.852 \\
\hline
\end{tabular}

Based on estimated marginal means 
a Adjustment for multiple comparisons: Sidak.

Table D 26. Descriptive statistics of maximum plantarflexion angle during gait with 1) anterior 2) posterior and 3) no walker.

\begin{tabular}{lccc}
\hline \hline & Mean & Std. Deviation & $\mathrm{N}$ \\
\hline ANT ANKLE PF (DEG) & 27.30 & 9.370 & 20 \\
POST ANKLE PF & 26.05 & 9.327 & 20 \\
NONE ANKLE PF & 27.50 & 9.099 & 20 \\
\hline
\end{tabular}

Table D 27. Within subject effects of walker type on maximum plantarflexion angle.

\begin{tabular}{|c|c|c|c|c|c|c|c|c|c|}
\hline Source & & $\begin{array}{l}\text { Type III } \\
\text { Sum of } \\
\text { Squares }\end{array}$ & df & $\begin{array}{l}\text { Mean } \\
\text { Square }\end{array}$ & $\mathrm{F}$ & Sig. & $\begin{array}{l}\text { Partial } \\
\text { Eta } \\
\text { Squar } \\
\text { ed }\end{array}$ & $\begin{array}{l}\text { Noncent } \\
\text {. Para- } \\
\text { meter } \\
\end{array}$ & $\begin{array}{l}\text { Observed } \\
\text { Power(a) }\end{array}$ \\
\hline \multirow[t]{4}{*}{ walker } & $\begin{array}{l}\text { Sphericity } \\
\text { Assumed }\end{array}$ & 24.700 & 2 & 12.350 & .388 & .681 & .020 & .776 & .108 \\
\hline & $\begin{array}{l}\text { Greenhous } \\
\text { e-Geisser }\end{array}$ & 24.700 & 1.983 & 12.455 & .388 & .679 & .020 & .769 & .108 \\
\hline & $\begin{array}{l}\text { Huynh- } \\
\text { Feldt }\end{array}$ & 24.700 & 2.000 & 12.350 & .388 & .681 & .020 & .776 & .108 \\
\hline & $\begin{array}{l}\text { Lower- } \\
\text { bound }\end{array}$ & 24.700 & 1.000 & 24.700 & .388 & .541 & .020 & .388 & .091 \\
\hline \multirow[t]{4}{*}{$\begin{array}{l}\text { Error } \\
\text { (walker) }\end{array}$} & $\begin{array}{l}\text { Sphericity } \\
\text { Assumed }\end{array}$ & 1209.967 & 38 & 31.841 & & & & & \\
\hline & $\begin{array}{l}\text { Greenhous } \\
\text { e-Geisser }\end{array}$ & 1209.967 & $\begin{array}{r}37.68 \\
0\end{array}$ & 32.112 & & & & & \\
\hline & $\begin{array}{l}\text { Huynh- } \\
\text { Feldt }\end{array}$ & 1209.967 & $\begin{array}{r}38.00 \\
0\end{array}$ & 31.841 & & & & & \\
\hline & $\begin{array}{l}\text { Lower- } \\
\text { bound }\end{array}$ & 1209.967 & $\begin{array}{r}19.00 \\
0\end{array}$ & 63.682 & & & & & \\
\hline
\end{tabular}

a Computed using alpha $=.05$

Table D 28. Estimated marginal means for maximum plantarflexion angle with 1) anterior 2) posterior and 3) no walker.

\begin{tabular}{ccccc}
\hline \hline & & & \multicolumn{2}{c}{$95 \%$ Confidence Interval } \\
\cline { 3 - 5 } walker & Mean & Std. Error & Lower Bound & Upper Bound \\
\hline 1 & 27.300 & 2.095 & 22.915 & 31.685 \\
2 & 26.050 & 2.086 & 21.685 & 30.415 \\
3 & 27.500 & 2.035 & 23.242 & 31.758 \\
\hline
\end{tabular}


Table D 29. Pairwise comparisons for maximum plantarflexion angle during gait with 1) anterior 2) posterior and 3) no walker.

\begin{tabular}{|c|c|c|c|c|c|c|}
\hline \multirow[b]{2}{*}{ (I) walker } & \multirow[b]{2}{*}{ (J) walker } & \multirow{2}{*}{$\begin{array}{c}\text { Mean } \\
\text { Difference } \\
(\mathrm{I}-\mathrm{J})\end{array}$} & \multirow[b]{2}{*}{ Std. Error } & \multirow[b]{2}{*}{ Sig.(a) } & \multicolumn{2}{|c|}{$\begin{array}{c}95 \% \text { Confidence Interval for } \\
\text { Difference(a) }\end{array}$} \\
\hline & & & & & Upper Bound & Lower Bound \\
\hline \multirow{2}{*}{1} & 2 & 1.250 & 1.818 & .875 & -3.508 & 6.008 \\
\hline & 3 & -.200 & 1.832 & .999 & -4.994 & 4.594 \\
\hline \multirow{2}{*}{2} & 1 & -1.250 & 1.818 & .875 & -6.008 & 3.508 \\
\hline & 3 & -1.450 & 1.701 & .789 & -5.901 & 3.001 \\
\hline \multirow{2}{*}{3} & 1 & .200 & 1.832 & .999 & -4.594 & 4.994 \\
\hline & 2 & 1.450 & 1.701 & .789 & -3.001 & 5.901 \\
\hline
\end{tabular}

Based on estimated marginal means

a Adjustment for multiple comparisons: Sidak.

Table D 30. Descriptive statistics for maximum dorsiflexion angle during gait with 1) anterior 2) posterior and 3) no walker.

\begin{tabular}{lccc}
\hline \hline & Mean & Std. Deviation & $\mathrm{N}$ \\
\hline ANT ANKLE DF & -1.15 & 6.753 & 20 \\
$\begin{array}{l}\text { (DEG; - = DF) } \\
\text { POST ANKLE DF }\end{array}$ & -3.05 & 5.404 & 20 \\
NONE ANKLE DF & -2.25 & 6.608 & 20 \\
\hline
\end{tabular}

Table D 31. Within subject effects of walker type on maximum dorsiflexion angle during gait.

\begin{tabular}{|c|c|c|c|c|c|c|c|c|c|}
\hline Source & & $\begin{array}{l}\text { Type III } \\
\text { Sum of } \\
\text { Squares }\end{array}$ & $\mathrm{df}$ & $\begin{array}{l}\text { Mean } \\
\text { Square }\end{array}$ & $\mathrm{F}$ & Sig. & $\begin{array}{l}\text { Partial } \\
\text { Eta } \\
\text { Squar } \\
\text { ed }\end{array}$ & $\begin{array}{c}\text { Noncent } \\
\text {. Para- } \\
\text { meter }\end{array}$ & $\begin{array}{l}\text { Observed } \\
\text { Power(a) }\end{array}$ \\
\hline \multirow[t]{4}{*}{ walker } & $\begin{array}{l}\text { Sphericity } \\
\text { Assumed }\end{array}$ & 36.400 & 2 & 18.200 & $\begin{array}{c}1.05 \\
6\end{array}$ & .358 & .053 & 2.112 & . 221 \\
\hline & $\begin{array}{l}\text { Greenhouse- } \\
\text { Geisser }\end{array}$ & 36.400 & 1.829 & 19.897 & $\begin{array}{c}1.05 \\
6\end{array}$ & .353 & .053 & 1.932 & 212 \\
\hline & Huynh-Feldt & 36.400 & 2.000 & 18.200 & $\begin{array}{c}1.05 \\
6\end{array}$ & .358 & .053 & 2.112 & .221 \\
\hline & Lower-bound & 36.400 & 1.000 & 36.400 & $\begin{array}{c}1.05 \\
6\end{array}$ & .317 & .053 & 1.056 & .164 \\
\hline $\begin{array}{l}\text { Error } \\
\text { (walker) }\end{array}$ & $\begin{array}{l}\text { Sphericity } \\
\text { Assumed }\end{array}$ & 654.933 & 38 & 17.235 & & & & & \\
\hline
\end{tabular}




\begin{tabular}{llcc}
\hline \hline Greenhouse- & 654.933 & 34.75 & 18.842 \\
Geisser & 9 & 184 \\
Huynh-Feldt & 654.933 & 38.00 & 17.235 \\
& 0 & \\
Lower-bound & 654.933 & $\begin{array}{c}19.00 \\
0\end{array}$ & 34.470 \\
\hline
\end{tabular}

a Computed using alpha $=.05$

Table D 32. Estimated marginal means for maximum dorsiflexion angle during gait with 1) anterior 2) posterior and 3) no walker

\begin{tabular}{lrrrr}
\hline \hline & & & \multicolumn{2}{c}{$95 \%$ Confidence Interval } \\
\cline { 4 - 5 } walker & Mean & Std. Error & Lower Bound & Upper Bound \\
\hline 1 & -1.150 & 1.510 & -4.311 & 2.011 \\
2 & -3.050 & 1.208 & -5.579 & -.521 \\
3 & -2.250 & 1.478 & -5.343 & .843 \\
\hline
\end{tabular}

Table D 33. Pairwise comparisons for maximum dorsiflexion angle during gait with 1) anterior 2) posterior and 3) no walker.

\begin{tabular}{|c|c|c|c|c|c|c|}
\hline \multirow[b]{2}{*}{ (I) walker } & \multirow[b]{2}{*}{ (J) walker } & \multirow{2}{*}{$\begin{array}{c}\text { Mean } \\
\text { Difference } \\
(\mathrm{I}-\mathrm{J})\end{array}$} & \multirow[b]{2}{*}{ Std. Error } & \multirow[b]{2}{*}{ Sig.(a) } & \multicolumn{2}{|c|}{$\begin{array}{l}\text { 95\% Confidence Interval for } \\
\text { Difference (a) }\end{array}$} \\
\hline & & & & & Upper Bound & Lower Bound \\
\hline \multirow{2}{*}{1} & 2 & 1.900 & 1.384 & .460 & -1.722 & 5.522 \\
\hline & 3 & 1.100 & 1.433 & .835 & -2.649 & 4.849 \\
\hline \multirow{2}{*}{2} & 1 & -1.900 & 1.384 & .460 & -5.522 & 1.722 \\
\hline & 3 & -.800 & 1.097 & .855 & -3.671 & 2.071 \\
\hline \multirow{2}{*}{3} & 1 & -1.100 & 1.433 & .835 & -4.849 & 2.649 \\
\hline & 2 & .800 & 1.097 & .855 & -2.071 & 3.671 \\
\hline
\end{tabular}

Based on estimated marginal means

a Adjustment for multiple comparisons: Sidak.

Table D 34. Descriptive statistics for preferred gait speed (m/s) with 1) anterior 2) posterior and 3) no walker.

\begin{tabular}{lccc}
\hline \hline & Mean & Std. Deviation & $\mathrm{N}$ \\
\hline AVGANTVEL (M/S) & .8985 & .38961 & 20 \\
AVGPOSTVEL (M/S) & .8433 & .35048 & 20 \\
AVGNONEVEL (M/S) & .908 & .3962 & 20 \\
\hline
\end{tabular}

Table D 35. Within subject effect of walker type on gait speed. 


\begin{tabular}{|c|c|c|c|c|c|c|c|c|c|}
\hline Source & & $\begin{array}{l}\text { Type III } \\
\text { Sum of } \\
\text { Squares }\end{array}$ & $d f$ & $\begin{array}{l}\text { Mean } \\
\text { Squar } \\
\text { e }\end{array}$ & $\mathrm{F}$ & Sig. & $\begin{array}{c}\text { Partial } \\
\text { Eta } \\
\text { Squared }\end{array}$ & $\begin{array}{l}\text { Noncent } \\
\text {. Para- } \\
\text { meter }\end{array}$ & $\begin{array}{l}\text { Observed } \\
\text { Power(a) }\end{array}$ \\
\hline \multirow[t]{4}{*}{ walker } & $\begin{array}{l}\text { Sphericity } \\
\text { Assumed }\end{array}$ & .048 & 2 & .024 & 2.579 & .089 & .119 & 5.157 & .484 \\
\hline & $\begin{array}{l}\text { Greenhouse- } \\
\text { Geisser }\end{array}$ & .048 & 1.602 & .030 & 2.579 & .102 & .119 & 4.132 & .427 \\
\hline & Huynh-Feldt & .048 & 1.727 & .028 & 2.579 & .098 & .119 & 4.454 & .446 \\
\hline & Lower-bound & .048 & 1.000 & .048 & 2.579 & .125 & .119 & 2.579 & .332 \\
\hline \multirow[t]{4}{*}{$\begin{array}{l}\text { Error } \\
\text { (walker) }\end{array}$} & $\begin{array}{l}\text { Sphericity } \\
\text { Assumed }\end{array}$ & .357 & 38 & .009 & & & & & \\
\hline & $\begin{array}{l}\text { Greenhouse- } \\
\text { Geisser }\end{array}$ & .357 & $\begin{array}{c}30.44 \\
7\end{array}$ & .012 & & & & & \\
\hline & Huynh-Feldt & .357 & $\begin{array}{c}32.81 \\
7\end{array}$ & .011 & & & & & \\
\hline & Lower-bound & .357 & $\begin{array}{c}19.00 \\
0\end{array}$ & .019 & & & & & \\
\hline
\end{tabular}

a Computed using alpha $=.05$

Table D 36. Estimated marginal means of gait speed (m/s) with 1) anterior, 2) posterior and 3) no walker.

\begin{tabular}{ccccc}
\hline \hline & & \multicolumn{3}{c}{$95 \%$ Confidence Interval } \\
walker & Mean & Std. Error & Lower Bound & Upper Bound \\
\hline 1 & .899 & .087 & .716 & 1.081 \\
2 & .843 & .078 & .679 & 1.007 \\
3 & .908 & .089 & .722 & 1.093 \\
\hline
\end{tabular}

Table D 37. Pairwise comparisons of gait speed with 1) anterior 2) posterior and 3) no walker.

\begin{tabular}{|c|c|c|c|c|c|c|}
\hline \multirow[b]{2}{*}{ (I) walker } & \multirow[b]{2}{*}{ (J) walker } & \multirow{2}{*}{$\begin{array}{c}\text { Mean } \\
\text { Difference } \\
(\mathrm{I}-\mathrm{J})\end{array}$} & \multirow[b]{2}{*}{ Std. Error } & \multirow[b]{2}{*}{ Sig.(a) } & \multicolumn{2}{|c|}{$\begin{array}{l}\text { 95\% Confidence Interval for } \\
\text { Difference(a) }\end{array}$} \\
\hline & & & & & Upper Bound & Lower Bound \\
\hline \multirow{2}{*}{1} & 2 & .055 & .022 & .063 & -.003 & .113 \\
\hline & 3 & -.009 & .033 & .990 & -.094 & .076 \\
\hline \multirow{2}{*}{2} & 1 & -.055 & .022 & .063 & -.113 & .003 \\
\hline & 3 & -.064 & .036 & .239 & -.157 & .029 \\
\hline \multirow[b]{2}{*}{3} & 1 & .009 & .033 & .990 & -.076 & .094 \\
\hline & 2 & .064 & .036 & .239 & -.029 & .157 \\
\hline
\end{tabular}


Based on estimated marginal means

a Adjustment for multiple comparisons: Sidak.

Table D 38. Descriptive statistics for stride length (m) with 1) anterior 2) posterior and 3) no walker.

\begin{tabular}{cccc}
\hline \hline & Mean & Std. Deviation & N \\
\hline AVGANTSTRLEN (M) & .9615 & .21137 & 20 \\
AVGPOSTSTRLEN (M) & .890 & .2208 & 20 \\
AVGNONESTRLEN (M) & .9490 & .24170 & 20 \\
\hline
\end{tabular}

Table D 39. Within subject effects of walker type on stride length (m).

\begin{tabular}{|c|c|c|c|c|c|c|c|c|c|}
\hline Source & & $\begin{array}{l}\text { Type III } \\
\text { Sum of } \\
\text { Squares }\end{array}$ & df & $\begin{array}{l}\text { Mean } \\
\text { Square }\end{array}$ & $\mathrm{F}$ & Sig. & $\begin{array}{l}\text { Partial } \\
\text { Eta } \\
\text { Squar } \\
\text { ed } \\
\end{array}$ & $\begin{array}{l}\text { Noncent } \\
\text { Para- } \\
\text { meter }\end{array}$ & $\begin{array}{l}\text { Observed } \\
\text { Power(a) }\end{array}$ \\
\hline \multirow[t]{4}{*}{ walker } & $\begin{array}{l}\text { Sphericity } \\
\text { Assumed }\end{array}$ & .059 & 2 & .030 & 3.993 & .027 & .174 & 7.985 & .680 \\
\hline & $\begin{array}{l}\text { Greenhouse- } \\
\text { Geisser }\end{array}$ & .059 & $\begin{array}{c}1.97 \\
5\end{array}$ & .030 & 3.993 & .027 & .174 & 7.884 & .676 \\
\hline & Huynh-Feldt & .059 & $\begin{array}{c}2.00 \\
0\end{array}$ & .030 & 3.993 & .027 & .174 & 7.985 & .680 \\
\hline & Lower-bound & .059 & $\begin{array}{c}1.00 \\
0\end{array}$ & .059 & 3.993 & .060 & .174 & 3.993 & .475 \\
\hline \multirow[t]{4}{*}{$\begin{array}{l}\text { Error } \\
\text { (walker) }\end{array}$} & $\begin{array}{l}\text { Sphericity } \\
\text { Assumed }\end{array}$ & .282 & 38 & .007 & & & & & \\
\hline & $\begin{array}{l}\text { Greenhouse- } \\
\text { Geisser }\end{array}$ & .282 & $\begin{array}{c}37.5 \\
19\end{array}$ & .008 & & & & & \\
\hline & Huynh-Feldt & .282 & $\begin{array}{c}38.0 \\
00\end{array}$ & .007 & & & & & \\
\hline & Lower-bound & .282 & $\begin{array}{c}19.0 \\
00\end{array}$ & .015 & & & & & \\
\hline
\end{tabular}

a Computed using alpha $=.05$

Table D 40. Estimated marginal means for stride length (m) during gait with 1) anterior 2) posterior and 3) no walker. 


\begin{tabular}{ccccc}
\hline \hline & & & \multicolumn{2}{c}{$95 \%$ Confidence Interval } \\
\cline { 3 - 5 } walker & Mean & Std. Error & Lower Bound & Upper Bound \\
\hline 1 & .962 & .047 & .863 & 1.060 \\
2 & .890 & .049 & .786 & .993 \\
3 & .949 & .054 & .836 & 1.062 \\
\hline
\end{tabular}

Table D 41. Pairwise comparisons for stride length (m) with 1) anterior, 2) posterior and 3) no walker.

\begin{tabular}{|c|c|c|c|c|c|c|}
\hline \multirow[b]{2}{*}{ (I) walker } & \multirow[b]{2}{*}{ (J) walker } & \multirow{2}{*}{$\begin{array}{c}\text { Mean } \\
\text { Difference } \\
(\mathrm{I}-\mathrm{J})\end{array}$} & \multirow[b]{2}{*}{ Std. Error } & \multirow[b]{2}{*}{ Sig.(a) } & \multicolumn{2}{|c|}{$\begin{array}{c}95 \% \text { Confidence Interval for } \\
\text { Difference(a) }\end{array}$} \\
\hline & & & & & Upper Bound & Lower Bound \\
\hline \multirow{2}{*}{1} & 2 & .072 & .029 & .062 & -.003 & .147 \\
\hline & 3 & .013 & .026 & .952 & -.056 & .081 \\
\hline \multirow{2}{*}{2} & 1 & -.072 & .029 & .062 & -.147 & .003 \\
\hline & 3 & -.060 & .027 & .113 & -.130 & .011 \\
\hline \multirow{2}{*}{3} & 1 & -.013 & .026 & .952 & -.081 & .056 \\
\hline & 2 & .060 & .027 & .113 & -.011 & .130 \\
\hline
\end{tabular}

Based on estimated marginal means

a Adjustment for multiple comparisons: Sidak.

Table D 42. Paired statistics for obstacle course times (s) with anterior and posterior walkers.

\begin{tabular}{llcccc}
\hline \hline & & & & \multicolumn{2}{c}{ Std. Error } \\
& & Mean & N & Std. Deviation & Mean \\
\hline Pair 1 & Obstacle Anterior (s) & 35.4125 & 20 & 8.28758 & 1.85316 \\
& Obstacle Posterior (s) & 43.709 & 20 & 11.9719 & 2.6770 \\
\hline
\end{tabular}

Table D 43. Correlations between obstacle course times with anterior and posterior walkers.

\begin{tabular}{llccc}
\hline \hline & & $\mathrm{N}$ & Correlation & Sig. \\
\hline Pair 1 & $\begin{array}{l}\text { Obstacle Anterior (s) \& } \\
\text { Obstacle Posterior (s) }\end{array}$ & 20 & .797 & .000 \\
\hline
\end{tabular}


Table D 44. Paired t-test with obstacle course times with anterior and posterior walkers

\begin{tabular}{|c|c|c|c|c|c|c|c|c|}
\hline & \multicolumn{5}{|c|}{ Paired Differences } & \multirow[b]{3}{*}{$\mathrm{t}$} & \multirow[b]{3}{*}{$\mathrm{df}$} & \multirow{3}{*}{$\begin{array}{l}\text { Sig. } \\
(2- \\
\text { tailed })\end{array}$} \\
\hline & \multirow[b]{2}{*}{ Mean } & \multirow{2}{*}{$\begin{array}{c}\text { Std. } \\
\text { Deviatio } \\
n\end{array}$} & \multirow{2}{*}{$\begin{array}{l}\text { Std. } \\
\text { Error } \\
\text { Mean }\end{array}$} & \multicolumn{2}{|c|}{$\begin{array}{c}95 \% \text { Confidence } \\
\text { Interval of the } \\
\text { Difference } \\
\end{array}$} & & & \\
\hline & & & & Lower & Upper & & & \\
\hline $\begin{array}{l}\text { Obstacle Anterior (s) - } \\
\text { Obstacle Posterior (s) }\end{array}$ & -8.29600 & 7.33277 & 1.63966 & -11.72784 & -4.86416 & -5.060 & 19 & .000 \\
\hline
\end{tabular}

Table D 45 Within subject effects of rater and walker on GARS scores

\begin{tabular}{|c|c|c|c|c|c|c|}
\hline Source & & $\begin{array}{l}\text { Type III } \\
\text { Sum of } \\
\text { Squares }\end{array}$ & $\mathrm{df}$ & $\begin{array}{l}\text { Mean } \\
\text { Square }\end{array}$ & $\mathrm{F}$ & Sig. \\
\hline \multirow[t]{4}{*}{ rater } & Sphericity Assumed & 13.920 & 4 & 3.480 & .621 & .654 \\
\hline & Greenhouse-Geisser & 13.920 & 1.961 & 7.099 & .621 & .559 \\
\hline & Huynh-Feldt & 13.920 & 3.827 & 3.638 & .621 & 648 \\
\hline & Lower-bound & 13.920 & 1.000 & 13.920 & .621 & .475 \\
\hline \multirow[t]{4}{*}{ Error(rater) } & Sphericity Assumed & 89.680 & 16 & 5.605 & & \\
\hline & Greenhouse-Geisser & 89.680 & 7.843 & 11.434 & & \\
\hline & Huynh-Feldt & 89.680 & $\begin{array}{r}15.30 \\
7\end{array}$ & 5.859 & & \\
\hline & Lower-bound & 89.680 & 4.000 & 22.420 & & \\
\hline \multirow[t]{4}{*}{ walker } & Sphericity Assumed & .500 & 1 & .500 & .400 & .561 \\
\hline & Greenhouse-Geisser & .500 & 1.000 & .500 & .400 & .561 \\
\hline & Huynh-Feldt & .500 & 1.000 & .500 & .400 & .561 \\
\hline & Lower-bound & .500 & 1.000 & .500 & .400 & .561 \\
\hline \multirow{4}{*}{$\begin{array}{l}\text { Error } \\
\text { (walker) }\end{array}$} & Sphericity Assumed & 5.000 & 4 & 1.250 & & \\
\hline & Greenhouse-Geisser & 5.000 & 4.000 & 1.250 & & \\
\hline & Huynh-Feldt & 5.000 & 4.000 & 1.250 & & \\
\hline & Lower-bound & 5.000 & 4.000 & 1.250 & & \\
\hline $\begin{array}{l}\text { rater * } \\
\text { walker }\end{array}$ & Sphericity Assumed & 18.400 & 4 & 4.600 & 1.859 & .167 \\
\hline
\end{tabular}




\begin{tabular}{llrrrrr} 
& Greenhouse-Geisser & 18.400 & 1.746 & 10.541 & 1.859 & .225 \\
& Huynh-Feldt & 18.400 & 2.984 & 6.166 & 1.859 & .191 \\
& Lower-bound & 18.400 & 1.000 & 18.400 & 1.859 & .244 \\
\hline Error(rater & Sphericity Assumed & 39.600 & 16 & 2.475 & & \\
*walker) & & 39.600 & 6.982 & 5.671 & & \\
& Greenhouse-Geisser & 39.600 & 11.93 & 7 & 3.317 & \\
& Huynh-Feldt & 39.600 & 4.000 & 9.900 & & \\
& Lower-bound & & &
\end{tabular}

Table D 46 Multivariate tests of within subject effects on GARS scores

\begin{tabular}{|c|c|c|c|c|c|c|}
\hline \multicolumn{7}{|c|}{ Multivariate Tests(b) } \\
\hline \multicolumn{2}{|c|}{ Effect } & \multirow{2}{*}{$\begin{array}{l}\text { Value } \\
0.999812\end{array}$} & \multirow{2}{*}{$\frac{F}{1326.718}$} & \multicolumn{2}{|c|}{ Hypothesis df Error df } & \multirow{2}{*}{$\begin{array}{l}\text { Sig. } \\
0.020588\end{array}$} \\
\hline rater & Pillai's Trace & & & 4 & 1 & \\
\hline & Wilks' Lambda & 0.000188 & 1326.718 & 4 & 1 & 0.020588 \\
\hline & Hotelling's Trace & 5306.872 & 1326.718 & 4 & 1 & 0.020588 \\
\hline & Roy's Largest Root & 5306.872 & 1326.718 & 4 & 1 & 0.020588 \\
\hline \multirow[t]{4}{*}{ walker } & Pillai's Trace & 0.090909 & 0.4 & 1 & 4 & 0.561438 \\
\hline & Wilks' Lambda & 0.909091 & 0.4 & 1 & 4 & 0.561438 \\
\hline & Hotelling's Trace & 0.1 & 0.4 & 1 & 4 & 0.561438 \\
\hline & Roy's Largest Root & 0.1 & 0.4 & 1 & 4 & 0.561438 \\
\hline \multirow[t]{4}{*}{ rater * walker } & Pillai's Trace & 0.766993 & 0.822931 & 4 & 1 & 0.667824 \\
\hline & Wilks' Lambda & 0.233007 & 0.822931 & 4 & 1 & 0.667824 \\
\hline & Hotelling's Trace & 3.291725 & 0.822931 & 4 & 1 & 0.667824 \\
\hline & Roy's Largest Root & 3.291725 & 0.822931 & 4 & 1 & 0.667824 \\
\hline
\end{tabular}

a Exact statistic

b Design: Intercept within subjects design: rater + walker + rater $\mathrm{x}$ walker

Table D 47 Repeated measures ANOVA of GARS scores with anterior walker

\begin{tabular}{lcrr}
\hline \hline Source of variance df & Sum of Sq & Mean Sq \\
\hline Between subjects & 4 & 86.96 & 21.74 \\
Within subjects & & &
\end{tabular}

$\begin{array}{llll}\text { Between raters } \quad 4 \quad 26.16 & 6.54\end{array}$




\begin{tabular}{llll}
\hline Error & 16 & 71.84 & 4.49
\end{tabular}

Table D 48 Repeated measures ANOVA of GARS scores with posterior walker

\begin{tabular}{lrrr}
\hline \hline Source of variance df & \multicolumn{2}{c}{ Sum of Sq } & \multicolumn{2}{c}{ Mean Sq } \\
\hline Between subjects & 4 & 102.96 & 25.74 \\
Within subjects & & & \\
$\quad$ Between raters & 4 & 6.16 & 1.54 \\
$\quad$ Error & 16 & 57.44 & 3.59 \\
\hline
\end{tabular}

Table D 49 ICC form $(2,1)$ for GARS scores of 5 raters and 5 subjects

\begin{tabular}{lc}
\hline \hline & ICC \\
\hline GARS scores with anterior walker & 0.413 \\
GARS scores with posterior walker & 0.582 \\
\hline
\end{tabular}




\section{APPENDIX E: RECOMMENDATIONS FOR FUTURE RESEARCH}

Manuscript 1: Gait kinematics with an anterior vs. a posterior wheeled walker

1. Choose a more specific patient population with less variability of gait deficits who may benefit from a posterior walker. Possible populations might include adults with Parkinson's disease, adults with incomplete spinal cord injuries, or adults with MS. Re-assess gait kinematics with the anterior and posterior walker in this narrowed population.

2. Compare the gait kinematics with an anterior and posterior walker using an infrared video motion analysis system instead of electro goniometers.

3. Target adults who use walkers and who walk with extreme trunk flexion to determine if the posterior walker improves posture in this population.

4. Using an infrared motion analysis system and force plates, assess the joint moments while walking with an anterior walker, without a walker and with a posterior walker in older adults.

Manuscript 2: Use of an obstacle course and user preferences to compare anterior and posterior walkers in older adults

1. Improve the design of the posterior walker to allow for greater maneuverability. Compare obstacle course times and user preferences with the new posterior wheeled walker and a traditional anterior wheeled walker.

2. Add other assistive devices such as a cane and or a forearm crutch to compare the maneuverability across several assistive devices in older adults. 
3. Develop a new simple obstacle course to help clinicians determine one's ability to use an assistive device in a household setting. Determine reference values for adults who are living independently and safely with an assistive device.

Manuscript 3: Therapist evaluations of adult gait with anterior and posterior walkers

1. Create a new gait rating system which is better able to differentiate gait between different assistive devices. Compare this new system to the GARS or to gait kinematics to determine its effectiveness. Perform inter-rater reliability analysis on this new instrument.

2. Use quantitative analysis methods and have therapists perform open ended, essay analysis of gait with different assistive devices. Code the results to determine agreement between the therapists' evaluations.

3. Have the therapists grade gait using the GARS with and without the assistive devices. The GARS was originally developed for evaluating gait without an assistive device. Compare the inter-rater reliability rating gait with and without assistive devices.

4. Determine the optimum number of training sessions in order to maximize interrater reliability with the GARS. 


\section{BIBLIOGRAPHY}

1. Van der Esch M., Heijmans M, Dekker J. Factors contributing to possession and use of walking aids among persons with rheumatoid arthritis and osteoarthritis. Arth \& Rheum. 2003; 49:838-842

2. Staten L.K., Scheu L.L., Bronson D. et al. Pasos Adelante: The effectiveness of a community-based chronic disease prevention program. Prev Chronic Dis. 2005; 2:A18

3. Albright C., Thompson D.L. The effectiveness of walking in preventing cardiovascular disease in women: a review of the current literature. J Womens Health (Larchmt ). 2006; 15:271-280

4. Gill T.M., Allore H.G., Hardy S.E. et al. The dynamic nature of mobility disability in older persons. J Am Geriatr Soc. 2006; 54:248-254

5. Kernan W.N., Viscoli C.M., Brass L.M. et al. Decline in physical performance among women with a recent transient ischemic attack or ischemic stroke: opportunities for functional preservation a report of the Women's Estrogen Stroke Trial. Stroke. 2005; 36:630-634

6. Rice D.P., Fineman N. Economic implications of increased longevity in the United States. Annu Rev Public Health. 2004; 25:457-473

7. Kerrigan D.C., Lee L.W., Collins J.J. et al. Reduced hip extension during walking: healthy elderly and fallers versus young adults. Arch Phys Med Rehabil. $2001 ; 82: 26-30$

8. DeVita P., Hortobagyi T. Age causes a redistribution of joint torques and powers during gait. J Appl Physiol. 2000; 88:1804-1811

9. Wolfson L., Whipple R., Amerman P. et al. Gait assessment in the elderly: a gait abnormality rating scale and its relation to falls. J Gerontol. 1990; 45:M12-M19

10. McGibbon C.A., Krebs D.E.. Discriminating age and disability effects in locomotion: neuromuscular adaptations in musculoskeletal pathology. J Appl Physiol. 2004; 96:149-160

11. Nagano Y., Takahashi T., Ishida K. et al. Knee pain in people aged 80 years and older is not associated with gait parameter and functional performance. Int $\mathrm{J}$ Rehabil Res. 2003; 26:131-136

12. Lee L.W., Zavarei K., Evans J. et al. Reduced hip extension in the elderly: dynamic or postural? Arch Phys Med Rehabil. 2005; 86:1851-1854 
13. Jacobs J.V., Dimitrova D.M., Nutt JG et al. Can stooped posture explain multidirectional postural instability in patients with Parkinson's disease? Exp Brain Res. 2005; 166:78-88

14. Hausdorff J.M., Nelson M.E., Kaliton D. et al. Etiology and modification of gait instability in older adults: a randomized controlled trial of exercise. J Appl Physiol. 2001; 90:2117-2129

15. Silsupadol P., Siu K.C., Shumway-Cook A. et al. Training of balance under single- and dual-task conditions in older adults with balance impairment. Phys Ther. 2006; 86:269-281

16. Kerrigan D.C., Xenopoulos-Oddsson A., Sullivan M.J. et al. Effect of a hip flexor-stretching program on gait in the elderly. Arch Phys Med Rehabil. 2003; $84: 1-6$

17. Russell J.N., Hendershot G.E., LeClere F. et al. Trends and differential use of assistive technology devices: United States, 1994. Adv Data. 1997;1-9

18. Alkjaer T., Larsen P.K., Pedersen G. et al. Biomechanical analysis of rollator walking. Biomed Eng Online. 2006; 5:2

19. Grenier B.M., Czerniecki J.M., Deitz J.C. A comparison of effects of posterior walker and anterior walkers. Arch Phys Med Rehab. 1993; 74:381-384

20. Logan L., Byers-Hinkley K., Ciccone C.D. Anterior versus posterior walkers: a gait analysis study. Dev Med Child Neurol. 1990; 32:1044-1048

21. Park E.S., Park C.I., Kim J.Y. Comparison of anterior and posterior walkers with respect to gait parameters and energy expenditure of children with spastic diplegic cerebral palsy. Yonsei Med J. 2001; 42:180-184

22. Levangie P.K., Chimera M., Johnston M. et al. The effects of posterior rolling walkers vs. the standard rolling walker on gait characteristics of children with spastic cerebral palsy. Phys Occup Ther Pediatr. 1989; 9:1-17

23. Mattsson E, Andersson C. Oxygen cost, walking speed, and perceived exertion in children with cerebral palsy when walking with anterior and posterior walkers. Dev Med Child Neurol. 1997; 39:671-676

24. O'Sullivan S.B., Schmitz T.J. Physical Rehabilitation: Assessment and Treatment. Philadelphia: F.A. Davis, 1994

25. Norkin C.C, White D.J. Measurement of Joint Motion: A Guide to Goniometry. 2 ed. Philadelphia: F.A. Davis Company, 1995 
26. Burnfield J.M., Few C.D., Mohamed O.S. et al. The influence of walking speed and footwear on plantar pressures in older adults. Clinical Biomechanics. 2004; 19:78-84

27. National Center for Injury Prevention and Control. Check for safety: A home fall prevention checklist for older adults. CDC. 2006;

28. Gehlsen G.M., Whaley M.H. Falls in the elderly: part I, gait. Arch Phys Med Rehab. 1990; 71:735-738

29. Feltner M.E., MacRae P.G., McNitt-Gray J.L. Quantitative gait assessment as a predictor of prospective adn retrospective falls in community-dwelling older women. Arch Phys Med Rehab. 1994; 75:447-453

30. Biometrics Ltd. http://www.biometricsltd.com/y\%20gonio.htm. UK . 2007.

31. Rome K., Cowieson F. A reliability study of the universal goniometer, fluid goniometer, and electrogoniometer for the measurement of ankle dorsiflexion. Foot Ankle Int. 1996; 17:28-32

32. Collins M.M., Piazza S., and Bansal P.N. Validation of a protocol for motion analysis. McNair Scholar Award Report . 2003. 11-12-0006.

33. Results of comparison meeting of motion analysis systems. Japan Technical College, Tokyo, Japan . 2002. Tokyo, Japan. 7-27-0006.

34. Marks R., Karkouti E. Evaluation of the reliability of reflective marker placements. Physiotherapy Research International. 1996; 1:50-61

35. Kerrigan D.C, Lee L.W., Nieto T.J. et al. Kinetic alterations independent of walking speed in elderly fallers. Arch Phys Med Rehabil. 2000; 81:730-735

36. Nielsen D.H., Harris J.M., Minton Y.M. et al. Energy cost, exercise intensity, and gait efficiency of standard versus rocker-bottom axillary crutch walking. Phys Ther. 1990; 70:487-493

37. Hughes B, Sawatzky B.J., Hol A.T. A comparison of spinergy versus standard steel-spoke wheelchair wheels. Arch Phys Med Rehabil. 2005; 86:596-601

38. Chafetz R., McDonald C., Mulcahey M.J. et al. Timed motor test for wheelchair users: initial development and application in children with spinal cord injury. $\mathrm{J}$ Spinal Cord Med. 2004; 27 Suppl 1:S38-S43

39. Gitlin L.N., Schemm R.L., Landsberg L. et al. Factors predicting assistive device use in the home by older people following rehabilitation. J Aging Health. 1996; 8:554-575 
40. Gitlin L.N., Levine R., Geiger C. Adaptive device use by older adults with mixed disabilities. Arch Phys Med Rehabil. 1993; 74:149-152

41. Kressig R.W., Wolf S.L., Sattin R.W. et al. Associations of Demographic, Functional, and Behavioral Characteristics with Activity-Related Fear of Falling Among Older Adults Transitioning to Frailty. Journal of the American Geriatrics Society. 2001; 49:1456-1462

42. Campbell S.K. Physical Therapy for Children. Philadelphia: W.B. Saunders, 1995

43. Clark R.D., Lord S.R., Webster I.W. Clinical parameters associated with falls in an elderly population. Gerontology. 1993; 39:117-123

44. Eriksrud O., Bohannon R.W. Relationship of knee extension force to independence in sit-to-stand performance in patients receiving acute rehabilitation. Physical Therapy. 2003; 83:544-551

45. Damiano D.L., Quinlivan J., Owen B.F. et al. Spasticity versus strength in cerebral palsy: relationships among involuntary resistance, voluntary torque, and motor function. Eur J Neurol. 2001; 8 Suppl 5:40-49

46. Lin C.J., Guo L.Y., Su F.C. et al. Common abnormal kinetic patterns of the knee in gait in spastic diplegia of cerebral palsy. Gait \& Posture. 2000; 11:224-232

47. Gait Training. Encyclopedia of Nursing \& Allied Health. 2006;

48. May J.B. Mobility Training for the Older Adult. Topics in Geriatric Rehabilitation. 2003; 19:191-198

49. VanSwearingen J.M., Paschal K.A., Bonino P. et al. Assessing recurrent fall risk of community-dwelling frail older veterans using specific test of mobility and the physical performance test of function. J Gerontol Biol Sci Med Sci. 1998; 53:M457-M464

50. Brach J.S., VanSwearingen J.M. Physical impairment and disability: relationship to performance of activities of daily living in community-dwelling older men. Phys Ther. 2002; 82:752-761

51. Shumway-Cook A., Wollacott M. Motor Control: Theory and Practical Applications. Baltimore: Williams \& Wilkins, 1995

52. Molony D.C., Sparkes J., Noonan J. et al. The orthopaedic angle on angles: The accuracy of health care professionals in assessing angular displacement. Eur J Orthop Surg Traumatol. 2004; 14:80-83

53. Shrout P.E., Fleiss J.L. Intraclass correlations: Uses in assessing rater reliability. Psychol Bulletin. 1979; 86:420-427 
54. Portney LG, Watkins M.P. Foundations of Clinical Research: Applications to Practice. 1 ed. Nowalk, CT: Appleton \& Lange, 1993

55. Russell D.J., Rosenbaum P.L., Lane M. et al. Training users in the Gross Motor Function Measure: Methodological and practical Issues. Physical Therapy. 1994; 74:630-636

56. Russell D.J., Rosenbaum P.L., Cadman D.T. et al. The gross motor function measure: A means to evaluate the effects of physical therapy. Developmental medicine and Child Neurology. 1989; 31:341-352

57. Saito $Y$, Sozu T, Hamada $C$ et al. Effective number of subjects and number of raters for inter-rater reliability studies. Statistics in Medicine. 2006; 25:1547-1560

58. Nagi SZ. A study in the evaluation of disability and rehabilitation potential: Concepts, methods, and procedures. Am J Public Health Nations Health. 1964; 54:1568-1579

59. Smith L.K., Weiss E.L., Lehmkuhl L.D. Brunnstrom's Clinical Kinesiology. 5 ed. Philadelphia: F.A. Davis Company, 1996

60. Lee HJ, Chou LS. Detection of gait instability using the center of mass and center of pressure inclination angles. Arch Phys Med Rehabil. 2006; 87:569-575

61. Gill TM, Gahbauer EA, Allore HG et al. Transitions between frailty states among community-living older persons. Arch Intern Med. 2006; 166:418-423

62. Graafmans WC, Lips P, Wijlhuizen GJ et al. Daily physical activity and the use of a walking aid in relation to falls in elderly people in a residential care setting. $Z$ Gerontol Geriatr. 2003; 36:23-28

63. Melis EH, Torres-Moreno R, Barbeau $\mathrm{H}$ et al. Analysis of assisted-gait characteristics in persons with incomplete spinal cord injury. Spinal Cord. 1999; $37: 430-439$

64. Anton L. Pressure ulcer prevention in older people who sit for long periods. Nurs Older People. 2006; 18:29-35

65. Gefen A, Gefen N, Linder-Ganz E et al. In vivo muscle stiffening under bone compression promotes deep pressure sores. J Biomech Eng. 2005; 127:512-524

66. Steele LL. Disability among adults in New York State, 2001-2003: Prevalence and health risk behavior. Results from the Behavioral Risk Factor Surveillance System. Albany, NY: NYSDOH. 2005;

67. Cutler DM. Declining disability among the elderly. Health Aff (Millwood ). 2001; 20:11-27 
68. Manton $\mathrm{KG}, \mathrm{Gu} \mathrm{X}$. Changes in the prevalence of chronic disability in the United States black and nonblack population above age 65 from 1982 to 1999. Proc Natl Acad Sci U S A. 2001; 98:6354-6359

69. CDC. Prevalence and impact of arthritis by race and ethnicity - United States, 1989-1991. Morb Mortal Wkly Rep. 1996; 45:373-378

70. Kaye, H. S., Kang, T, and LaPlante, M. P. Mobility Device Use in the United States: Disability Statistics Report. 14, 1-60. 2000. U.S. Department of Education, National Institute on Disability and Rehabilitation Research.

71. Suzuki T, Bean JF, Fielding RA. Muscle power of the ankle flexors predicts functional performance in community-dwelling older women. J Am Geriatr Soc. 2001; 49:1161-1167

72. Whipple RH, Wolfson LI, Amerman PM. The relationship of knee and ankle weakness to falls in nursing home residents: an isokinetic study. J Am Geriatr Soc. $1987 ; 35: 13-20$

73. Van Hook FW, Demonbreun D, Weiss BD. Ambulatory devices for chronic gait disorders in the elderly. Am Fam Physician. 2003; 67:1717-1724

74. Phillips B, Zhao H. Predictors of assistive technology abandonment. Assist Technol. 1993; 5:36-45 